Issued by Sandia National Laboratories, operated for the United States Department of Energy by Sandia Corporation.

NOTICE: This report was prepared as an account of work sponsored by an agency of the United States Government. Neither the United States Government, nor any agency thereof, nor any of their employees, nor any of their contractors, subcontractors, or their employees, make any warranty, express or implied, or assume any legal liability or responsibility for the accuracy, completeness, or usefulness of any information, apparatus, product, or process disclosed, or represent that its use would not infringe privately owned rights. Reference herein to any specific commercial product, process, or service by trade name, trademark, manufacturer, or otherwise, does not necessarily constitute or imply its endorsement, recommendation, or favoring by the United States Government, any agency thereof, or any of their contractors or subcontractors. The views and opinions expressed herein do not necessarily state or reflect those of the United States Government, any agency thereof, or any of their contractors.

Printed in the United States of America. This report has been reproduced directly from the best available copy.

Available to DOE and DOE contractors from Office of Scientific and Technical Information

P.O. Box 62

Oak Ridge, TN 37831

Prices available from (703) 605-6000

Web site: http://www.ntis.gov/ordering.htm

Available to the public from

National Technical Information Service

U.S. Department of Commerce

5285 Port Royal Rd

Springfield, VA 22161

NTIS price codes

Printed copy: A04

Microfiche copy: $\mathrm{AO} 1$

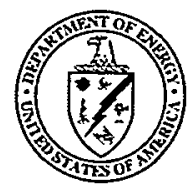




\section{DISCLAIMER}

Portions of this document may be illegible in electronic image products. Images are produced from the best available original document. 
SAND99-2898

Unlimited Distribution

Printed April 2000

\title{
Consideration of Nuclear Criticality When Disposing of Transuranic Waste at the Waste Isolation Pilot Plant
}

\author{
Rob P. Rechard, Lawrence C. Sanchez, \\ Christine T. Stockman, Holly R. Trellue \\ Nuclear Waste Management Programs Center \\ Sandia National Laboratories \\ P.O. Box 5800 \\ Albuquerque, NM 87185-0776
}

\begin{abstract}
Based on general arguments presented in this report, nuclear criticality was eliminated from performance assessment calculations for the Waste Isolation Pilot Plant (WIPP), a repository for waste contaminated with transuranic (TRU) radioisotopes, located in southeastern New Mexico. At the WIPP, the probability of criticality within the repository is low because mechanisms to concentrate the fissile radioisotopes dispersed throughout the waste are absent. In addition, following an inadvertent human intrusion into the repository (an event that must be considered because of safety regulations), the probability of nuclear criticality away from the repository is low because (1) the amount of fissile mass transported over $10,000 \mathrm{yr}$ is predicted to be small, (2) often there are insufficient spaces in the advective pore space (e.g., macroscopic fractures) to provide sufficient thickness for precipitation of fissile material, and (3) there is no credible mechanism to counteract the natural tendency of the material to disperse during transport and instead concentrate fissile material in a small enough volume for it to form a critical concentration. Furthermore, before a criticality would have the potential to affect human health after closure of the repository-assuming that a criticality could occur-it would have to either (1) degrade the ability of the disposal system to contain nuclear waste or (2) produce significantly more radioisotopes than originally present. Neither of these situations can occur at the WIPP; thus, the consequences of a criticality are also low.
\end{abstract}




\section{Preface}

To certify the compliance of the Waste Isolation Pilot Plant (WIPP), a geologic facility for the disposal of wastes containing transuranic (TRU) radioisotopes, the U.S. Environmental Protection Agency (EPA) required estimates of the disposal system's future probable behavior. The estimates were prepared by means of models that captured essential features, events, and processes of the disposal system. To help demonstrate the completeness of the analysis, the features, events, and processes were formally selected and documented. This report describes the reasons why nuclear criticality was omitted from consideration of events and processes for the performance assessment calculations of the WIPP, as initially argued in Rechard et al., 1996a. Although concern about criticality in TRU waste has never been great because of the low initial concentration of fissile material, the approach used to address it in this report can be applied to repositories with other types of waste with higher initial concentrations of fissile material.

\section{Acknowledgments}

The authors wish to thank J.M. Chapman, S.K. Best, and L.C. Tartaglia, of Tech Reps, Inc., Albuquerque, NM, for editorial, illustration, and desktop publishing support, respectively. The authors also wish to thank the reviewers at Sandia National Laboratories, Albuquerque, NM, M.S. Tierney, M. Martell, P. Brady, and W. Weart, for their helpful suggestions to the text. In addition, we wish to acknowledge several people who contributed to various aspects of this report: R. Blaine, Ecodynamics Inc., ran the transport calculations in 1996 for the original screening argument; these calculations were the basis of the transport calculations described herein by M. Wallace, The Plus Group; D.K. Rudeen, New Mexico Engineering Research Institute (NMERI), reviewed the new calculations and assisted with plotting the results; J.S. Rath of Sandia generated the original plots of concentrations and fissile masses in 1996; his work formed the basis for the plots used herein by J.D. Miller, Sandia. 


\section{Contents}

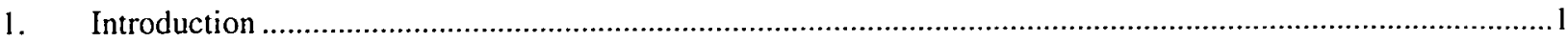

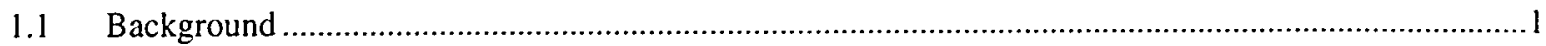

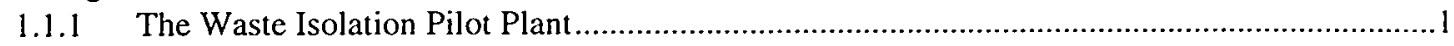

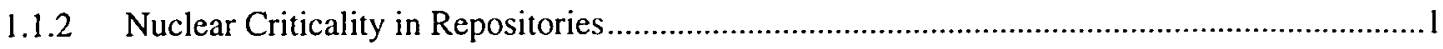

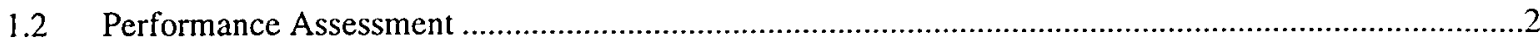

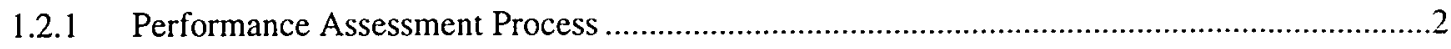

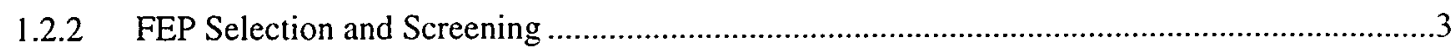

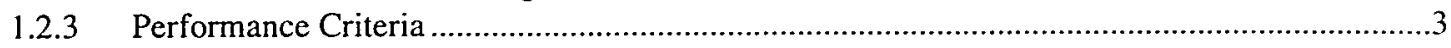

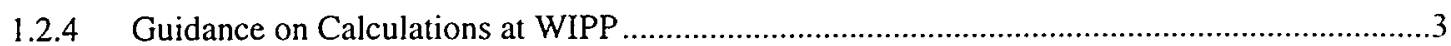

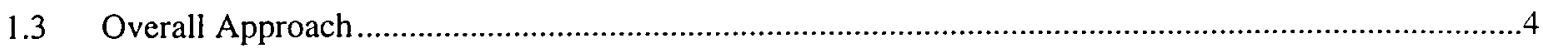

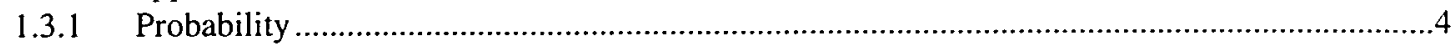

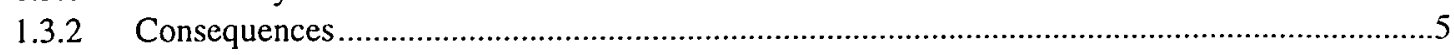

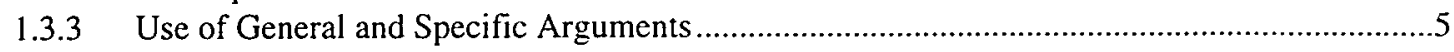

2. Description of WIPP Disposal System

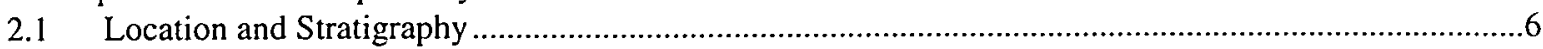

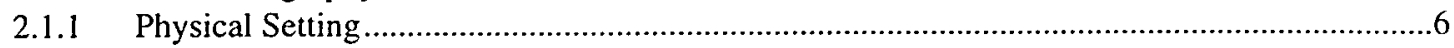

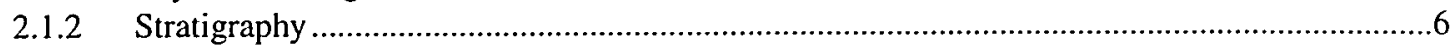

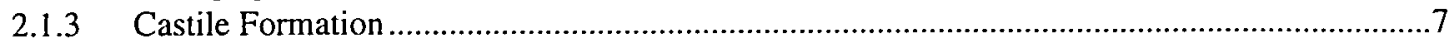

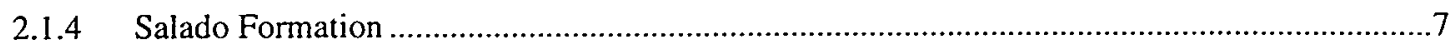

2.1.5 Culebra Dolomite Member of Rustler Formation …….......................................................

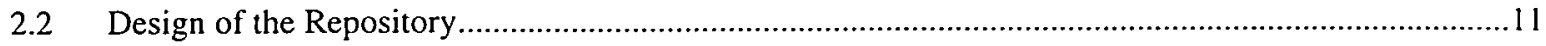

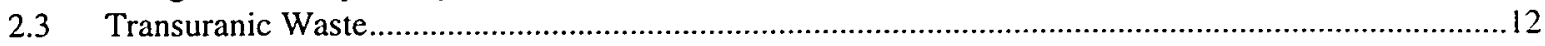

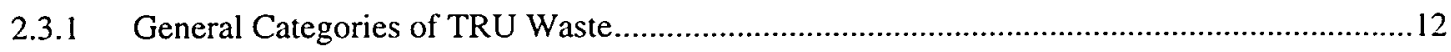

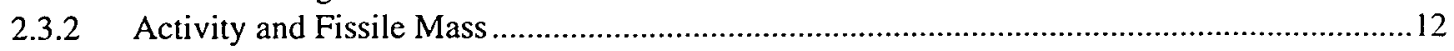

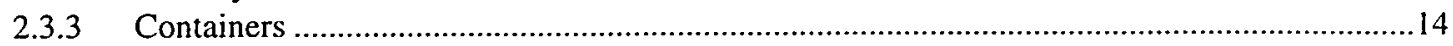

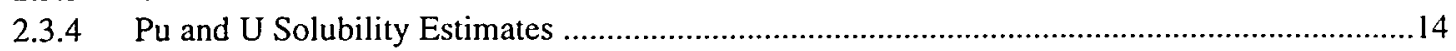

2.3.5 Plutonium Total Concentration in 1996 Calculations ..............................................................15

2.3.6 Uranium Total Concentration in 1996 Calculations .........................................................17

2.3.7 New Solubilities for Actinides with Plus Four Valence …....................................................17

2.3.8 Deposited Forms of Plutonium and Uranium ............................................................................19

$2.4 \quad$ Basic Scenarios and Calculated Brine Flows ................................................................................

2.4.1 Undisturbed Scenario ..................................................................................................... 19

2.4.2 Basic Human Intrusion Scenarios for which Radioisotope Releases are Calculated.................19

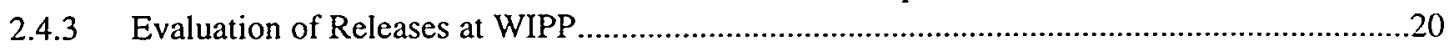

2.4.4 Range of Brine Flow through Repository and up Intrusion Borehole .................................20

3. Low Probability Based on Physical Constraints on Critical Concentration..................................................22

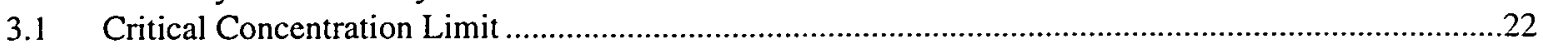

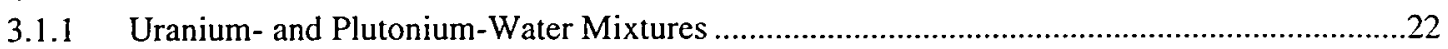

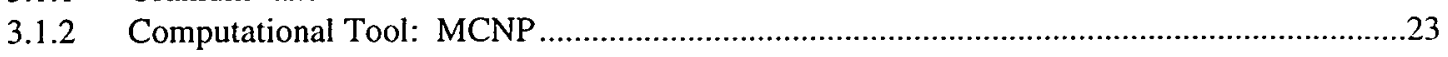

3.2 Criticality Limits Based on Homogeneous Spherical Shapes in Various Materials .............................23

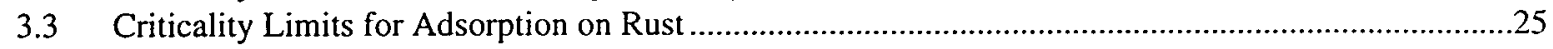

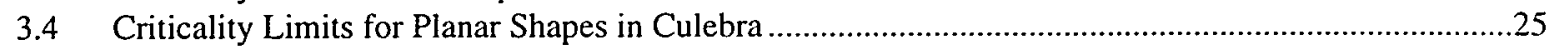

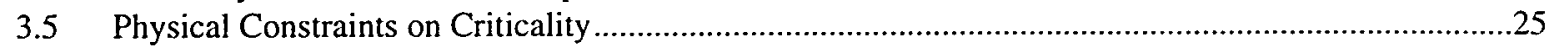

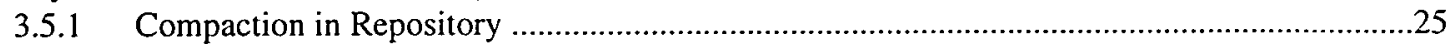

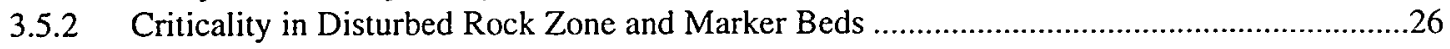

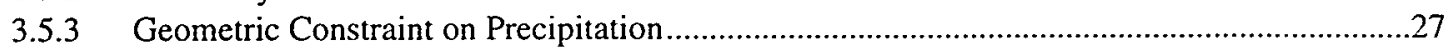

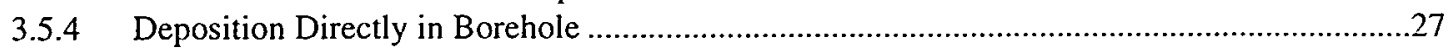

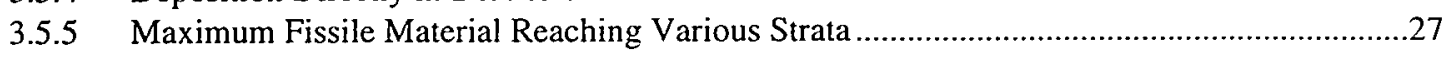


4. Low Probability of Criticality in Culebra Based on Information from Ore Deposits....................................29

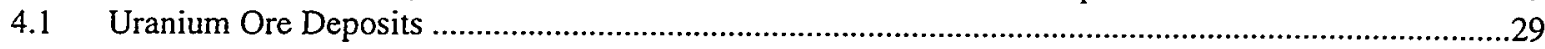

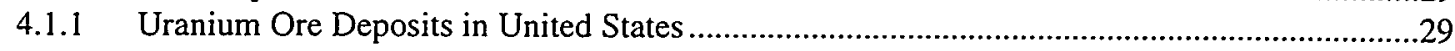

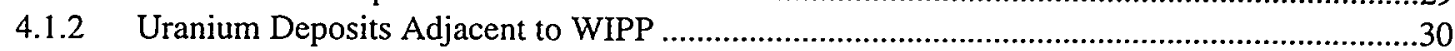

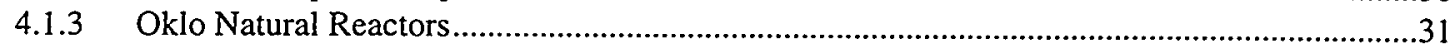

4.1.4 Lack of Favorable Depositional Features in WIPP Disposal System .......................................31

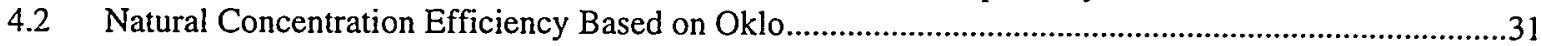

4.2.1 Required Actinide Concentration Based on Maximum Flow ..................................................32

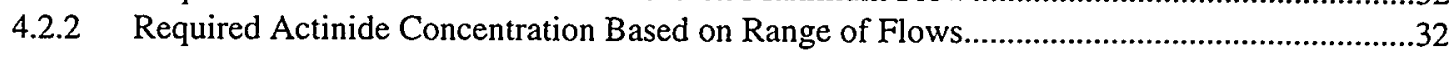

5. Low Probability Based on Geochemical Constraints on Concentration Mechanisms ......................................33

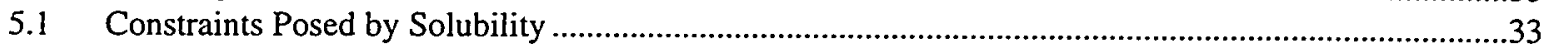

5.1.1 Solubility Constraint on Radioisotope Concentration ............................................................33

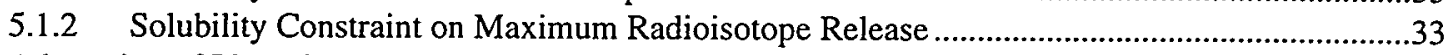

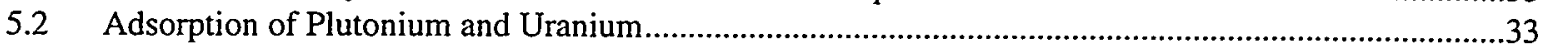

5.2.1 Adsorption of Fissile Material on Mineral Surfaces in Repository ...........................................33

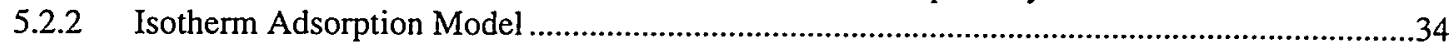

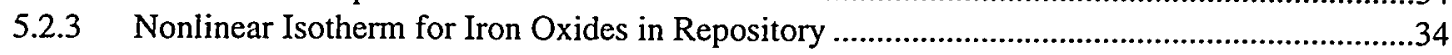

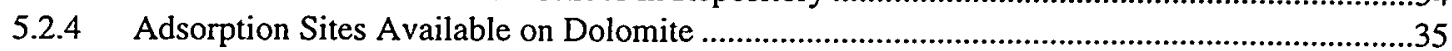

5.3 Concentration of Colloid Material in the WIPP Disposal System ......................................................37

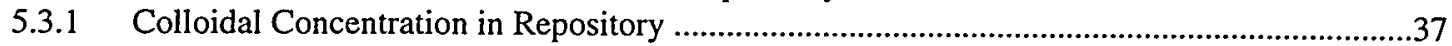

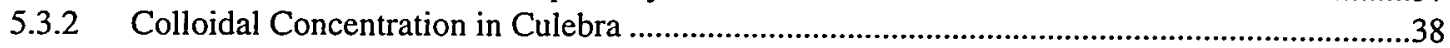

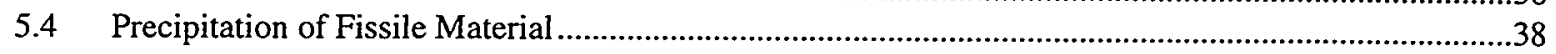

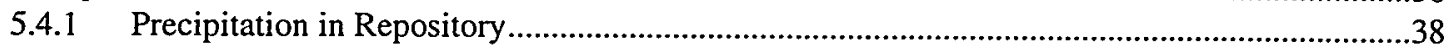

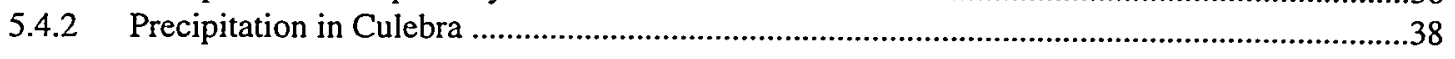

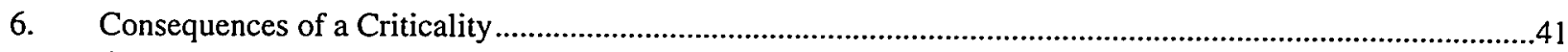

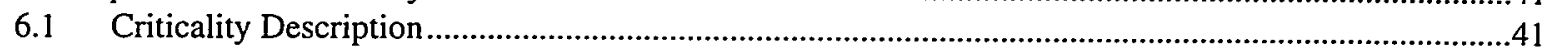

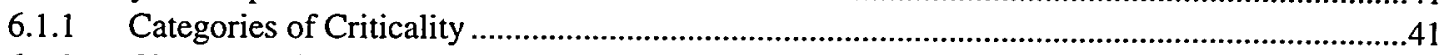

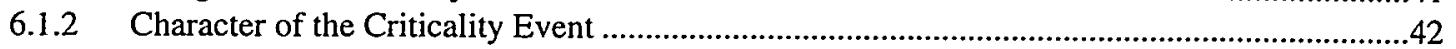

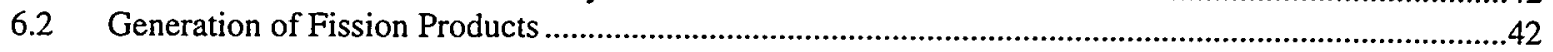

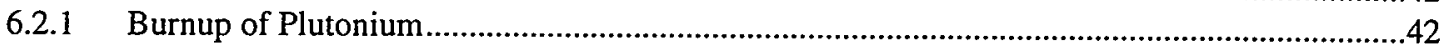

6.2.2 Fission Products Generated from Uranium Fission in the Repository .....................................43

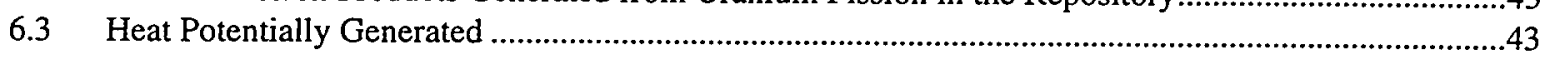

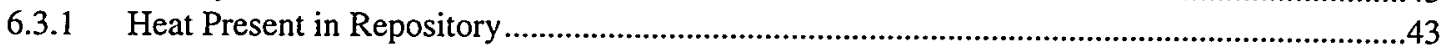

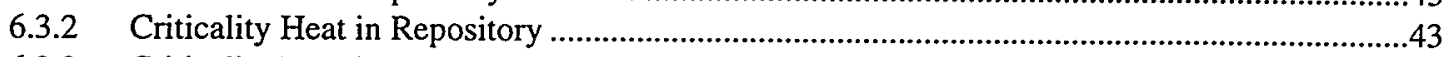

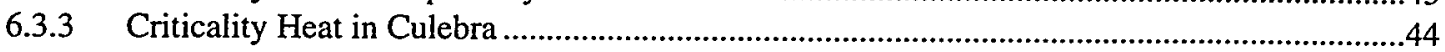

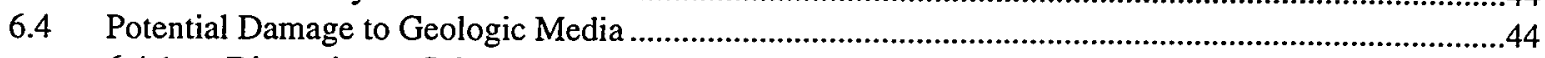

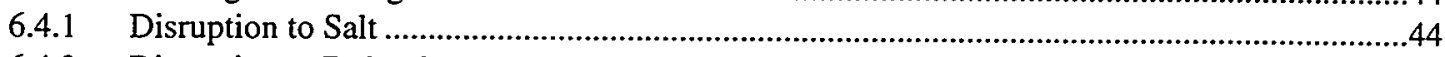

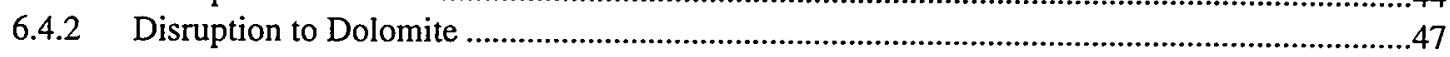

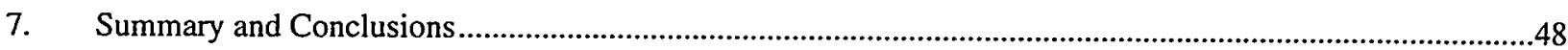

7.1 Use of Critical Concentration of Plutonium in Evaluating Probabilities ................................................48

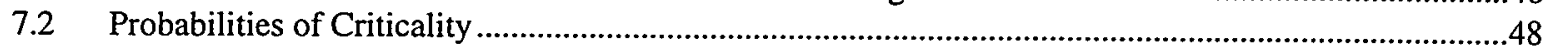

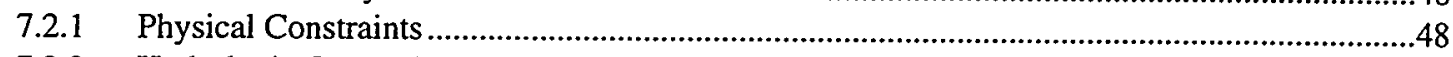

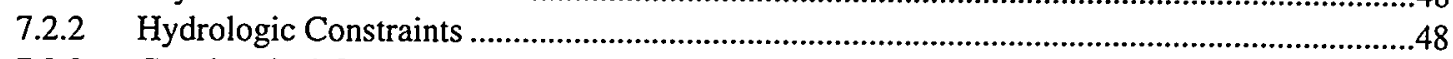

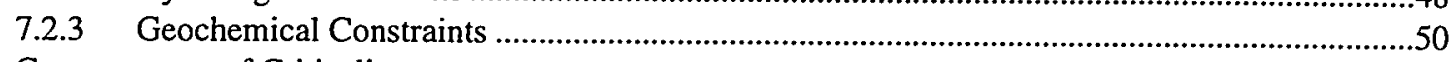

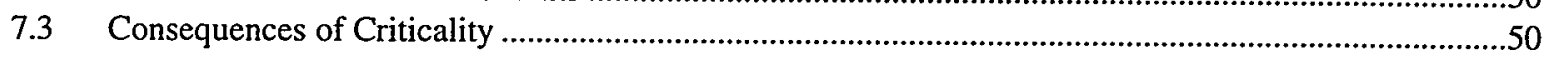

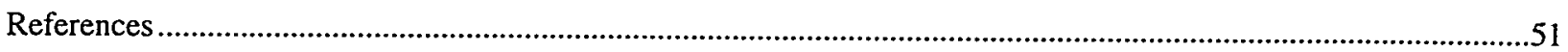




\section{Figures}

1 The influence of criticality on the performance measure (distribution of cumulative release)

depends on both the probability and consequence of the occurrence .........................................................

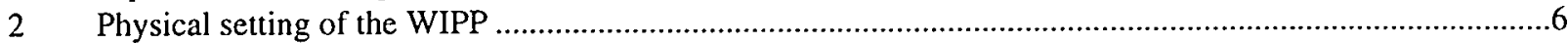

3 Stratigraphic column of formations interior to the Capitan reef in the Delaware Basin ...............................6

$4 \quad$ Stratigraphy above and below the WIPP repository ..................................................................................

5 Stratigraphic subdivisions of Culebra Dolomite Member of Rustler Formation .........................................9

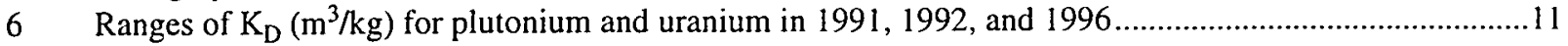

7 The WIPP repository in bedded salt, showing transuranic waste disposal area with eight panels, $657 \mathrm{~m}$ below surface and $436 \mathrm{~m}$ below Culebra Dolomite Member of Rustler Formation ..............12

8 Anticipated volumes of contact-handled transuranic (CH-TRU) waste per site ...........................................13

9 Anticipated activity and thermal power of waste in the WIPP repository ................................................13

10 Probability histograms for total concentration (dissolved species-assumed equal to solubility plus suspended colloidal material) for $\mathrm{Pu}^{\mathrm{III}}, \mathrm{Pu}^{\mathrm{IV}}, \mathrm{U}^{\mathrm{IV}} \mathrm{U}^{\mathrm{VI}}$, and $\mathrm{Th}^{\mathrm{IV}}$ in Salado and Castile brines obtained from sampling used in 1996 performance assessment.

11 Assumed total concentration of fissile material under oxiding and reducing conditions in Culebra and Castile/Salado brine at WIPP repository for calculations described in this report .................18

12 Human intrusion summary scenario (E2) considered in 1996 performance assessment simulations for Environmental Protection Agency standard 40 CFR 191

14 Cumulative brine flow up an intrusion borehole over $10,000 \mathrm{yr}$ after an intrusion that occurs 1000 yr after closure of the repository for the E2 scenario (intrusion without hitting a brine reservoir) in the first replication of the 1996 performance assessment calculation (R1S5)..............21

15 Comparison of calculated and measured critical masses in a homogeneous, spherical shape as a function of fissile solid concentration when mixed and reflected with water.

16 Calculated critical masses of ${ }^{239} \mathrm{Pu}$ in a spherical shape as a function of ${ }^{239} \mathrm{Pu}$ concentration

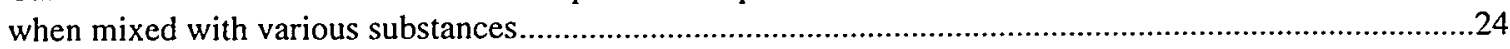

17 Critical masses of ${ }^{235} \mathrm{U}$ in a spherical shape as a function of ${ }^{235} \mathrm{U}$ concentration when mixed

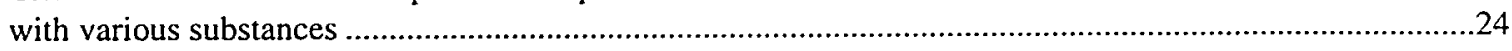

18 Calculated critical mass versus solid concentration of homogenous solutions of fissile, metallic ${ }^{235} \mathrm{U}$ and ${ }^{239} \mathrm{Pu}$ in hemispherical shape of water and goethite at $20 \%$ porosity ..

19 Critical thickness of plates of plutonium and uranium as a function of plutonium solid concentration in the Culebra.

20 Volume-average porosity in room (waste, any backfill, and empty space) for replication 1,

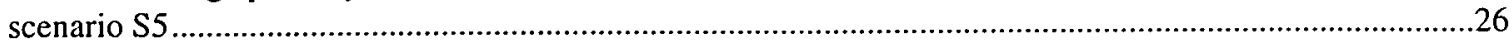

21 Liquid concentrations of plutonium in brine reaching Culebra in R1S5 ................................................2.27

22 Cumulative mass of ${ }^{239} \mathrm{Pu}$ reaching the Culebra through intrusion borehole over $10,000 \mathrm{yr}$ for R1S2, R1S3, R1S4, R1S5, and R1S6

23 General Eh-pH diagram of uranium formed by superimposing Eh-pH diagrams from several systems (U-C-O-H, U-O-H, U-Si-C-O-H, U-Si-O-H) .....................................................................

24 Speculative Eh-pH diagram of plutonium formed by superimposing Eh-pH diagrams from several systems (Pu-O-H and Pu-O-H-C system) .................................................................................. 30

25 Variation of adsorbed radioisotopes on iron oxides as function of solution concentration at neutral $\mathrm{pH}$

26 Solid concentration of plutonium from adsorption for R1S5 (replication 1, scenario 5), based on concentrations in Figure 21 (i.e., $C_{T} \cdot K_{D} \cdot \rho_{g}[1-\phi]$ ).

27 Calculated mixing of Castile $\left(309 \mathrm{~kg} / \mathrm{m}^{3}\right)$ minor discrepancy with Table 1) brine in Culebra with liquid injected from intrusion borehole using discharge and flow field from vector 23 , replicate 1 , shows that mixing zone area is too large to cause solid concentration at critical limit ...............39

28 Six basic types of criticality events. Similarities with natural or engineered systems are noted ..................41

29 Typical result of nuclear excursion using point reactor kinetics model ......................................................47 


\section{Tables}

$1 \quad$ Element Concentrations in Culebra, Salado, and Castile Brine .............................................................

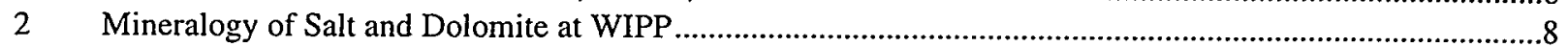

3 Percentages by Weight of Various Element Oxides that Form after Heating the Culebra

Dolomite and Oklo Sandstone ...........................................................................................................11

4 Anticipated Mass of Fissile Material in the WIPP Repository ...................................................................14

5 Example Calculation of Median Total Concentration for Actinides in Salado and Castile Brines for 1996 WIPP Performance Assessment ....................................................................................16

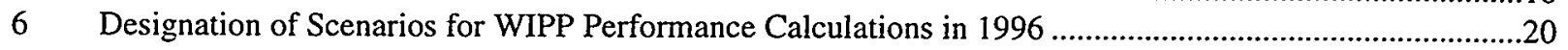

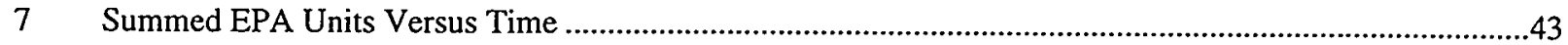

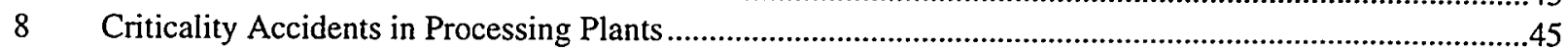

9 Criticality Accidents Involving Moderated Metal and Oxide Systems ........................................................46

10 Summary of Geophysical Arguments Supporting Low Probability of Criticality from Plutonium at WIPP 


\section{Introduction}

The purpose of this report is to present arguments that support the omission of the criticality event from the performance assessment calculations for the Waste Isolation Pilot Plant (WIPP), which is an operating facility for the disposal of waste contaminated with transuranic (TRU) radioisotopes created during manufacture of nuclear weapons. The work reported here supported the 1996 WIPP performance assessment as part of the Compliance Certification Application (CCA) (DOE, 1996) submitted to the U.S. Environmental Protection Agency (EPA) in October 1996 and approved in May 1998. Like any surface facility that handles fissile mate-

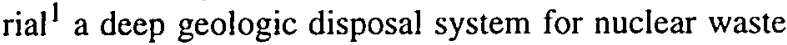
has to assess the probability and consequences of a sustained, nuclear chain reaction ${ }^{2}$ (i.e., a criticality ${ }^{3}$ ). The likelihood of assembling a critical mass at a location in or near a repository depends upon the geologic processes within the disposal system and the ability of these processes to facilitate the concentration of fissile radioisotopes so that they meet certain criteria necessary for a sustained nuclear chain reaction. Hence, in this report, both the likelihood of geologic processes (of interest to earth scientists) and the criteria necessary for criticality (of interest to nuclear engineers) are examined to develop a sense about the probability of occurrence of criticality. The consequences of criticality, should one occur, are also estimated.

\subsection{Background}

\subsubsection{The Waste Isolation Pilot Plant}

During World War II, radioactive waste produced by the Manhattan project was either disposed of in tanks or buried in trenches (e.g., Rechard, 1995; 1999). In 1970, the Atomic Energy Commission (AEC) began storing waste contaminated with TRU radioisotopes at the surface for eventual burial in a deep geologic repository. Although an abandoned mine near Lyons, Kansas, was initially examined as a salt repository, the AEC, at the invitation of New Mexico civic leaders, settled in 1974 on characterizing the $600-\mathrm{m}$-thick salt beds in the Delaware Basin in southeastern New Mexico for dis- posal of its waste. In December 1979, Congress authorized the then recently formed U.S. Department of Energy (DOE) to build at the selected site. The WIPP was designed and built as a full-scale pilot repository that accepts only the TRU portion of the military nuclear waste. Construction of the repository was essentially complete in 1988. The WIPP received its first shipment of waste in March 1999.

\subsubsection{Nuclear Criticality in Repositories}

Ideally, a radioactive waste repository prevents the release of radioisotopes for very long periods. However, this ideal situation implies that the initial solid concentration of fissile material in waste also remains for long periods. Prior to Congressional authorization of the WIPP in December 1979, the DOE considered disposing of defense high-level waste (i.e., waste from recycling spent fuel from government-owned nuclear reactors) at the WIPP in addition to TRU waste. During this early period, Allen (1978) reported that the critical mass of spherically shaped masses of fissile material, which might be included in the high-level waste, were surprisingly small. When these calculations were applied to proposed containers of high-level nuclear waste, the masses of fissile material in each container either were only slightly smaller or, in a few cases, were of similar size to these limits. Also in 1978, Winchester (1979) hypothesized a mechanism to segregate ${ }^{234} \mathrm{Am}$ from other actinides through preferential adsorption; the ${ }^{234} \mathrm{Am}$ could then decay to ${ }^{239} \mathrm{Pu}$ and then ${ }^{235} \mathrm{U}$, both of which are fissile material. In 1979, Clayton (1979) suggested a positive feedback mechanism for a critical event in soil, based on calculations by Carter (1973), who had evaluated the potential for criticality as part of a safety analysis of nuclear waste disposal in trenches at the Hanford, Washington, reservation. Allen's calculations (1978), together with Winchester's (1979) hypothesis, prompted a report by Brookins (1978), which described several geochemical constraints on accumulating critical masses of actinides in geologic repositories. In 1983, Stratton (1983) dismissed the allegations that a nuclear explosion had occurred at a waste disposal

1 Fissile material consists of primarily ${ }^{233} \mathrm{U},{ }^{235} \mathrm{U}$, and ${ }^{239} \mathrm{Pu}$ radioisotopes, which are fissioned by slow neutrons. Slow (thermal) neutrons have a much greater probability of being absorbed by a nucleus of fissile material.

2 Fission (splitting) of the nucleus of fissionable atoms (e.g., ${ }^{235} \mathrm{U}$ ) may occur when the fissionable atom absorbs a neutron (e.g., 5 out of 6 times for thermal neutrons by ${ }^{235} U$ ). Because more neutrons are emitted (e.g., 2 to 3 for ${ }^{235} U$ ) than the one required to start the fission, a chain reaction can occur if the loss of neutrons is not too great.

3 A critical condition (commonly called "criticality") denotes the assembly of sufficient fissile mass such that a threshold is reached whereby, over the long term, sufficient neutrons are generated from fissions to create a self-sustaining nuclear chain reaction and readily generate heat energy. Note, however, that the use of the word criticality, with regard to a nuclear chain reaction, does not bear the connotation of its medical equivalent, which infers threshold of death or human crisis, nor does it necessarily denote a nuclear explosion. 
site in the Ural Mountains in Russia. When the option to place high-level waste and spent nuclear fuel was blocked by Congress in 1979, the concern for criticality at the WIPP diminished because of the low initial concentrations of fissile material in TRU waste (in comparison to the potentially high concentration of fissile material in some DOE-owned spent nuclear fuel).

Nonetheless, criticality has been listed as an event for consideration in scenario development by the WIPP since 1979 (Bingham and Barr, 1979; 1980), prepared in support of the Draft and Final Environmental Impact Statements (EISs) in 1979 and 1980 (DOE, 1979; 1980). Based in part on studies of the WIPP, the International Atomic Energy Agency (IAEA) has listed criticality for consideration in its guidance to member countries that desire to site nuclear waste repositories for spent nuclear fuel and high-level waste since 1981 (IAEA, 1981). The DOE conducted traditional nuclear criticality safety studies on the storage and initial emplacement of the drums in the repository in the early 1980s (Lipner and Ravets, 1980; Blyckert and Carter, 1980) and concluded that the drum storage array in the WIPP would be subcritical $\left(k_{e f f}<1\right){ }^{4}$ The same conclusion was independently confirmed by an analysis done for the State of New Mexico Environmental Evaluation Group (EEG), although the EEG analysis disagreed with some aspects of the DOE analysis (Cohen, 1996a; 1996b). The EEG analysis also explored the possibility of dissolution, transport, and concentration of the fissile material in a dolomite rock with $10 \%$ porosity. With assumed concentrations in the rock of $27.6 \mathrm{mM}\left(6.6 \mathrm{~kg} / \mathrm{m}^{3}\right)$ for ${ }^{239} \mathrm{Pu}$ and $4.7 \mathrm{mM}\left(1.1 \mathrm{~kg} / \mathrm{m}^{3}\right)$ for ${ }^{233} \mathrm{U}$, a fissile mixture that was greater than $0.5 \mathrm{~m}$ thick was supercritical $\left(k_{\text {eff }}>1\right)$ (Cohen, 1996c). The discussion noted that "the consequences to the accessible environment should not be very high" (Cohen, 1996c). The study also cited analogous aqueous criticality accidents reported by Stratton (1967; see also Stratton and Smith, 1989; Knief, 1985; and Rechard et al., 1996b) and the natural reactors in the Oklo ore deposit in Gabon, Africa (Cowan, 1976; see also Rechard et al., 1996b).

The preliminary screening of features, events, and processes (FEPs) performed for the WIPP by Hunter (1989) and Galson and Swift (1995) retained nuclear criticality for more thorough investigation. Also, news articles in 1995 (Taubes, 1995) drew attention to speculative scenarios proposed by Bowman and Venneri (1996) with regard to an atomic explosion occurring in the potential tuff repository at Yucca Mountain, Nevada, speculation that probably received more attention than it deserved (Whipple, 1996). Soon after, critics argued against the possibility of such a large energy release both qualitatively (Canavan et al., 1995; Van Konynenburg, 1996) and quantitatively (Sanchez et al., 1995; Kimpland, 1996; and Kastenberg et al., 1996). This report describes the difficulty of creating conditions conducive to any type of criticality-explosive or otherwise-with TRU waste.

\subsection{Performance Assessment}

The process of assessing whether a nuclear waste disposal system meets a set of performance criteria is a performance assessment (PA). Based on scientific information, the performance assessment provides important input to decisions about the safety of a nuclear waste disposal.

\subsubsection{Performance Assessment Process}

As far back as 1660 , probability's usefulness in helping with decisions was apparent to mathematicians, who noted that "fear of harm ought to be proportional not only to the gravity of the harm, but also the probability of the event" (Hacking, 1975, p. 77). Today's concept of performance assessment includes both probability and consequences and adds a third component, different scenarios ${ }^{5}$ to a harmful condition. Specifically, the performance assessment process answers three basic questions (Kaplan and Garrick, 1981; Helton et al., 1993; Rechard, 1995): What unwanted features, events, and processes (FEPs) or scenarios may occur? What is the probability of each FEP or scenario? What are the consequences of each FEP or scenario? The first question is answered through a scenario development process. The second and third questions are answered through a modeling process. Several iterations of the PA process are usually necessary to eliminate those FEPs or scenarios with negligible influence and to improve the modeling of retained FEPs or scenarios. The former is usually called FEP or scenario screening.

4 If n "stray" neutrons are introduced into a region of fissile material initially, there will be $k n$ in the second generation, $k^{2} n$ in the third generation, and so on. In all, the total number of neutrons that would appear is $n \sum k^{r}$ where $k$ is the multiplication factor ( $k_{\text {eff }}$ in real systems) equal to the ratio of number of neutrons in one generation to number of neutrons in the preceding generation. Three possible situations exist for $k: k<1$ subcritical (i.e., zero or decreasing fission rate or power); $k=1 \mathrm{critical}$

5 (i.e., constant fission rate or power); $k>1$ supercritical (i.e., increasing fission rate or power). development requires system characterization. Also, once probabilities and consequences of scenarios have been calculated, they must be combined and compared to established regulatory performance criteria. Finally, for the modeling results to be meaningful to the waste disposal program, a sensitivity analysis on the model parameters may be performed. 


\subsubsection{FEP Selection and Screening}

The formal and defensible selection of FEPs for inclusion in modeling is an important step in performance assessment and one of the aspects that sets performance assessment apart from typical scientific modeling or engineering analysis. In this report, one potential event—criticality-is discussed.

Screening of FEPs requires well defined criteria. The criteria employed to omit FEPs are based on either regulatory guidance for the modeling style (such as the regulatory period) or predictions of negligible influence on the performance measure (here composed of both probability and consequence).

\subsubsection{Performance Criteria}

The U.S. Congress, in the Nuclear Waste Policy Act (NWPA) of 1982, established the policy that the present generation would bear the political and financial costs of developing a permanent disposal option for nuclear waste. In 1985, in response to the NWPA, the EPA promulgated the standard, 40 CFR Part 19I-Environmental Standards for the Management and Disposal of Spent Nuclear Fuel, High-Level and Transuranic Radioactive Wastes (EPA, 1985a), which had been under study since 1977 . The standard was remanded by the courts shortly thereafter but was repromulgated with only minor changes in 1993 (EPA, 1993). In the WIPP Land Withdrawal Act (WIPP LWA) of 1992, Congress directed that the EPA implement this standard for the WIPP Project. In response, EPA promulgated $40 \mathrm{CFR}$ Part 194-Criteria for the Certification and Re-Certification of the Waste Isolation Pilot Plant's Compliance with the 40 CFR Part 191 Disposal Regulations (EPA, 1996).

Neither 40 CFR 191 nor 40 CFR 194 provides specific guidance regarding the occurrence of criticality after closure of the WIPP repository. Rather, risks associated with a critical condition are evaluated under the general provisions of the standard. The Ground Water Protection Requirement requires that the activity from alpha decaying radioisotopes remain below $15 \mathrm{pCi}$. The Individual Protection Requirement requires that the mean individual dose remain below $15 \mu \mathrm{Sv} / \mathrm{yr}$. The primary provision of 40 CFR 191, the Containment Requirements, requires an evaluation of probabilities of cumulative release at the disposal system boundary over 10,000 yr (actually a complementary cumulative distribution function [CCDF]) to remain less than two points in probability space: a summed normalized release less than 1 with a probability of 0.1 and a summed normal- ized release less than 10 with a probability of 0.001 . A distribution of release is produced because uncertainty from various sources must be included in the analysis.

\subsubsection{Guidance on Calculations at WIPP}

Because the performance criteria must be compared with predictions of future behavior, it is necessary to use a system model rather than monitor the actual system itself. Hence, performance assessment is intimately tied to the process of building scientific models. The model must represent the actual environment ("real-world") in those aspects vital to disposal system performance. The EPA set the guiding philosophy for selection of the environmental aspects and construction of models, including the regulatory period, the type of natural and anthropogenic phenomena to be considered in the model, and criteria for omitting features, events, and processes.

\subsubsection{Regulatory Period}

The EPA's goal for the disposal standard was to provide protection for as long as the wastes presented an unacceptable risk (EPA, 1985b, pp. 64-68). The EPA selected $10,000 \mathrm{yr}$ as the time period of regulation for the Containment Requirements. The agency believed that within 10,000 $\mathrm{yr}$ "many of the radionuclides that [could] pass through groundwater transport paths [would] have reached surface water and the accessible environment" and that "the radiological hazard of the wastes would be substantially reduced through the decay of most of the significant fission products and many of the actinides" (EPA, 1985b, p. 66). The EPA also stated that, because $10,000 \mathrm{yr}$ is a short period of time geologically, changes in geological conditions were expected to be small (EPA, 1985b, p. 67). Time periods of 100 and $1000 \mathrm{yr}$ were rejected because few health effects were predicted for that time span-many radioisotopes would be in transit toward the accessible environment, the probability of disruptive events would be low, and many of the important radioisotopes would not have undergone significant radioactive decay. Periods of time longer than $10,000 \mathrm{yr}$ were rejected because making quantitative assessments of the potential environmental impacts of waste disposal over such time periods would be difficult and predictions of geological changes would not be reliable.

\subsubsection{Human Intrusion}

The standard, 40 CFR 191, and the implementing regulation, $40 \mathrm{CFR} 194$, require the DOE to demonstrate that the WIPP will comply with the performance criteria after inadvertent human intrusion, i.e., humans 
unknowingly intruding into the repository with an exploratory drill hole. According to regulatory guidance (EPA, 1985a; 1993; 1996), once the borehole is abandoned, any plug, such as concrete, is conservatively assumed to degrade to the permeability of sand, which represents complete degradation of the plug without any salt creep or salt precipitation of chemical species in the brine flowing into the pores. The assumption of no closure of the borehole (either through salt creep or precipitation minerals from solution) is conservative over the 10,000 -yr regulatory period and certainly unrealistic for a period longer than 10,000 yr (i.e., it is unrealistic to assume that the flow system that potentially results from degradation of the concrete plugs remains active forever in a formation of creeping salt).

The requirement by the EPA to address human intrusion defeats, to a large degree, the advantage of the nearly ideal properties of salt in containing the nuclear waste and focuses instead on other aspects of the WIPP disposal system, such as adsorption of radioisotopes and the existence of nonpotable water in an aquifer above the salt beds. ${ }^{6}$ Hence, it is important to emphasize that without inadvertent intrusion, the probability of criticality is easily argued as being practically zero; only with intrusion do the arguments require more sophistication.

\subsubsection{Regulatory Criteria for Screening Features, Events, and Processes}

In Appendix C of $40 \mathrm{CFR} 191$ and in 40 CFR 194.32, the EPA allows omission of categories of features, events, and processes with probabilities of occurrence less than $10^{-4}$ in 10,000 yr. $^{7}$ In this context, a feature is an aspect or condition of the disposal system, an event is a short-term natural or anthropogenic phenomenon, and a process is a long-term natural phenomenon (i.e., a phenomenon that occurs over a significant portion of the time frame of interest).

\subsection{Overall Approach}

Because the performance measure (i.e., CCDF) includes both a probability component and consequence component, the overall approach in this report is to use arguments of both low probability and low consequence to demonstrate that criticality could be appropriately eliminated from inclusion in the compliance perfor- mance assessment for the WIPP. Although the distribution of the performance measure is actually used, conceptually this approach is readily shown using the expected value of the performance measure (probability times consequence).

\subsubsection{Probability}

Support for the low probability (or the low consequences discussed later) depends upon constraints from two types of modeling: nuclear criticality and geophysical modeling (Figure 1).

Concerning the probability of occurrence, nuclear criticality modeling is used to develop physical constraints on fissile mass and geochemical constraints on fissile concentration. Geophysical modeling is used to evaluate the feasibility of exceeding these bounds by examining whether physical, hydrologic, or geochemical constraints exist.

To elaborate, if the probability of any scenarios containing the criticality event is less than $10^{-4}$ (i.e., $P\left\{S_{j}\right\}<10^{-4}$ ), then the criticality event can be omitted, as mentioned in Section 1.2.4.3. Assuming that probabilities of events that make up a scenario $S_{j}$ are independent, then any scenario containing a criticality event is less than $10^{-4}$ if the probability of criticality is less than $10^{-4}$. For example, if $P\left\{S_{j}\right\}=P\{H I\} \cdot \ldots \bullet P\{C\}$, then $P\left\{S_{j}\right\}<10^{-4}$ if $P\{C\}<10^{-4}$, where $P\{H I\}$ is the probability of a human intrusion event and $P\{C\}$ is the probability of a criticality event. In turn, the probability of criticality is the conditional probability times the probability that physical, hydrologic, and geochemical constraints are absent. That is, $P\{C\}=P(C \mid p \cap h \cap c) \cdot$ $P\{p\} \cdot P\{h\} \cdot P\{c\}$, where $P(C \mid p \cap h \cap c)$ is the conditional probability of criticality given no obvious physical, hydrologic, or geochemical constraints, $P\{p\}$ is the probability of no physical constraints, $P\{h\}$ is the probability of no hydrologic constraints, and $P\{c\}$ is the probability of no geochemical constraints to criticality. Geophysical arguments attempt to evaluate each of the four factors that comprise $P\{C\}$. For example, the conditional probability is evaluated through analogy with the Oklo natural reactors (Rechard et al., 1997). This simple abstract view of the probability of criticality is used herein to organize the arguments for the low probability of criticality at the WIPP.

6 The NAS (NAS/NRC, 1995; 1996) has commented on the EPA's emphasis on determining compliance based on results that assume human intrusion.

7 For engineered nuclear facilities, the Nuclear Regulatory Commission (NRC) at one time attempted to define an incredible event as an event with a frequency of occurrence less than at least $10^{-6} / \mathrm{yr}$. The EPA chose a conservative frequency of occurrence of $10^{-8} / \mathrm{yr}$. 


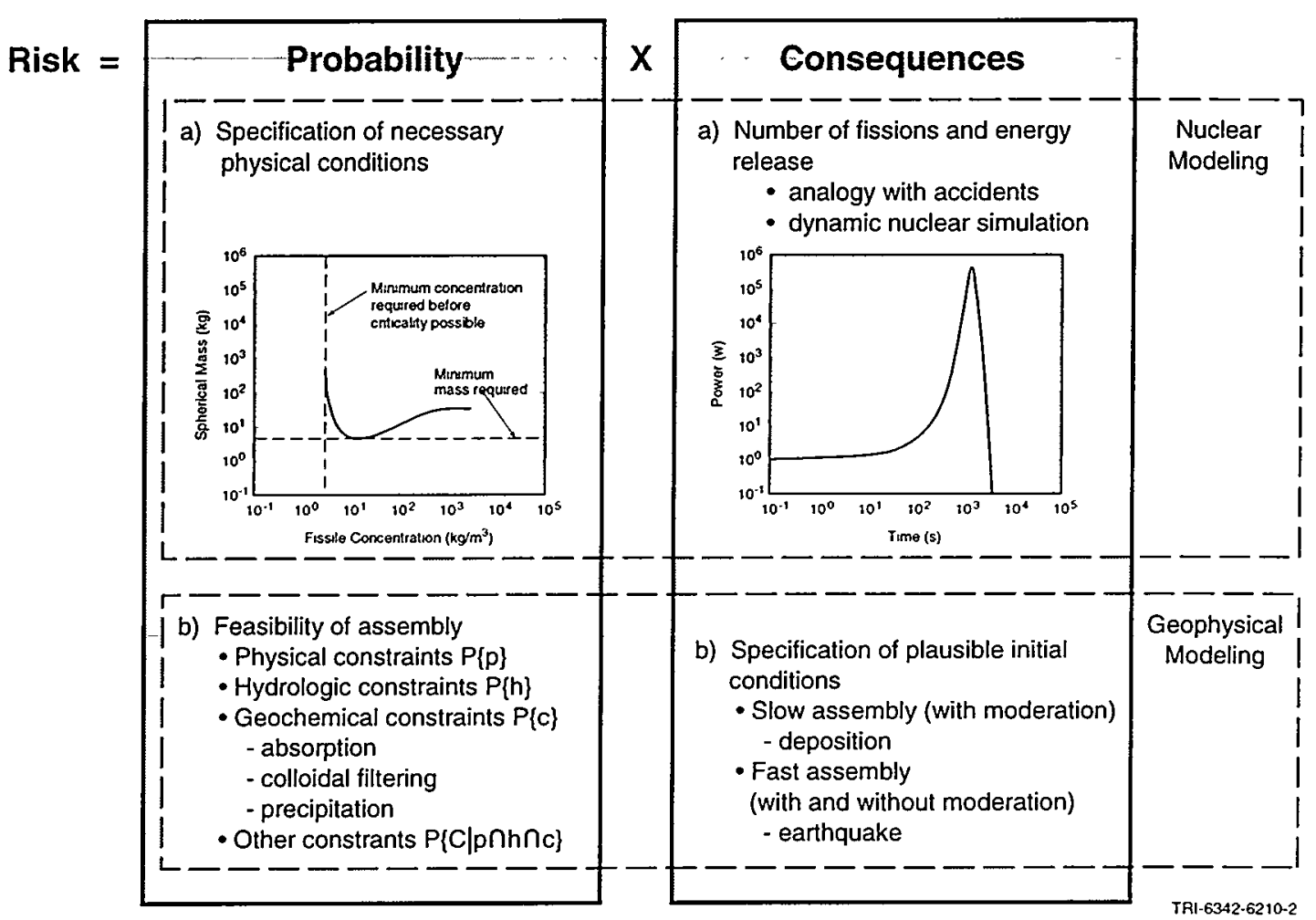

Figure 1. The influence of criticality on the performance measure (distribution of cumulative release) depends on both the probability and consequence of the occurrence. In turn, evaluation of either the probability or consequence depends on two types of simulation: nuclear criticality modeling and geophysical modeling. (Although the distribution of cumulative release is actually used, risk is shown schematically here as the expected value of the consequence.)

\subsubsection{Consequences}

For criticality to have the potential to affect human health after repository closure, assuming a criticality could occur, it would have to either (1) degrade the ability of the disposal system to contain nuclear waste or (2) produce more hazards than originally present. Hence, these two categories of consequences are examined at the end of the report through analogy with anthropogenic criticality accidents.

\subsubsection{Use of General and Specific Arguments}

When presenting arguments in this report, the authors first discuss general constraints from geophysical modeling. Although this approach does not always provide a definitive result, it can be useful in conveying the arguments to a wide audience. The authors then discuss arguments based upon specific calculations of the behavior of the WIPP. That is, the PA models simulate the evolution of the disposal system and the behavior is monitored to determine whether conditions exist in which a criticality could occur. For example, the argument for low probability of a criticality in the far field is supported both by arguments of the unlikelihood of adsorbing only ${ }^{239} \mathrm{Pu}$ on dolomite without adsorbing any other material from the brine and by examining results of the 1996 performance assessment for the WIPP, which shows that only small amounts of ${ }^{239} \mathrm{Pu}$ are transported from the repository over 10,000 yr. In addition, arguments are grouped by location, i.e., the repository (near field) and the Culebra Dolomite Member of the Rustler Formation (far field). The arguments are differentiated because location can affect specific arguments. That is, although both locations may lack a credible means to concentrate enough fissile material to form a critical mass, the specific reasons for the absence of such mechanisms might be different for each location.

Section 2 of this report is a fairly detailed discussion of information pertinent to specific arguments presented in Sections 3 through 6. The reader may prefer to skip over Section 2 now, using it as a reference later when examining specific arguments. 


\section{Description of WIPP Disposal System}

Over the past 20 years, the characteristics of the WIPP disposal system have been well documented (DOE, 1980; Rechard, 1995; 1999). Thus, the discussion below provides only a rudimentary introduction to the WIPP disposal system, followed by details of disposal system components that are pertinent to the arguments against criticality. For this discussion, the WIPP disposal system is grouped into three components: (1) geologic characteristics of the site and natural barriers, (2) design of the repository and engineered barriers, and (3) waste inventory and characteristics.

\subsection{Location and Stratigraphy}

\subsubsection{Physical Setting}

The WIPP is located in southeastern New Mexico $42 \mathrm{~km}$ east of Carlsbad, New Mexico. There is relatively little local topographic relief. Major geographical features in the area include Laguna Grande de la Sal playa lake $9.5 \mathrm{~km}$ to the southwest; the Pecos River, the principal surface-water drainage in southeastern New Mexico, $20 \mathrm{~km}$ to the southwest; and Nash Draw, $8 \mathrm{~km}$ to the west of the site (Figure 2). Nash Draw is a karst valley, with no surface drainage, formed by the coalescence of collapse features. It is $29 \mathrm{~km}$ long with a maximum relief of $120 \mathrm{~m}$ (Hill, 1996).

\subsubsection{Stratigraphy}

The geology of southeastern New Mexico has been of great interest because of the potash and hydrocarbon resources in the area and because of the academically interesting exposures of ancient reefs. Hence, extensive literature exists on the general stratigraphy (DOE, 1996, Chapter 2; Rechard, 1995; 1999). For the WIPP, the Delaware Basin's Permian-age sedimentary rock and the Capitan limestone reef rock that surrounds it (Figure 2) are the most important geologic aspects. The lowest strata depicted here are the formations of the Delaware Mountain group of the Guadalupian series (Figure 3). The Bell Canyon Formation, which is composed of nearly impermeable interbeds of anhydrite and halite, isolates the overlying strata from deeper strata. Overlying the Bell Canyon is the Castile Formation of the Ochoan series, which is found only on the interior of the Capitan limestone reef. The overlying Salado Formation extends far beyond the Capitan reef. Overlying the Salado are the Rustler and Dewey Lake Formations. Only thin deposits lie above the Dewey Lake Formation.

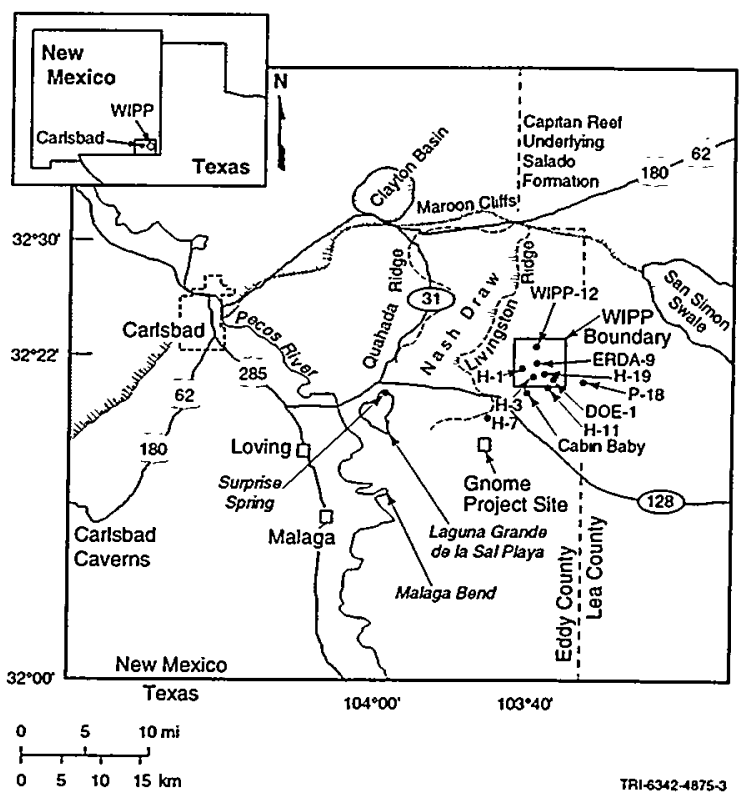

Figure 2. Physical setting of the WIPP (after Rechard, 1995, Figure 2.1-1).

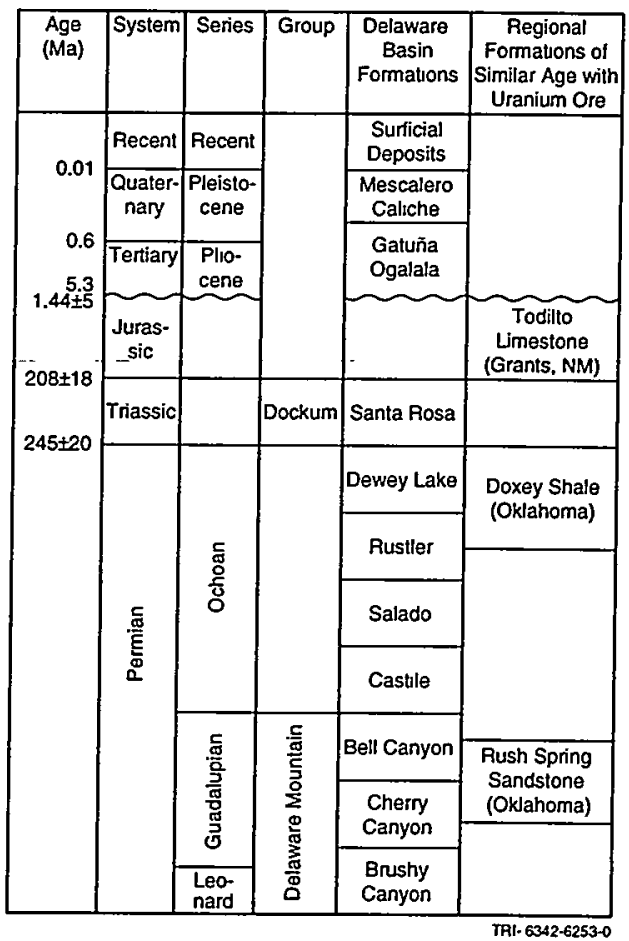

Figure 3. Stratigraphic column of formations interior to the Capitan reef in the Delaware Basin (after DOE, 1996, Figure 2-4). Other formations of similar age or material containing uranium deposits are also shown. 
Pertinent lithologic aspects of the Castile, Salado, and Rustler Formations are discussed below.

\subsubsection{Castile Formation}

The 500-m thick Castile Formation (hereafter shortened to the Castile) consists of three anhydrite members, and two interspersed halite members (Figure 4). Pressurized brine reservoirs have been intersected in the fractured Anhydrite III (uppermost) layer of the Castile by one well within the land-withdrawal boundary (WIPP-12) and, outside the boundary, by 11 out of about 100 nearby wells (Lappin et al., eds. 1989, Figure 3-26). The WIPP performance assessment traditionally assumes that a pressurized brine ${ }^{8}$ reservoir (with chemical composition as noted in Table 1) exists beneath a portion of the repository for the next $10,000 \mathrm{yr}$.

\subsubsection{Salado Formation}

The 600-m-thick Salado Formation (hereafter shortened to the Salado) hosts the repository about $655 \mathrm{~m}$ below the surface. The Salado consists primarily of nearly horizontal $\left(<1^{\circ}\right.$ dip) halite $(\mathrm{NaCl})$ (Table 2$)$ and occasional interbeds of minerals such as clay and anhydrites $\left(\mathrm{CaSO}_{4}\right)$ of the Late Permian Period ( 255 million year old [255 Ma]). Anhydrite interbeds directly above (anhydrite layers "a" and "b") and $1 \mathrm{~m}$ below (Marker Bed 139) the repository floor are three of about 45 interbed units within the Salado that can potentially drain brine (Table 1) into the repository (Figure 4).

\subsubsection{Culebra Dolomite Member of Rustler Formation}

The Rustler Formation overlies the Salado (Figure 4). The Culebra Dolomite Member of the Rustler Formation (hereafter shortened to the Culebra), which consists of dolomite and dolomitic limestone, is the most permeable stratigraphic unit near the repository. Although radioisotope release via groundwater is unlikely overall (Rechard, 1999; Helton et al., 1998), the Culebra is the most likely pathway relative to other pathways for lateral transport of radioisotopes away from the repository. Although the character of the Culebra varies over its great area $\left(25,000 \mathrm{~km}^{2}\left[\sim 9650 \mathrm{mi}^{2}\right]\right)$, it changes little within the WIPP land-withdrawal boundary ( $\left.41 \mathrm{~km}^{2}\left[16 \mathrm{mi}^{2}\right]\right)$. Close to the repository, the Culebra has an average thickness of $7.0 \mathrm{~m}$ (Holt, 1997).

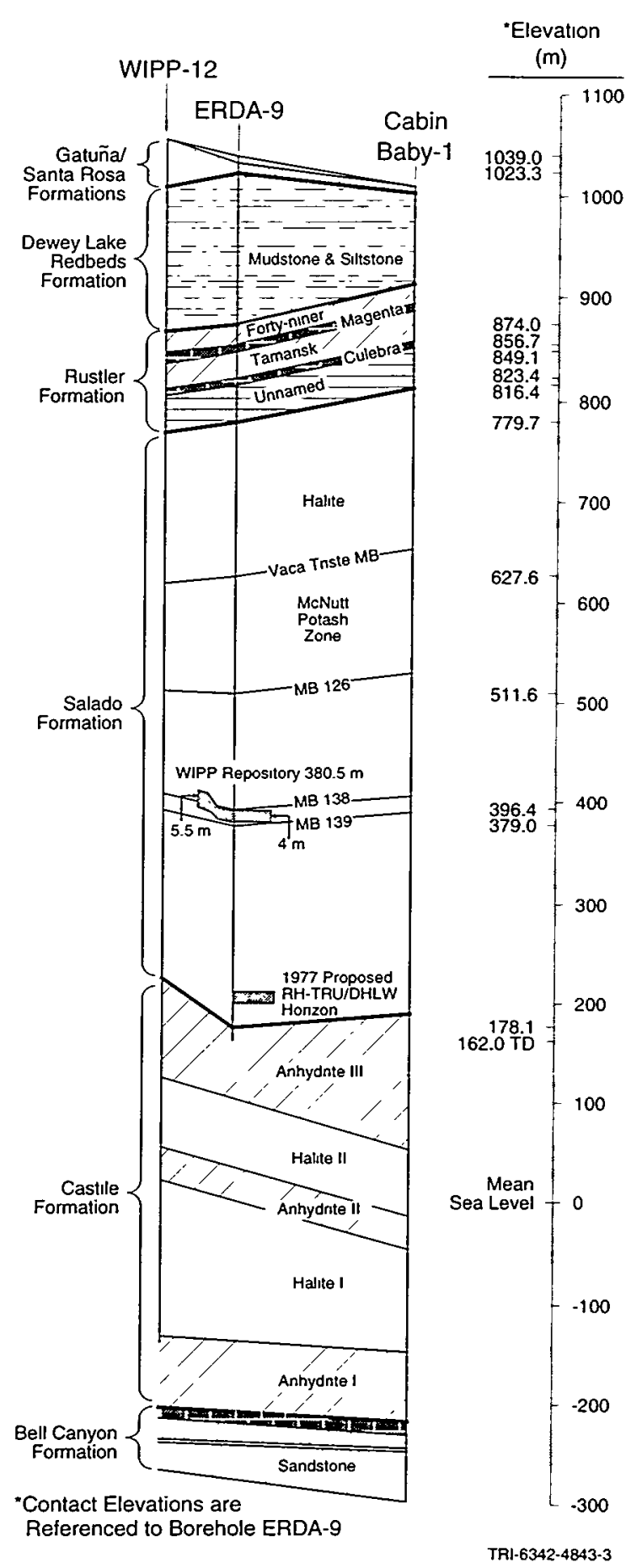

Figure 4. Stratigraphy above and below the WIPP repository (Rechard, 1999, Figure 3-3).

8 Herein brine refers to an aqueous solution with total dissolved solids (TDS) greater than $30,000 \mathrm{mg} / \mathrm{l}$. For comparison, brackish water refers to solutions with TDS between 3000 and $30,000 \mathrm{mg} / \mathrm{l}$; fresh water refers to solutions with TDS less than $3000 \mathrm{mg} / \mathrm{l}$. 
Table 1. Element Concentrations in Culebra, Salado, and Castile Brine (Papenguth and Behl, 1996a, Table 2).

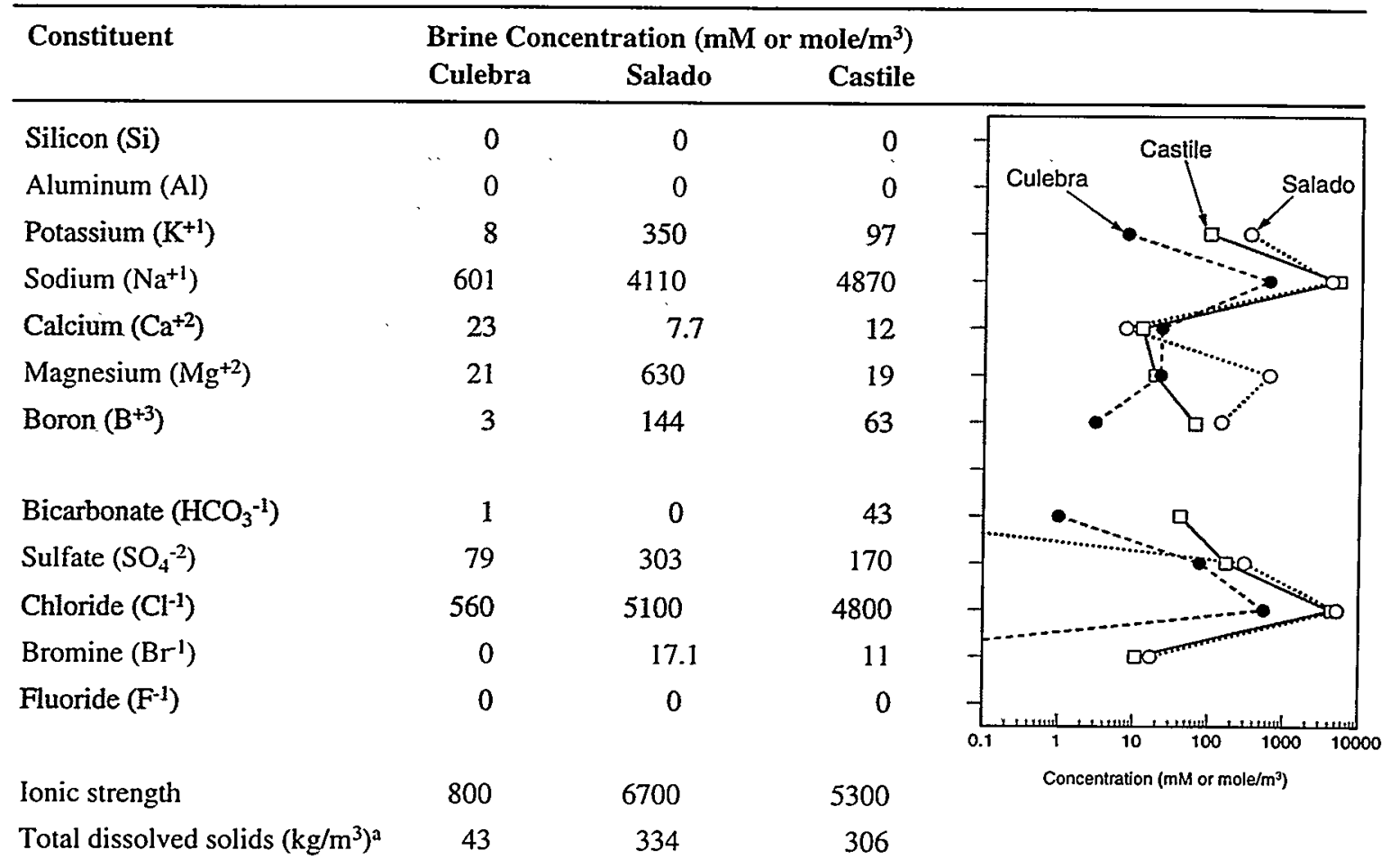

a Sum of constituents reported here

TR1-6342-4852-2

Table 2. Mineralogy of Salt and Dolomite at WIPP

\begin{tabular}{|c|c|c|c|}
\hline \multicolumn{2}{|r|}{ Mineral } & Density $\left(\mathrm{kg} / \mathbf{m}^{3}\right)$ & $\%$ wt \\
\hline \multicolumn{4}{|c|}{ Culebra Dolomite $^{a}$} \\
\hline Dolomite & $\mathrm{CaMg}\left(\mathrm{CO}_{3}\right)_{2}$ & 2872 & 91.5 \\
\hline Gypsum & $\mathrm{CaSO}_{4} \cdot 2 \mathrm{H}_{2} \mathrm{O}$ & 2320 & 3 \\
\hline Quartz & $\mathrm{SiO}_{2}$ & 2650 & 1.5 \\
\hline \multicolumn{4}{|l|}{ Clay } \\
\hline Corrensite & $\begin{array}{l}\mathrm{Ca}_{0.07} \mathrm{Na}_{0.22} \mathrm{~K}_{0.66}\left(\mathrm{Al}_{3.13} \mathrm{Fe}_{0.09} \mathrm{Mg}_{12.86}\right) \\
\mathrm{Al}_{1.91} \mathrm{Si}_{14.09} \mathrm{O}_{40}(\mathrm{OH})_{20} \\
\mathrm{~K} \mathrm{Al}_{4}\left(\mathrm{Si}_{7} \mathrm{Al}_{20}\right)(\mathrm{OH})_{4}\end{array}$ & $\begin{array}{c}2950^{b \cdot c} \\
2750^{c}\end{array}$ & $\begin{array}{l}2.4 \\
1.6\end{array}$ \\
\hline Illite & Average density & 2850 & \\
\hline \multicolumn{4}{|c|}{ Salado Halite $^{d}$} \\
\hline Halite & $\mathrm{NaCl}$ & 2165 & 93.2 \\
\hline Polyhalite & $\mathrm{K}_{2} \mathrm{MgCa}_{2}\left(\mathrm{SO}_{4}\right)_{4} \cdot 2 \mathrm{H}_{2} \mathrm{O}$ & 2775 & 1.7 \\
\hline Anhydrite & $\mathrm{CaSO}_{4}$ & 2610 & 1.7 \\
\hline Gypsum & $\mathrm{CaSO}_{4} \cdot 2 \mathrm{H}_{2} \mathrm{O}$ & 2320 & 1.7 \\
\hline \multirow[t]{2}{*}{ Magnesite } & $\mathrm{MgCO}_{3}$ & $\underline{3009}$ & 1.7 \\
\hline & Average density & 2160 & \\
\hline $\begin{array}{l}\text { Sewards et a } \\
\text { Density of cl. } \\
\text { Weast, ed., } 1 \\
\text { Brush, 1990. }\end{array}$ & $\begin{array}{l}\text { 1992, WIPP-12; Siegel et al., 1991, Chapter } 3 \text {. } \\
\text { rite, which derives from corrensite. } \\
4, \text { pp. B-193-B-195. } \\
\text { sumed asence of silica for PA modeling. }\end{array}$ & & \\
\hline
\end{tabular}




\subsubsection{Description}

Within the WIPP Project, the Culebra has been divided into four hydrostratigraphic units described by Holt (1997) (Figure 5). The uppermost unit, Culebra Unit 1 , is generally distinct, parallel bedded strata. Its thickness ranges from 2.5 to $3.2 \mathrm{~m}$ and averages $2.99 \mathrm{~m}$ (Figure 5). Any fractures tend to occur along bedding planes. Subvertical fracturing occurs only locally.

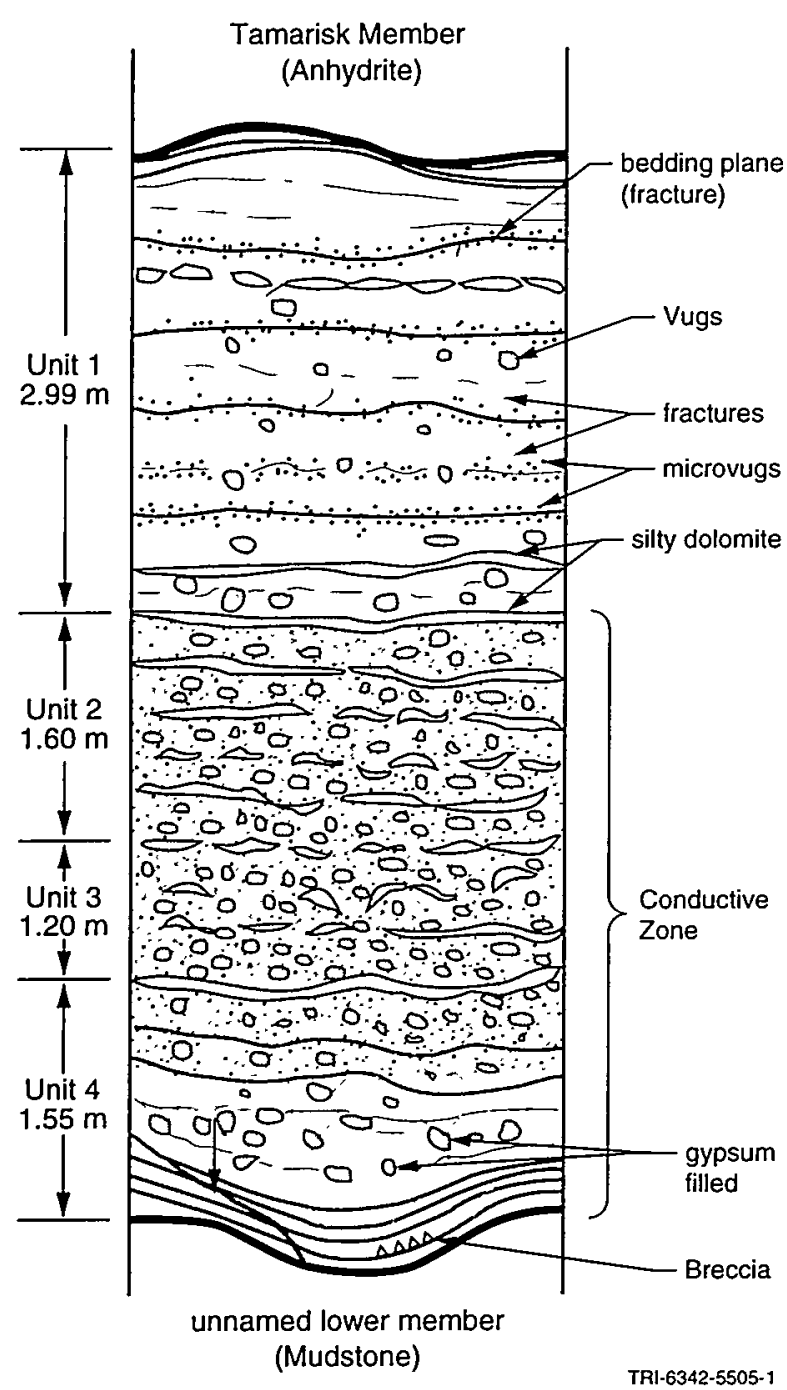

Figure 5. Stratigraphic subdivisions of Culebra Dolomite Member of Rustler Formation (Rechard, 1999, Figure 3-6).
The middle Culebra Units, 2 and 3, are similar (Figure 5). Both units have thin, discontinuous interbeds of silty dolomite and are highly fractured. The fractures typically extend less than $5 \mathrm{~cm}$ and connect numerous vug units. The fractures are open or gypsum-filled, with apertures up to $0.2 \mathrm{~cm}$ wide. Originally, the vugs were anhydrite pockets that hydrated to gypsum nodules during sedimentation; subsequent dissolution and removal of gypsum left the vugs. Culebra Unit 2 is between 1.4 and $1.8 \mathrm{~m}$ thick, with silty dolomite beds more persistent areally than in the lower Culebra Unit 3, and with vugs that are often partially or completely collapsed. Culebra Unit 3 is between 1.0 and $1.5 \mathrm{~m}$ thick, with an average of $1.2 \mathrm{~m}$. Larger (up to $5-\mathrm{cm}$ diameter) vugs and gypsum nodules are present. Because of fracturing, intact pieces of core from Culebra Unit 3 are rare.

The lowermost Culebra Unit 4 is typically between 1.4 and $1.9 \mathrm{~m}$ thick, with an average thickness of $1.55 \mathrm{~m}$ near the repository. The lower contact of Culebra Unit 4 with the unnamed member of the Rustler Formation is irregular, with undulations up to $1.0 \mathrm{~m}$ in WIPP shafts. Small, open microvugs $(<3 \mathrm{~mm})$ are common in the vicinity of the bedding planes. Occasionally, large vugs and gypsum nodules (up to $8 \mathrm{~cm}$ in diameter) may occur near the lower contact.

\subsubsection{Effective Thickness}

Mercer and Orr (1979) reported that based on ${ }^{131} \mathrm{I}$ tracer tests at $\mathrm{H}-3$ hydropad, $100 \%$ of the flow came from the lower $3 \mathrm{~m}$ ( $10 \mathrm{ft}$ ) of the Culebra. In descriptions of the Air Intake Shaft, Holt and Powers (1990) noted that most of the fluid observed came from the lower portion of the Culebra. Also, hydraulic tests and fluid logging at $\mathrm{H}-19$ hydropad suggested that the permeability of Culebra Unit 1 was significantly lower than the permeability of the lower Culebra. Tracer tests in 1996 at H-19 confirmed that Culebra Unit 1 does not contribute to solute transport. Therefore, the hydrologic effective thickness of Culebra was taken as $\sim 4 \mathrm{~m}$ ( $7.34 \mathrm{~m}$ minus the $3 \mathrm{~m}$ for Culebra Unit 1 ) (Meigs and McCord, 1996).

\subsubsection{Transmissivity}

In the vicinity of the WIPP, the transmissivity ${ }^{9}$ of the Culebra has been measured at 47 locations. The highest transmissivity is west of the WIPP landwithdrawal boundary at Nash Draw (H-7, $1.5 \times 10^{-3}$

9 Transmissivity $\left(T_{h}\right)\left(\mathrm{m}^{2} / \mathrm{s}\right)$ is the rate at which water, driven by a unit hydraulic gradient, is transmitted through a unit depth of aquifer, i.e., it is the hydraulic conductivity $\left(K_{h}\right)(\mathrm{m} / \mathrm{s})$ of the aquifer times its thickness $(B)(\mathrm{m})$, where hydraulic conductivity is the constant of proportionality in Darcy's law of flow through porous media. Hydraulic conductivity $\left(K_{h}\right)$ is the permeability $\left(k_{h 1}\right)\left(\mathrm{m}^{2}\right)$ times fluid unit weight $(\mathrm{kg} / \mathrm{m} \cdot \mathrm{s})$ (fluid density times acceleration due to gravity, $\left.\gamma=\rho \mathrm{g}\left[\left(\mathrm{kg} / \mathrm{m}^{3}\right)\left(\mathrm{m}^{2} / \mathrm{s}\right)\right]\right) \mathrm{divided}$ by the fluid dynamic viscosity $(\mu)\left(\mathrm{kg} / \mathrm{m}^{3} \cdot \mathrm{s}\right)$ (i.e., $\left.T_{h}=K_{h} B=(\mathrm{k} \rho \mathrm{g} / \mu) B\right)$. 
$\mathrm{m}^{2} / \mathrm{s}$ ); the lowest is east of the boundary (P-18, $7.5 \times 10^{-11} \mathrm{~m}^{2} / \mathrm{s}$ ). Because wells $\mathrm{H}-14$ and $\mathrm{H}-19$ have similar hydraulic conductivities for Culebra Unit 1 (between $2 \times 10^{-8}$ and $2 \times 10^{-7} \mathrm{~m}^{2} / \mathrm{s}$ ), and a very different conductivity for the Culebra overall, the WIPP Project attributes most of the variation in transmissivity to the lower three units (Beauheim, 1987; Holt, 1997). Based on measured pumping and slug tests, Beauheim and Holt (1990) note that the Culebra behaves hydraulically as a double-porosity medium where the transmissivity is greater than $2 \times 10^{-6} \mathrm{~m}^{2} / \mathrm{s}$ and as a singleporosity medium where the transmissivity is less than $2 \times 10^{-6} \mathrm{~m}^{2} / \mathrm{s}$, which occurs directly above the repository. For example, the transmissivity values for WIPP12, ERDA-9 and H-3, located near the repository, are $1.1 \times 10^{-7}, 4.9 \times 10^{-7}$, and $9.4 \times 10^{-7} \mathrm{~m}^{2} / \mathrm{s}$, respectively.

\subsubsection{Porosity}

Within the WIPP land-withdrawal boundary (Figure 2), the porosity within the dolomite consists of intergranular porosity, fractures, and vugs (connected through fractures). More significant secondary porosity, such as collapse at karst features from total dissolution of underlying salt (e.g., in Nash Draw), occurs west of the land-withdrawal boundary. In the performance assessment calculations, the combined porosity is assumed equal to the porosity through which contaminants could diffuse into the dolomite (i.e., the diffusive or matrix porosity used for the transport calculations, assuming a double-porosity transport model). The combined porosity measured from intact core samples from the Culebra varies only slightly based on helium measurements or water resaturation measurements (Kelley and Saulnier, 1990, Table 4.4). Since 1991, the range for the composite porosity in performance assessment calculations has been set between 0.10 and 0.25 (WIPP Performance Assessment Division, 1991, Table 2.6-3). The median value assumed for the CCA was 0.16 (Meigs and McCord, 1996), which is equal to the estimated porosity directly above the repository (WIPP Performance Assessment Division, 1991, Figure 2.6-10).

Prior to 1994, performance assessment calculations assumed a range of 0.0001 to 0.01 (Rechard et al., 1990, p. II-30) as the advective fracture, i.e., porosity through which fluid is conducted, based on an order-of-magnitude bracket around the tracer test results at $\mathrm{H}-3$ and $\mathrm{H}-11$ (advective porosities of 0.002 and 0.001 , respectively; Kelley and Pickens, 1986). Results from the tracer tests at $\mathrm{H}-19$, which estimated the advective porosity at 0.04 (Meigs et al., 1997), were used for the CCA.

\subsubsection{Elemental Composition of Culebra Brine, Culebra Dolomite, and Oklo Sandstone}

In the evaluation of the interaction of neutrons from the fission process with the surrounding material, the elemental composition of the Culebra brine as defined by Papenguth (1996a, 1996b) and the Culebra dolomite as defined by Siegel et al. (1991) and Sewards et al. (1992) was used (Tables 1 and 2). A distinction is made between intergranular brine in the Salado and brine from the Castile. In the Salado, the intergranular brine has substantially more magnesium and potassium. (In addition, minute amounts of brine can be found in fluid inclusions [intragranular] in the Salado, which are thought to be the concentrated remnants of the original brine that precipitated the Salado [Stein and Krumhansal, 1988], but the fluid would not move under a pressure gradient and is not reported in Table 1.)

Because it can serve as an analog, the elemental oxides that form after heating the sandstone that hosts the Oklo uranium ore deposit in Gabon, Africa, are also presented in Table 3. The deposit contains at least 16 natural reactors that operated intermittently for between $2 \times 10^{5}$ and $8 \times 10^{5}$ yr starting about $1.97 \mathrm{Ga}$ (GauthierLafaye and Weber, 1989; Rechard et al., 1996a; 1996b; 1997); it is discussed more thoroughly in Section 4.0. The Oklo sandstone is high in silica (84\%wt) (Table 3).

\subsubsection{Range of Matrix Distribution Coefficients for Plutonium and Uranium}

Adsorption on mineral surfaces is frequently modeled through a simple distribution coefficient $\left(K_{D}\right)$. Based on batch adsorption experiments (Brady et al., 1999), the distribution coefficient $\left(K_{D}\right)$ on dolomite for $\mathrm{Pu}^{\mathrm{III}}$ in the Salado and Castile brines in the 1996 performance assessment was first assumed to be uniformly distributed between 0.02 and $0.5 \mathrm{~m}^{3} / \mathrm{kg}$ (Brush, 1998) (upper endpoint was later slightly changed to $0.4 \mathrm{~m}^{3} / \mathrm{kg}$; Brush and Storz, 1996). For $\mathrm{Pu}^{\mathrm{IV}}, K_{D}$ was first assumed to be uniformly distributed between 0.9 and $20 \mathrm{~m}^{3} / \mathrm{kg}$ (Brush, 1998). This range was later changed to 0.7 to $10 \mathrm{~m}^{3} / \mathrm{kg}$ (Brush and Storz, 1996) (Figure 6). As explained by Brush (1998) and Brush and Storz (1996), the maximum and minimum $K_{D}$ values for $\mathrm{Pu}^{\mathrm{III}}$ were established by assuming that batch experiments with crushed dolomite for $\mathrm{Pu}^{\mathrm{V}}$ and $\mathrm{Np}^{\mathrm{V}}$ bound the values. The maximum and minimum $K_{D}$ values for $\mathrm{Pu}^{\mathrm{IV}}$ were obtained from batch experiments with $\mathrm{Th}^{\mathrm{IV}}$. The $K_{D}$ in the Salado and Castile brines was used because limited mixing can occur directly around the borehole (as described in a later section). The use of a uniform distribution when the distribution coefficient ranges over an 
Table 3. Percentages by Weight of Various Element Oxides that Form after Heating the Culebra Dolomite and Oklo Sandstone

\begin{tabular}{|c|c|c|c|}
\hline \multicolumn{3}{|c|}{ Percent Weight } & \\
\hline $\begin{array}{l}\text { Element } \\
\text { Oxides }\end{array}$ & $\begin{array}{l}\text { Culebra } \\
\text { Dolomite }^{a}\end{array}$ & $\begin{array}{l}\text { Oklo } \\
\text { sandstone }\end{array}$ & \\
\hline $\mathrm{SiO}_{2}$ & 1.55 & 84.10 & \\
\hline $\mathrm{Al}_{2} \mathrm{O}_{3}$ & 0.26 & 7.70 & \\
\hline $\mathrm{K}_{2} \mathrm{O}$ & 0.09 & 1.84 & \\
\hline $\mathrm{Na}_{2} \mathrm{O}$ & 0.10 & 0.06 & \\
\hline $\mathrm{CaO}$ & 29.39 & 0.02 & 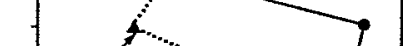 \\
\hline $\mathrm{MgO}$ & 21.08 & 0.68 & $\begin{array}{l}\text { Okio } \\
\text { sandstone }\end{array}$ \\
\hline $\mathrm{Fe}_{2} \mathrm{O}_{3}$ & $0.22^{\mathrm{c}}$ & 2.50 & \\
\hline $\mathrm{TiO}_{2}$ & na & 0.19 & \\
\hline $\mathrm{Mn}_{3} \mathrm{O}_{4}$ & na & 0.02 & \\
\hline Loss on ignition & na & 1.97 & \\
\hline $\mathrm{UO}_{2}$ & na & 0.10 & \\
\hline $\mathrm{SO}_{3}$ & 3.3 & na & $\bullet$ \\
\hline \multirow[t]{2}{*}{ Total } & 55.97 & 99.18 & 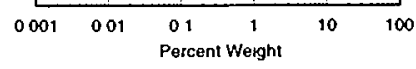 \\
\hline & & & TRI-6342-4879-0 \\
\hline $\begin{array}{l}\text { Sewards et al., 1992. } \\
\text { Gauthier-Lafaye et al. } \\
\text { Reported as FeO }\end{array}$ & $\begin{array}{l}\text { NIPP-12 at } 836 \\
\text { e } 3 \text {; near natural }\end{array}$ & $\begin{array}{l}\text { 1) depth } \\
\text { re slica has not }\end{array}$ & essively dissolved \\
\hline
\end{tabular}

order of magnitude means that most sampled values are at the high end of the range.

\subsection{Design of the Repository}

The WIPP repository is a $1.5 \times 10^{5}-\mathrm{m}^{2}$ facility constructed in a single, nearly level, stratigraphic unit of the Salado. The repository level consists of an experimental region at the northern end (now closed), an operations region with four shafts to the surface for ventilation and waste-handling, salt, and human transport; and a partially excavated disposal region at the southern end, which consists of four drifts down the center and eight groupings of disposal rooms (Figure 7). All the openings are rectangular in cross section and $4 \mathrm{~m}$ high. The drifts are usually $7.6 \mathrm{~m}$ wide. Rooms between access drifts in the eight panels are $10 \mathrm{~m}$ wide and $91 \mathrm{~m}$ long. The 7-pack drums or boxes (see Section 2.3.3) of waste are to be stacked three high and six wide across the rooms (Figure 7). The design volume for the waste in the disposal region is $1.75 \times 10^{5} \mathrm{~m}^{3}$ or about $40 \%$ of the excavated volume. A portion of the remaining volume will be backfilled with salt and $\mathrm{MgO}$ such that the average initial porosity (including the porosity in the waste) is about $85 \%$.

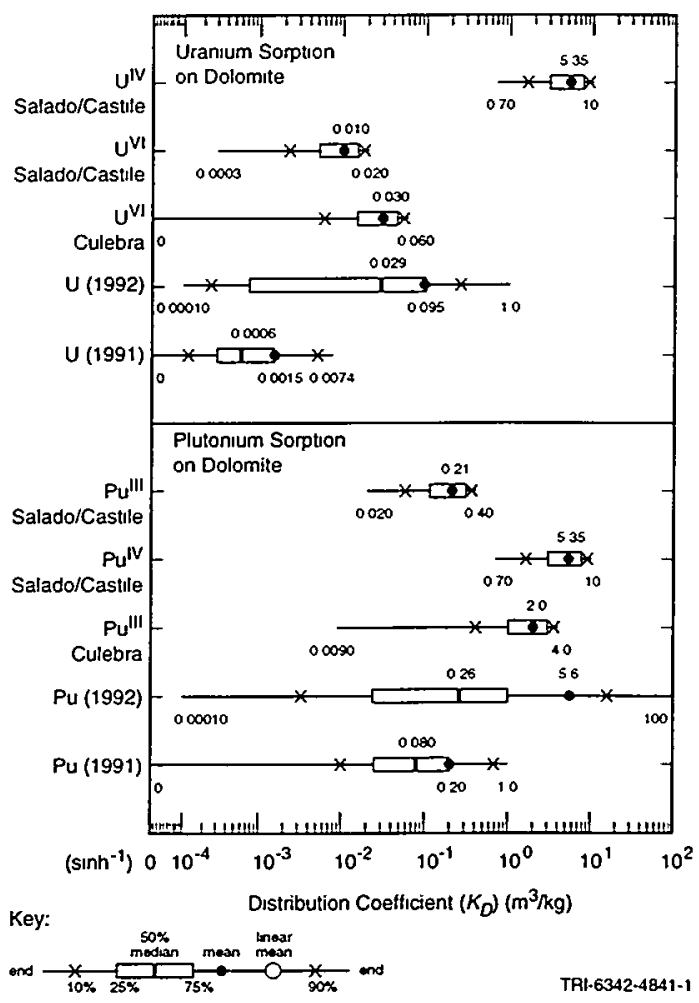

Figure 6. Ranges of $K_{\mathrm{D}}\left(\mathrm{m}^{3} / \mathrm{kg}\right)$ for plutonium and uranium in 1991, 1992, and 1996 (corrected values) performance assessments (Rechard, 1999, Figure 3-7). 


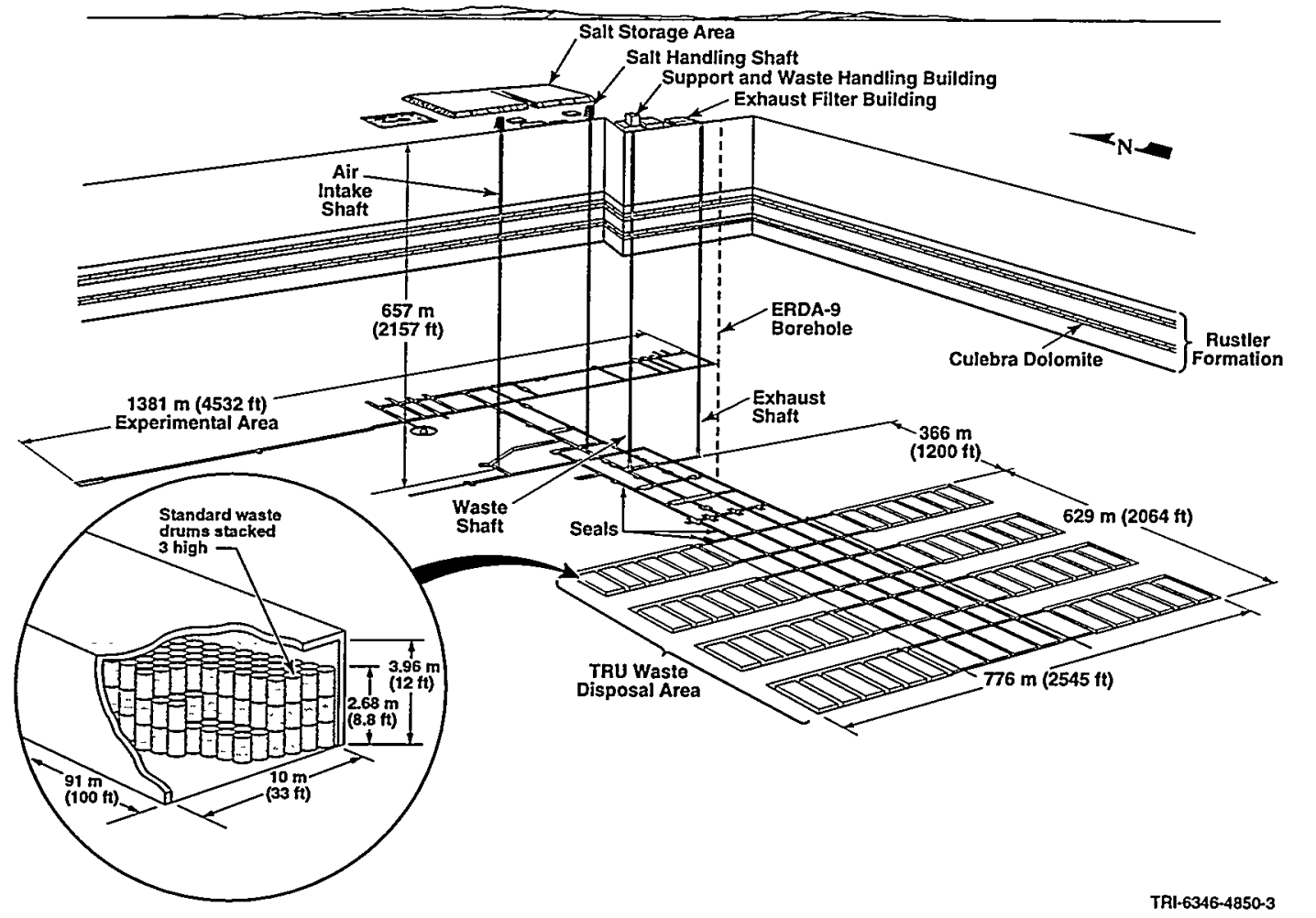

Figure 7. The WIPP repository in bedded salt, showing transuranic waste disposal area with eight panels, $657 \mathrm{~m}$ below surface and $436 \mathrm{~m}$ below Culebra Dolomite Member of Rustler Formation (Rechard, 1995, Figure 2.0).

\subsection{Transuranic Waste}

Waste planned for disposal at the WIPP repository consists of a broad variety of materials, including inorganics (e.g., iron and aluminum alloys, equipment, concrete, glass, firebrick, ceramics), organics (e.g., cellulosics, such as paper, cardboard, laboratory tissues, wood, cloth, rubber, plastics), solidified materials (e.g., waste water treatment sludge, cemented liquid waste, inorganic particles and soils), and solvents generated during the production of nuclear weapons. Most of these wastes have been contaminated by alpha-emitting TRU radioisotopes (i.e., radioisotopes with atomic numbers greater than uranium-[92]). To be classified as TRU waste in the United States, the average activity per mass in the container must be over $100 \mathrm{nCi} / \mathrm{g}$ from radioisotopes with half-lives greater than $20 \mathrm{yr}$. Ten TRU waste generator and/or storage sites around the country are scheduled to ship waste to the WIPP (Figure 8).

\subsubsection{General Categories of TRU Waste}

Current plans show a wide variety of waste to be placed at the WIPP. Two general types are (1) contact- handled transuranic (CH-TRU) waste $\left(\sim 1.68 \times 10^{5} \mathrm{~m}^{3}\right.$ or $-806,00055$-gal drums), which is TRU waste with an external dose rate of less than $5.6 \times 10^{-7} \mathrm{~Sv} / \mathrm{s}(200$ $\mathrm{mrem} / \mathrm{h}$ ); and (2) remotely handled transuranic (RHTRU) waste $\left(7080 \mathrm{~m}^{3}\right.$ or $\left.4 \%\right)$, which exceeds an external dose rate of $5.6 \times 10^{-7} \mathrm{~Sv} / \mathrm{s}$ but is less than $2.8 \times 10^{-3}$ $\mathrm{Sv} / \mathrm{s}(1000 \mathrm{mrem} / \mathrm{hr})$. For both types, the waste is grouped into 11 categories, and each waste category is present at each generator/storage site. Most of the volume is in the Heterogeneous Waste category; the second largest volume category is Uncategorized Metal (Rechard et al., 1996a) (Figure 8).

\subsubsection{Activity and Fissile Mass}

The projected activity of waste placed in the WIPP repository is $7.44 \mathrm{MCi}$ with a total heat power output of $136 \mathrm{~kW}$ when initially emplaced (Figure 9). The total energy released is $-9000 \mathrm{TJ}(2.5 \mathrm{~kW}-\mathrm{hr})$. Of the initial heat power of $136 \mathrm{~kW}, 97.8 \%$ is from the radioactive decay of CH-TRU elements. Of those $97.8 \% \mathrm{CH}-\mathrm{TRU}$ elements, $65 \%$ is from ${ }^{238} \mathrm{Pu}$ (generated at Savannah River for power generators in space and elsewhere), $18 \%$ is from ${ }^{239} \mathrm{Pu}, 5 \%$ is from ${ }^{240} \mathrm{Pu}$, and $11 \%$ is from ${ }^{241} \mathrm{Am}$ (Sanchez, 1996). The remaining heat power is 


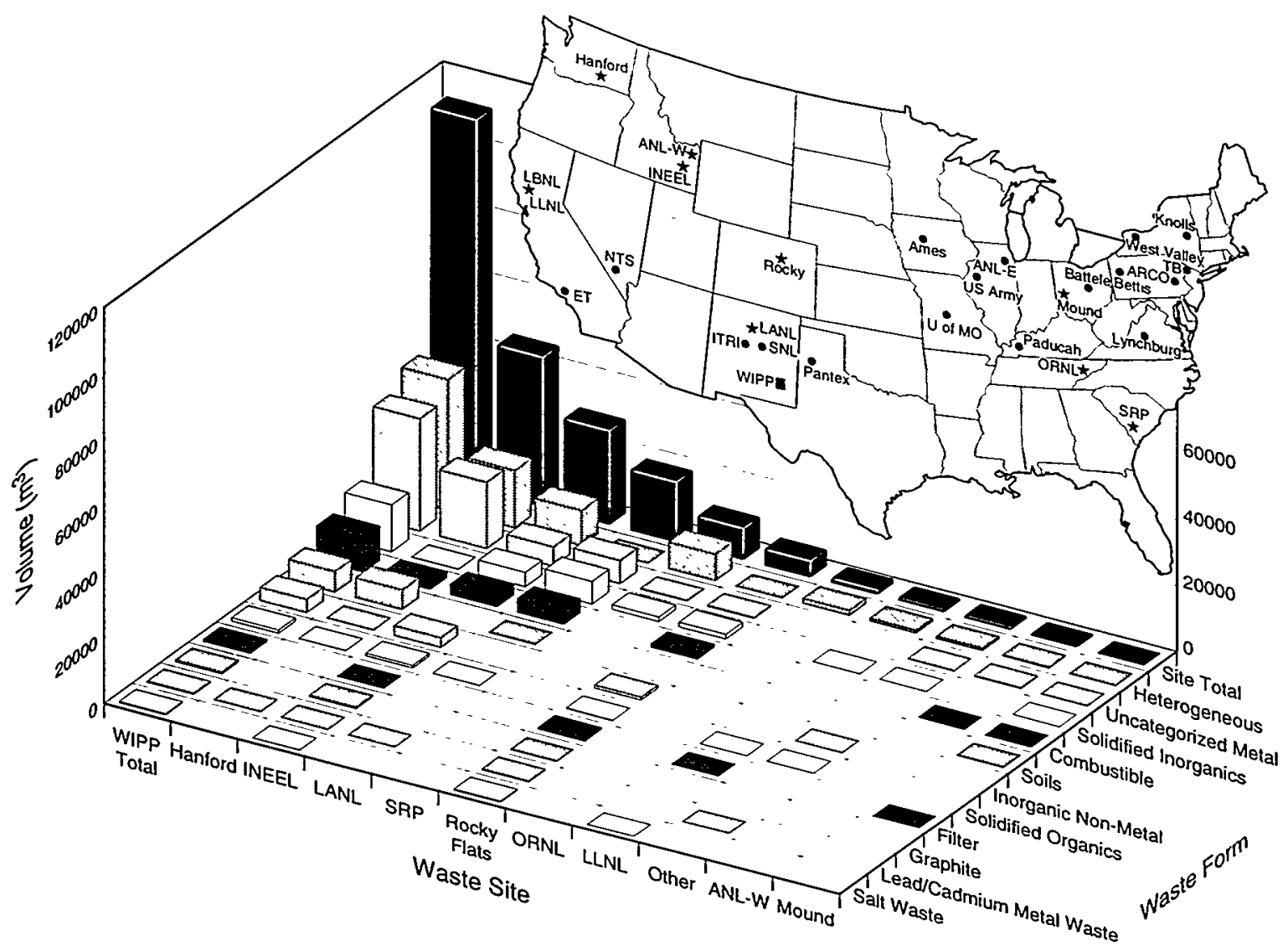

TA1-6342-4840-1

Figure 8. Anticipated volumes of contact-handled transuranic (CH-TRU) waste per site (data from Rechard et al., 1996b, Appendix B).
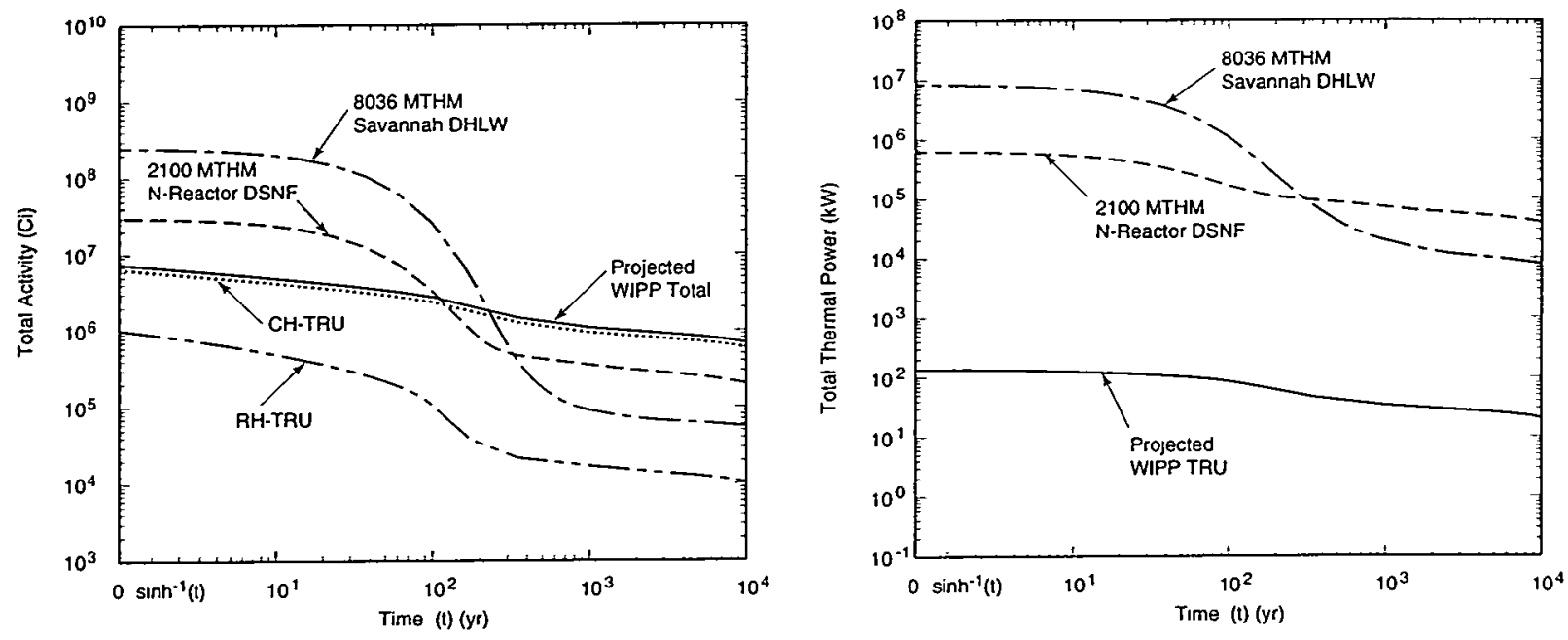

Figure 9. Anticipated activity and thermal power of waste in the WIPP repository (after Sanchez, 1996, Table 7 . and Sanchez et al., 1997, as evaluated from DOE, 1995). Activity of DOE-owned spent nuclear fuel and defense high-level waste (DSNF/DHLW) shown for comparison (after Rechard, ed., 1995, Figure 4-1I). 
primarily from radioactive decay of fission products that contaminated the RH-TRU waste when spent fuel was examined and tested at DOE facilities.

The projected total mass of radioisotopes in the WIPP repository is $\sim 180 \mathrm{Mg}$. Of these, $80 \%(150 \mathrm{Mg})$ is ${ }^{238} \mathrm{U}$ placed in the waste by Oak Ridge and elsewhere to prevent criticality during storage. The masses of the two most important fissile materials, ${ }^{235} \mathrm{U}$ and ${ }^{239} \mathrm{Pu}$, are $8 \mathrm{Mg}$ and $13 \mathrm{Mg}$, respectively (Table 4). Note that the average enrichment of uranium at emplacement is $5 \%$. Over $10,000 \mathrm{yr}$, the enrichment increases slightly to $7 \%$, because of the decay of ${ }^{239} \mathrm{Pu}$. The initial average enrichment of the combination of plutonium and uranium (in fissile gram equivalents [FGEs]) at emplacement is $14 \%$.

Table 4. Anticipated Mass of Fissile Material in the WIPP Repository (after Sanchez, 1996, as evaluated from DOE, 1995)

\begin{tabular}{|c|c|}
\hline Radioisotope $^{\mathrm{a}}$ & Mass (kg) \\
\hline \multicolumn{2}{|l|}{ Uranium } \\
\hline${ }^{232} U$ & $1.21 \times 10^{-3}$ \\
\hline${ }^{233} U$ & $2.01 \times 10^{2}$ \\
\hline${ }^{234} \mathrm{U}$ & $8.13 \times 10^{1}$ \\
\hline${ }^{235} \mathrm{U}$ & $8.07 \times 10^{3}$ \\
\hline${ }^{236} \mathrm{U}$ & $6.64 \times 10^{6}$ \\
\hline${ }^{237} \mathrm{U}$ & $7.36 \times 10^{-7}$ \\
\hline${ }^{238} \mathrm{U}$ & $1.49 \times 10^{5}$ \\
\hline \multicolumn{2}{|l|}{ Plutonium } \\
\hline${ }^{236} \mathrm{Pu}$ & $1.96 \times 10^{-8}$ \\
\hline${ }^{238} \mathrm{Pu}$ & $1.53 \times 10^{2}$ \\
\hline${ }^{239} \mathbf{P u}$ & $1.28 \times 10^{4}$ \\
\hline${ }^{240} \mathrm{Pu}$ & $9.44 \times 10^{2}$ \\
\hline${ }^{241} \mathrm{Pu}$ & $2.38 \times 10^{1}$ \\
\hline${ }^{242} \mathrm{Pu}$ & $3.07 \times 10^{2}$ \\
\hline${ }^{243} \mathrm{Pu}$ & $1.23 \times 10^{-18}$ \\
\hline${ }^{244} \mathrm{Pu}$ & $8.46 \times 10^{-5}$ \\
\hline $\begin{array}{l}{ }^{239} \mathrm{Pu} \text { fissile gram } \\
\text { equivalent (FGE) }\end{array}$ & $2.11 \times 10^{4}$ \\
\hline Total (all radioisotopes) & $1.81 \times 10^{5}$ \\
\hline
\end{tabular}

\subsubsection{Containers}

$\mathrm{CH}$-TRU waste is shipped in standard, steel, 55-gal drums (0.89-m high, $0.60-\mathrm{m}$ diameter) or steel boxes (0.94-m high, $1.3-\mathrm{m}$ wide, $1.8-\mathrm{m}$ long). Seven drums are grouped together to form a sextagonal shape. The reference design for RH-TRU waste is a 6.35 -mm-thick steel cylinder with an outside diameter of $0.65 \mathrm{~m}$ and length of $3 \mathrm{~m}$. The volume is $\sim 0.89 \mathrm{~m}^{3}$. Neither type of container has any special feature that acts as an engineered barrier and so the containers are considered part of the waste.

\subsubsection{Pu and U Solubility Estimates}

\subsubsection{Brine Type Dependence}

The range of $\mathrm{Pu}$ and $\mathrm{U}$ solubility is somewhat dependent upon the ionic strength and constituents (i.e., type) of brine. Consequently, the solubility is reported for both Salado and Castile brines. Occasionally, an estimate of the solubility of plutonium or uranium in Culebra brine is needed. For those situations, plutonium or uranium solubility in Castile brine is used because Culebra brine has relatively less ionic strength than either of the two repository brines and the Castile has the lower ionic strength of the two repository brines.

\subsubsection{2 pH Dependence}

The $\mathrm{pH}$ (i.e., activity of hydronium ion $[\mathrm{H}+]$ ) of the solution also influences the solubility of Pu and U. In its application, the DOE used (and the EPA subsequently required) enough $\mathrm{MgO}$ in the repository such that any $\mathrm{CO}_{2}$ generated by microbial degradation of organic material (e.g., cellulosic material) forms $\mathrm{MgCO}_{3}$, and dissolved $\mathrm{CO}_{2}\left(\mathrm{H}_{2} \mathrm{CO}_{3}{ }^{*}\right)$ is not formed; thus the $\mathrm{pH}$ of the brine stays within the range of 9.4 to 9.9 in the repository. Narrowing the range of $\mathrm{pH}$ narrows the solubility range of various radioisotopes (see Section 3.5). In all cases, the solubility values used herein have assumed an $\mathrm{MgO}$ backfill in the repository.

\subsubsection{Oxidation State Dependence}

For the actinium series of elements, i.e., actinides that have atomic numbers between 90 and 103, experimental evidence suggests that actinide elements in the same oxidation state exhibit the same chemical behavior (Langmuir, 1997, p. 536; Brady et al., 1999). Within the WIPP Project, this behavior is called the oxidation state analogy and describes the solubility behavior of actinides in the WIPP with sufficient accuracy. The actinides can exist in the III, IV, V, or VI oxidation states, e.g., plutonium can be present as either $\mathrm{Pu}^{\mathrm{III}}$, $\mathrm{Pu}^{\mathrm{IV}}, \mathrm{Pu}$, or $\mathrm{Pu}^{\mathrm{VI}}$, or as a combination of several of 
these oxidation states. Lower oxidation states of actinides are generally much less soluble than higher oxidation states. (That is, the lower oxidation states form solid species that are more thermodynamically stable when in contact with water than the solid species formed with higher oxidation states.) It is assumed that only one oxidation state will dominate the solubility; thus oxidation state is sampled in each vector of sampled parameters in the 1996 calculations. For example, the WIPP Project has assumed plutonium would exist $50 \%$ of the time as $\mathrm{a}+3$ state $\left(\mathrm{Pu}^{\mathrm{III}}\right)$ and $50 \%$ of the time as +4 state $\left(\mathrm{Pu}^{\mathrm{IV}}\right)$ (Weiner, 1996).

The median solubility (or dissolved concentration) $\left(S_{D, 50 \%}\right)$ for each valence state was calculated using the FMT code for each oxidation state $\left(O_{x}\right)$ (Babb and Novak, 1995) and a database containing Pitzer interaction coefficients. The Pitzer coefficients were used to predict the behavior of species in solutions of high ionic strength represented by the Castile and Salado brines $\left(B_{r}\right)$, i.e., $S_{D, 50 \%}=S_{F M T}\left(B_{r} O_{x}\right)$. The median solubility in Salado and Castile brines, respectively, was $5.5 \times 10^{-5} \mathrm{mM}$ and $6.5 \times 10^{-5} \mathrm{mM}$ for III valence actinides; $4.4 \times 10^{-3} \mathrm{mM}$ and $6.0 \times 10^{-6} \mathrm{mM}$ for IV valence actinides; $2.3 \times 10^{-3} \mathrm{mM}$ for $\mathrm{V}$ valence actinides in both brines; and $8.8 \times 10^{-3} \mathrm{mM}$ and $8.7 \times 10^{-3} \mathrm{mM}$ for VI valence actinides (Table 5; see also Helton et al., 1998, p. 4-39).

\subsubsection{Uncertainty in Solubility}

FMT calculates one solubility value, assumed equal to the median value. The uncertainty about the median was evaluated using a sampled scale factor $\left(f_{D}\right)$, i.e., $S_{D}$ $=10 S_{D, 50 \%}$, where the piecewise linear distribution of $f_{D}$ was established through analyst judgment. The same distribution was used for each actinide but sampled separately, i.e., no correlation was assumed in the uncertainty for each actinide. The minimum was 0.01 times smaller than the median calculated value (i.e., $f_{D}=-2$ ); the maximum, 25 times larger (i.e., $f_{D}=1.4$ ) (Helton et al., 1998, p. 5-15).

\subsubsection{Total Concentration}

For the WIPP Project, a total concentration is calculated that is the sum of the dissolved species (assumed equal to solubility) and four categories of colloids: mineral, intrinsic, humic and microbial (i.e., $C_{T}=S_{D}+$ $C_{\text {mineral }}+C_{m t}+C_{\text {humic }}+C_{\text {microbe }}$ ) (Papenguth and Behl, 1996b) (Table 5). The mineral type colloids are mineral substrates that readily adsorb actinides; the intrinsic colloids are polymeric plutonium; the microbial colloids are microbes that have bioaccumulated actinides; and the humic colloids are actinides complexed by humic organics. The mineral colloid concentration $\left(C_{\text {mnteral }}\right)$ was fixed at $2.6 \times 10^{-5} \mathrm{mM}$. Only $\mathrm{Pu}$ was assumed to form intrinsic colloids at a fixed concentration $\left(C_{m t}\right)$ of $10^{-6} \mathrm{mM}$. The concentration of humic and microbial colloids was assumed to be a specified fraction of the dissolved concentration $\left(S_{D}\right)$ where the fraction was a function of the ionic strength (or brine type), oxidation state, and radioisotope (e.g., $C_{\text {humic }}=f_{\text {humic }}\left(B_{r} O_{x}, R_{n}\right) \cdot$ $S_{D}$ ) (Table 5). The humic colloidal concentration was assumed to be bounded by $1.1 \times 10^{-2} \mathrm{mM}$. The microbial colloidal concentration bound was a function of ionic strength, oxidation state, and the radioisotope (Helton et al., 1998, p. 4-40).

\subsubsection{Plutonium Total Concentration in 1996 Calculations}

In Castile brine, the total concentration for $\mathrm{Pu}^{\text {III }}$ ranges from $10^{-5}$ to $2.4 \times 10^{-2} \mathrm{mM}$ with a median of $1.69 \times 10^{-4} \mathrm{mM}$. In Salado brine, the total concentration for $\mathrm{Pu}^{\mathrm{III}}$ ranges from $3 \times 10^{-5}$ to $2.4 \times 10^{-2} \mathrm{mM}$ with a median of $7.32 \times 10^{-4} \mathrm{mM}$. In Castile brine, the total concentration for $\mathrm{Pu}^{\mathrm{IV}}$ ranges from $10^{-5}$ to $3 \times 10^{-3} \mathrm{mM}$ with a median of $6.41 \times 10^{-5} \mathrm{mM}$. In Salado brine, the total concentration for $\mathrm{Pu}^{\mathrm{IV}}$ ranges from $3 \times 10^{-4}$ to $4 \times 10^{-1} \mathrm{mM}$ with a median of $1.57 \times 10^{-2} \mathrm{mM}$ (Figure 10 and Table 5).

For $\mathrm{Pu}^{\mathrm{III}}$, the dissolved concentrates account for $65 \%$ of the calculated total plutonium concentration in Salado brine, but colloidal plutonium dominates in Castile brine $(70 \%)$. Approximately $25 \%$ of the total concentration for $\mathrm{Pu}^{\mathrm{III}}$ (microbial and mineral colloids) might be separated by filtration in the repository. The filtration might occur in close proximity to where the colloids were formed within the repository (Section 5.4); nonetheless, the 1996 performance assessment did not take credit for that attenuation mechanism, and to be consistent with the conditions specified by the 1996 performance assessment, the microbial and mineral colloids are assumed to escape from the repository and are included here. For $\mathrm{Pu}^{\mathrm{IV}}$, the colloids account for $80 \%$ and $90 \%$ of the calculated total concentration in the Salado and Castile brines, respectively. Approximately $7 \%$ and $43 \%$ (i.e., the colloidal fraction) of the calculated total concentration in the Salado and Castile brines, respectively, has been shown to be filtered in the Culebra dolomite.

Because of the $\mathrm{MgO}$ backfill, this range of concentrations is narrow in comparison to the range used in the 1991 performance assessment of the WIPP, which incorporated solubility values that were determined by an expert panel (WIPP Performance Assessment Division, 1991; Trauth et al., 1992). However, the range does center around the mean and median values used in the 1991 WIPP PA and elsewhere (Figure 11). 
Table 5. Example Calculation of Median Total Concentration for Actinides in Salado and Castile Brines for 1996 WIPP Performance Assessment

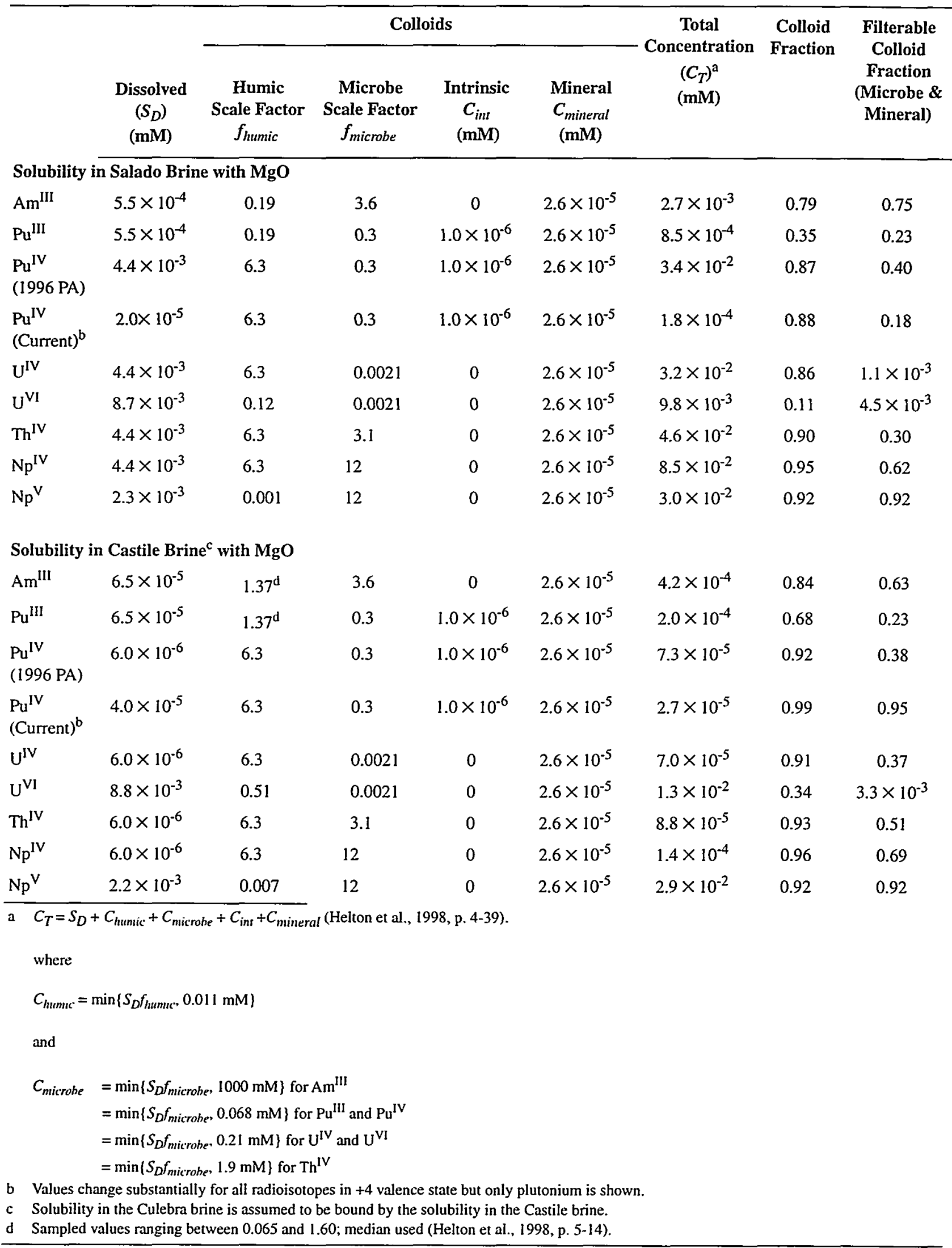



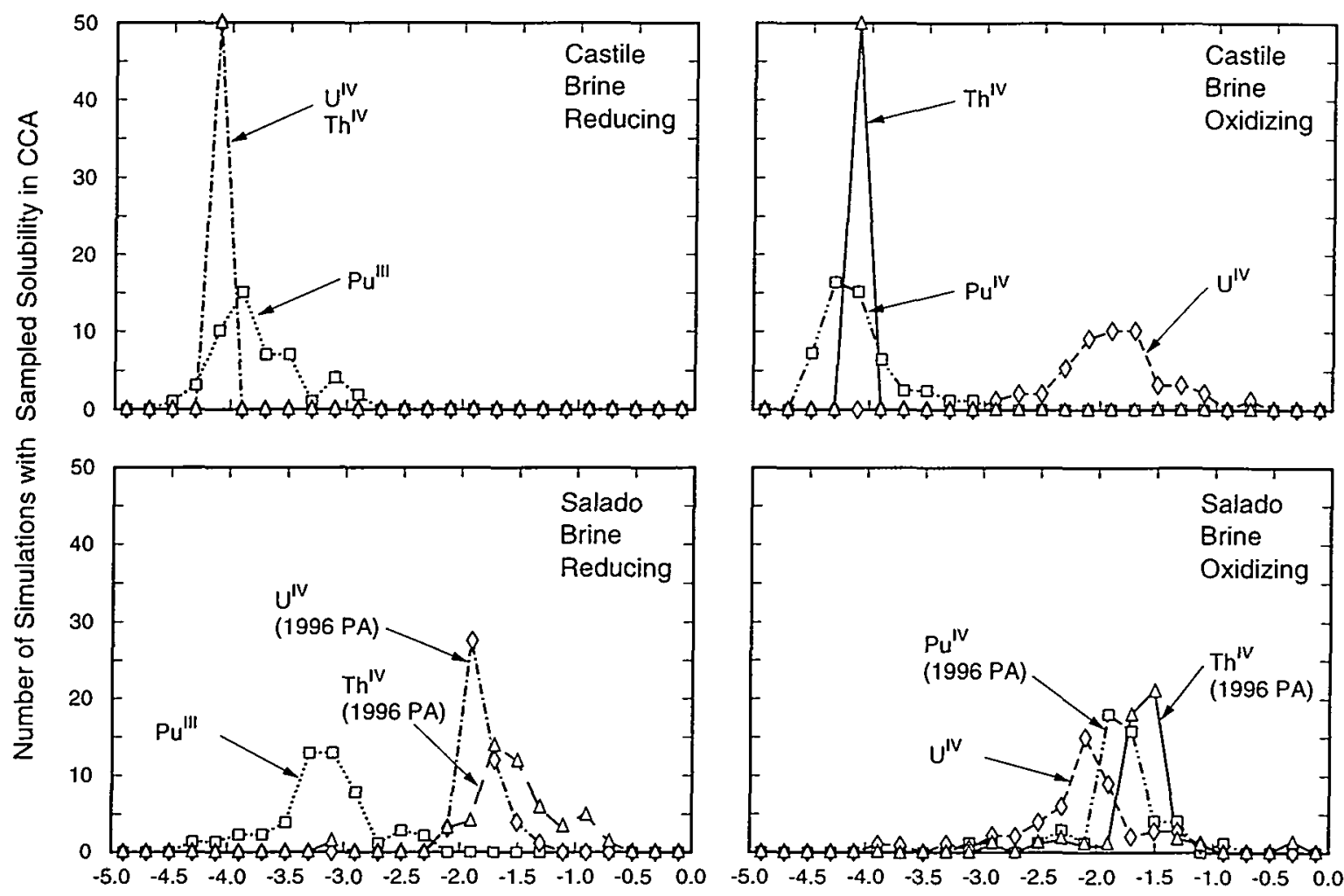

Log Concentration $(\mathrm{mM})$

TRI-6342-5457-2

Figure 10. Probability histograms for total concentration (dissolved species-assumed equal to solubility-plus suspended colloidal material) for $P u^{I I I}, P u^{I V}, U^{I V} U^{V I}$, and $T h^{I V}$ in Salado and Castile brines obtained from sampling used in 1996 performance assessment. In the performance assessment, 50\% of the simulations use the high oxidation state of the radioisotope and the other $50 \%$ use the low oxidation state. (Refer to Table 5 for an example calculation.)

\subsubsection{Uranium Total Concentration in 1996 Calculations}

Information for $\mathrm{U}^{\mathrm{IV}}$ and $\mathrm{U}^{\mathrm{VI}}$ is also tabulated in Table 5 and shown in Figure 10. The median $\mathrm{U}^{\mathrm{VI}}$ total concentration is $10^{-2} \mathrm{mM}$ in Castile brine. The maximum $\mathrm{U}^{\mathrm{VI}}$ total concentration is $2.3 \times 10^{-1} \mathrm{mM} \cong 10^{-0.6}$ in the Castile. Of this maximum, $37 \%$ is contributed by filterable colloids.

\subsubsection{New Solubilities for Actinides with Plus Four Valence}

In Salado brine, the very high solubility for $\mathrm{Pu}^{\mathrm{IV}}$ assumed in the 1996 performance assessment is higher than the solubility assumed for $U^{\mathrm{VI}}$. As mentioned ear- lier, the solubility was calculated with the software code, FMT, which requires Pitzer coefficients, many of which were set to zero (Novak, 1995; Babb and Novak, 1995). Because of the missing interaction coefficients, the solubility values in this distribution are possibly higher than reasonable. Because of this concern, the WIPP Project has continued to work on improving the estimation of Pitzer coefficients for FMT and currently believes that the $\mathrm{Pu}^{\text {IV }}$ solubility is too high by two orders of magnitude. The more recent solubility calculations estimate a median of $2.0 \times 10^{-5} \mathrm{mM}$ (Table 5). ${ }^{10}$ However, the distribution of the plutonium used in the 1996 performance assessment is used herein not only because the original arguments were based on this value, but also because a different interpretation may emerge from the continuing evaluation of plutonium solubility. 


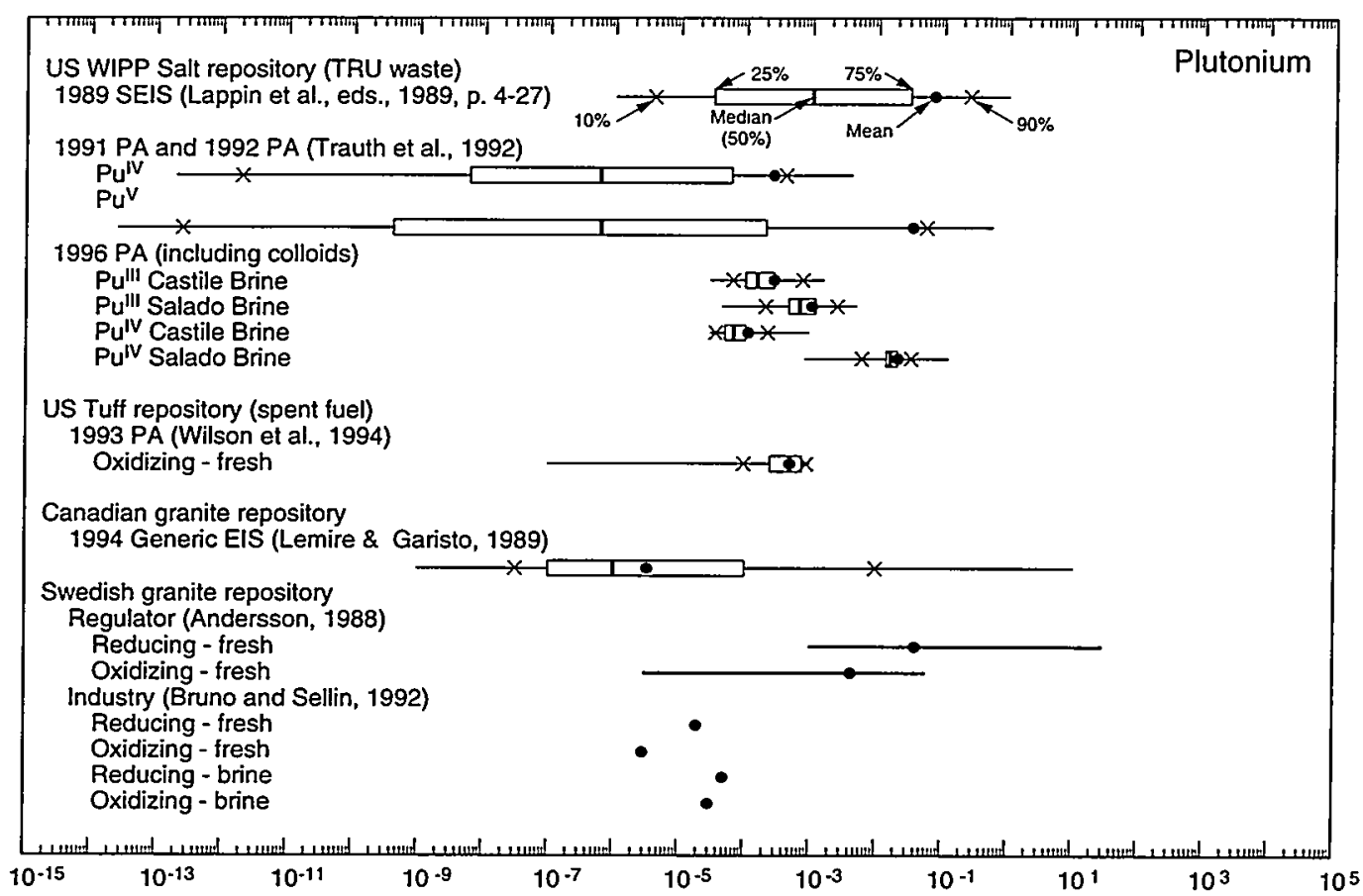

(a) Plutonium total concentration ( $\mathrm{mM}$ or moles $/ \mathrm{m}^{3}$ )

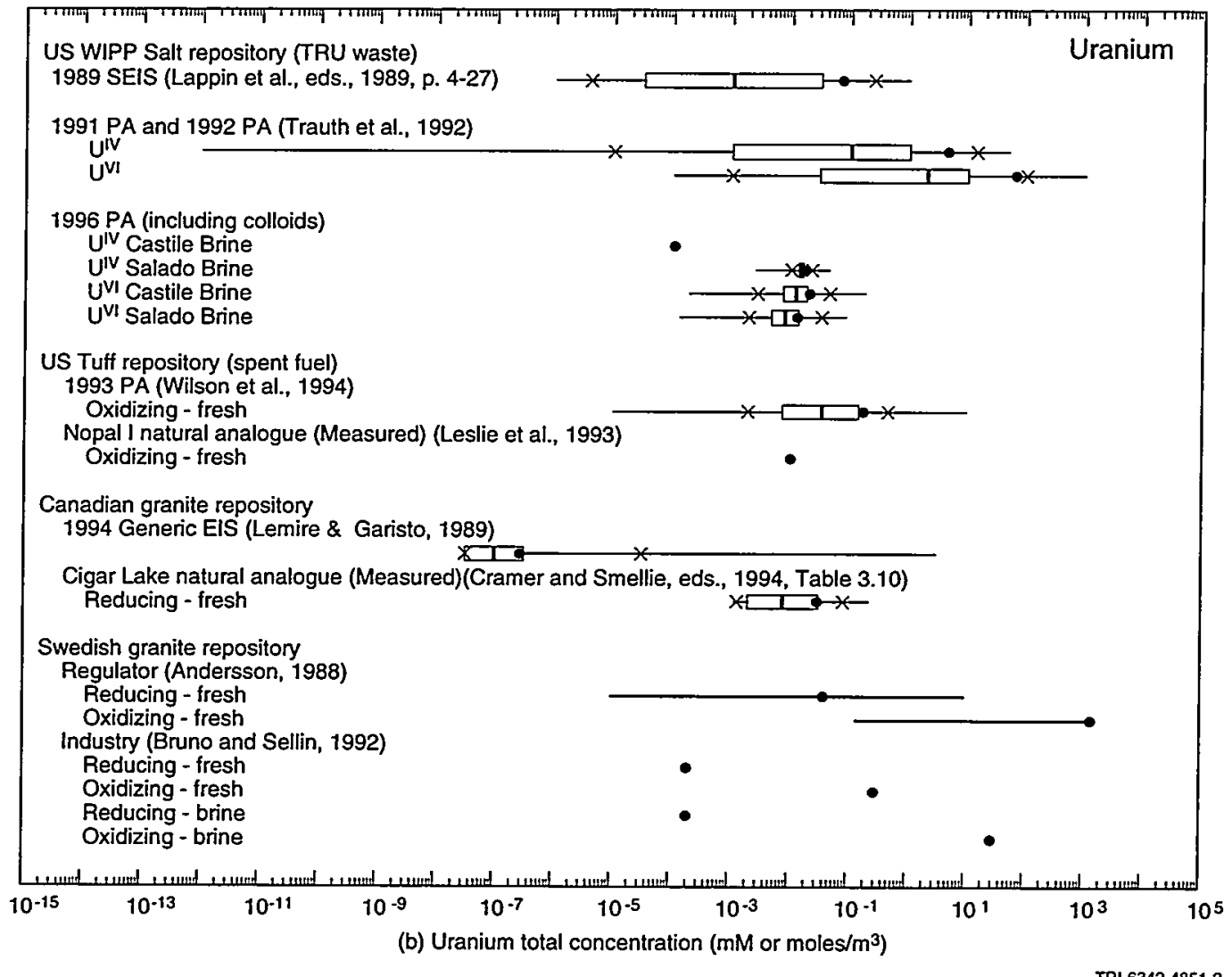

Figure 11. Assumed total concentration of fissile material under oxiding and reducing conditions in Culebra and Castile/Salado brine at WIPP repository for calculations described in this report. For purposes of comparison, the solubilities of uranium and plutonium used in other analyses are also shown. 


\subsubsection{Deposited Forms of Plutonium and Uranium}

For the criticality calculations described herein, the deposited form of plutonium is assumed to be $\mathrm{PuO}_{2}$; the deposited form of uranium is assumed to be $\mathrm{UO}_{2} \mathrm{CO}_{3}$ (Rutherfordine), because it is the thermodynamically stable form in a carbonate solution. Although the type of plutonium or uranium mineral greatly influences solubility, as shown later, the mineral form has only a small influence on criticality limits.

\subsection{Basic Scenarios and Calculated Brine Flows}

As noted earlier, the arguments presented herein occasionally use the results of the 1996 performance assessment to confirm that conditions (i.e., retained features, events, and processes) are not conducive to criticality. Hence, some of the retained events in the 1996 WIPP performance assessment and their grouping into scenarios are discussed below.

\subsubsection{Undisturbed Scenario}

The undisturbed or base-case scenario is the predicted behavior of the WIPP disposal system, including uncertainty, if the WIPP is not disrupted by human intrusion or unlikely natural events. The undisturbed scenario represents the predicted evolution of the WIPP disposal system over time through salt creep closure, precipitation of salts within waste pores, and possibly slow degradation of the waste form. In the performance assessment calculations, the undisturbed scenario was designated " $\mathrm{S} 1$ " (Table 6).

\subsubsection{Basic Human Intrusion Scenarios for which Radioisotope Releases are Calculated}

Based on guidance in Appendix C of 40 CFR 191 and 40 CFR 194, human intrusion was considered in the calculations by assuming exploratory drilling for oil and gas deposits with present technology near the WIPP. If the disposal area of the repository is penetrated by an exploratory borehole, radioisotopes may be released in several different ways and at different times. The shortterm result of intrusion is entrainment of wastes into the drilling fluid and their immediate release at the surface during drilling operations. At much later times, releases through groundwater flow into the overlying Culebra can also be important when the solubility of the actinides is high.

These later potential long-term releases were grouped into two categories based on whether a pressurized brine reservoir in the Castile Formation was intersected, and then further grouped into two subcategories based on the time of intrusion. A third category was developed from the first two categories (Table 6). The potential of these scenarios was explored through sets of different input parameters and randomly sampled parameters within assigned ranges (realizations) for each scenario. The results discussed in this report are from scenario S5 (Table 6 and Figure 12).

In drilling intrusion scenario S5, the initial breakthrough into a waste panel quickly depressurizes a disposal room. The drillers seal the borehole using present-day technology and abandon it. Sealing would permit the room to repressurize as the result of ongoing gas generation from corrosion and microbial degradation, if steel, cellulosics, and rubber were still available. Some releases over the long term can occur from selective degradation of the plugs that originally seal the abandoned borehole and migration of radioisotopes through the degraded borehole plug and the brine aquifer in the Culebra. As suggested by regulatory guidance (EPA, 1985a; 1993; 1996), the degraded concrete borehole plug is conservatively assumed to have properties of sand, but without intrusion by salt or the ability to filter/precipitate material in the brine (and thus self seal) over the 10,000-yr regulatory period. Degradation of the borehole plug throughout its length allows gases to migrate out of the room, with brine refilling any remaining voids (Figure 13). In scenario S5, brine flow from the Salado forces the liquid through the repository up

10 As noted earlier, the median solubility used in the 1996 performance assessment was calculated using the FMT code (Babb and Novak, 1995) and a database containing Pitzer interaction coefficients. The Pitzer Model is considered the best model for explaining and predicting behavior of species in solutions of high ionic strength, but it requires a large number of experimentally determined interaction coefficients. In practice, many interaction coefficients are quite small and can be neglected (left as zero); experimental programs are designed to obtain only the most important interaction parameters. If an important interaction parameter is left out, however, the resulting stability of a species may be off by many orders of magnitude. At the time of the 1996 performance assessment, there were no data for the $\mathrm{Th}\left(\mathrm{CO}_{3}\right)_{5}^{-6}-\mathrm{Cl}^{-}$interaction parameter, and it was left as zero. Using zero resulted in an artificially high $\mathrm{Th}\left(\mathrm{CO}_{3}\right)_{5}^{-6}$ stability in Salado brine and a high Th ${ }^{\mathrm{N}}$ solubility. Recently, a single data point has been used to estimate the $\mathrm{Th}\left(\mathrm{CO}_{3}\right)_{5}^{-6}-\mathrm{ClO}_{4}^{-}$interaction parameters and, by analogy, the $\mathrm{Th}\left(\mathrm{CO}_{3}\right)_{5}^{-6}-\mathrm{Cl}^{-} \mathrm{inter}-$ action parameters. Calculations using this new database show a much lower $\mathrm{Th}\left(\mathrm{CO}_{3}\right)_{5}^{-6}$ stability, and a much lower $\mathrm{Th}^{\mathrm{IV}}$ solubility in Salado brine. Because the oxidation state analogy (Langmuir, 1997, p. 536) is used, Th ${ }^{\mathrm{IV}}$ solubility is used for all IV actinides and results in a lower Pu ${ }^{\mathrm{IV}}$ solubility. 
Table 6. Designation of Scenarios for WIPP Performance Calculations in 1996

\begin{tabular}{|c|c|c|}
\hline ID & Short Description & Description \\
\hline S1 & Undisturbed or Base Case & $\begin{array}{l}\text { Predicted behavior of the WIPP disposal system when not disrupted by } \\
\text { human intrusion or unlikely natural events }\end{array}$ \\
\hline S2 & E1 intrusion after $300 \mathrm{yr}$ & $\begin{array}{l}300 \mathrm{yr} \text { after closure, inadvertent intrusion into the repository and pressurized } \\
\text { brine reservoir in the Castile; after abandonment, seals rapidly degrade }\end{array}$ \\
\hline S3 & E1 intrusion after $1000 \mathrm{yr}$ & $\begin{array}{l}1000 \mathrm{yr} \text { after closure, inadvertent intrusion into the repository and pressur- } \\
\text { ized brine reservoir in the Castile }\end{array}$ \\
\hline S4 & E2 intrusion after $300 \mathrm{yr}$ & 300 yr after closure, inadvertent intrusion into the repository \\
\hline S5 & E2 intrusion after $1000 \mathrm{yr}$ & $1000 \mathrm{yr}$ after closure, inadvertent intrusion into the repository \\
\hline S6 & Eland E2 after $1000 \mathrm{yr}$ & $\begin{array}{l}\text { Two inadvertent intrusions into the repository around } 1000 \mathrm{yr} \text { after closure; } \\
\text { one intrusion also intersects a brine reservoir; after abandonment, seals } \\
\text { degrade such that flow is forced through entire repository }\end{array}$ \\
\hline
\end{tabular}

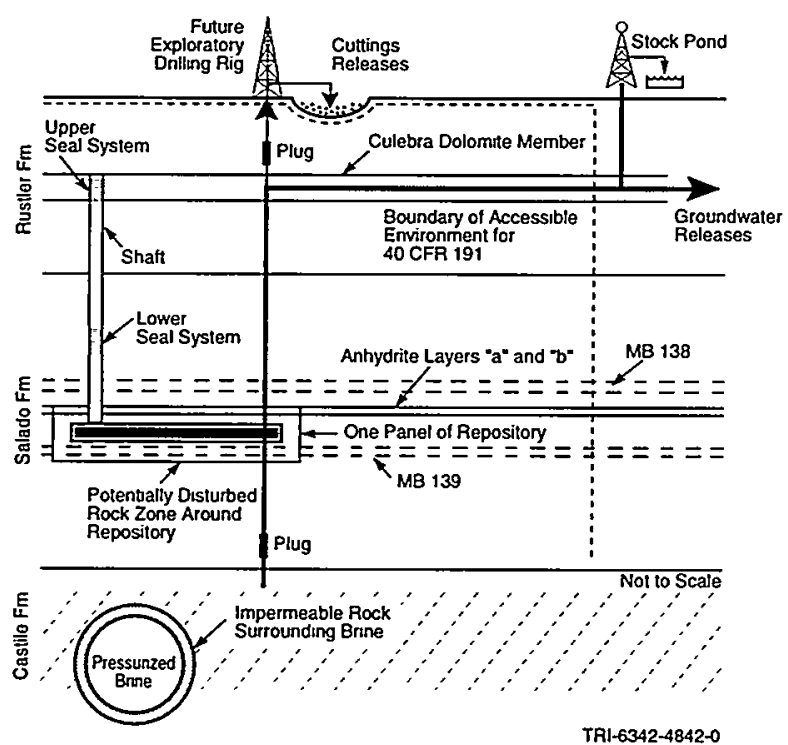

Figure 12. Human intrusion summary scenario (E2) considered in 1996 performance assessment simulations for Environmental Protection Agency standard 40 CFR 191. Heavy arrow indicates pathway of radioisotopes to accessible environment or to food chain (after Rechard, 1995, Figure 3.2-4).

into the Culebra, assuming that the Salado is at lithostatic pressure. In part because of the assumption of continued borehole permeability, the primary zone considered outside the repository is the Culebra, but most of the situations considered also apply to other areas outside the repository, such as the borehole itself.

\subsubsection{Evaluation of Releases at WIPP}

In the 1996 performance assessment, three replications of the entire calculation set, each with a different starting random number, were run to evaluate potential variation in results. In this report, we use the first replicate, R1. (For a complete description of the calculations, see DOE, 1996, or Helton et al., 1998; additional information on the modeling system can be found in Rechard, 1991; 1995; and Rechard, ed., 1992.)

\subsubsection{Range of Brine Flow through Repository and up Intrusion Borehole}

The rate of accumulation of fissile material in the far field is dependent upon the total concentration and the discharge of brine $(q)$ through the repository; in turn, the flow through the repository is dependent upon the type of human intrusion scenario. The 1996 performance assessment calculations show that the maximum $\left(3.6 \times 10^{4} \mathrm{~m}^{3} / 10^{4} \mathrm{yr}\right)$ for the 100 simulations in the first replication is an upper bound for brine flow through the repository and to the Culebra following one borehole intrusion (Figure 14). This maximum occurred for the R1S5 scenario on vector 23 , where vector 23 refers to the simulation with the 23rd set of parameters sampled through Latin Hypercube sampling (LHS), a constrained Monte Carlo sampling method (Iman and Conover, 1980). The other intrusion scenarios for vector 23 (R1S2, R1S3, R1S4) have similar maximum values. This situation occurs because the source of the large volume of brine in vector 23 is the marker beds; their being such a large-volume source is, in turn, the result of the high sampled value of permeability. Intrusions into the brine reservoir actually pressurize the repository to a very small degree and so brine volumes are slightly reduced in R1S2, R1S3, and R1S4. 


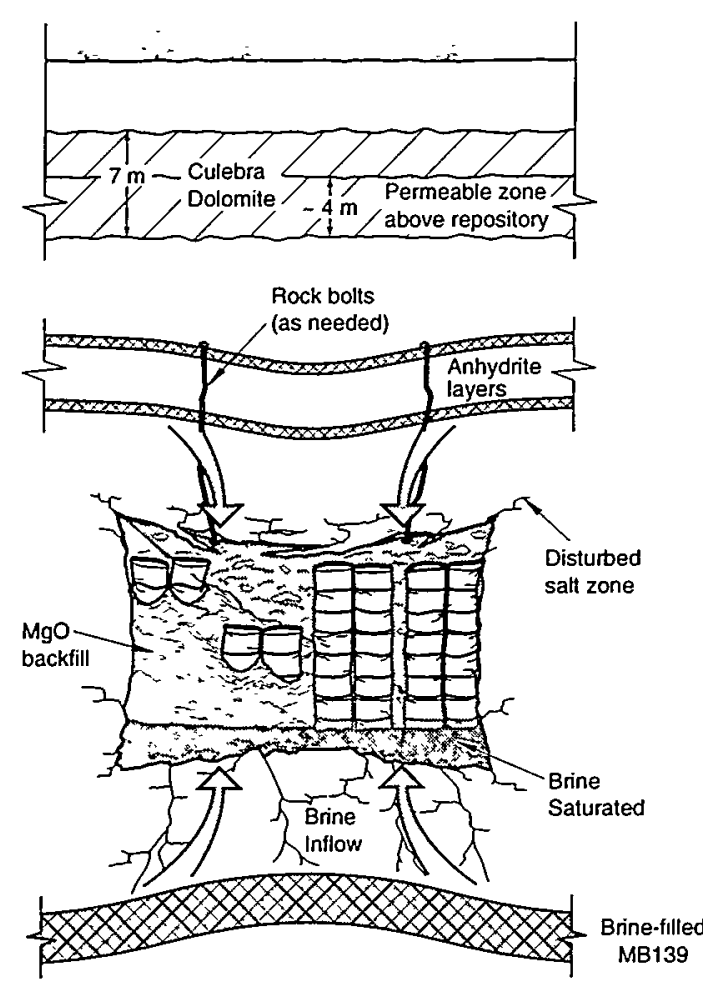

(a)

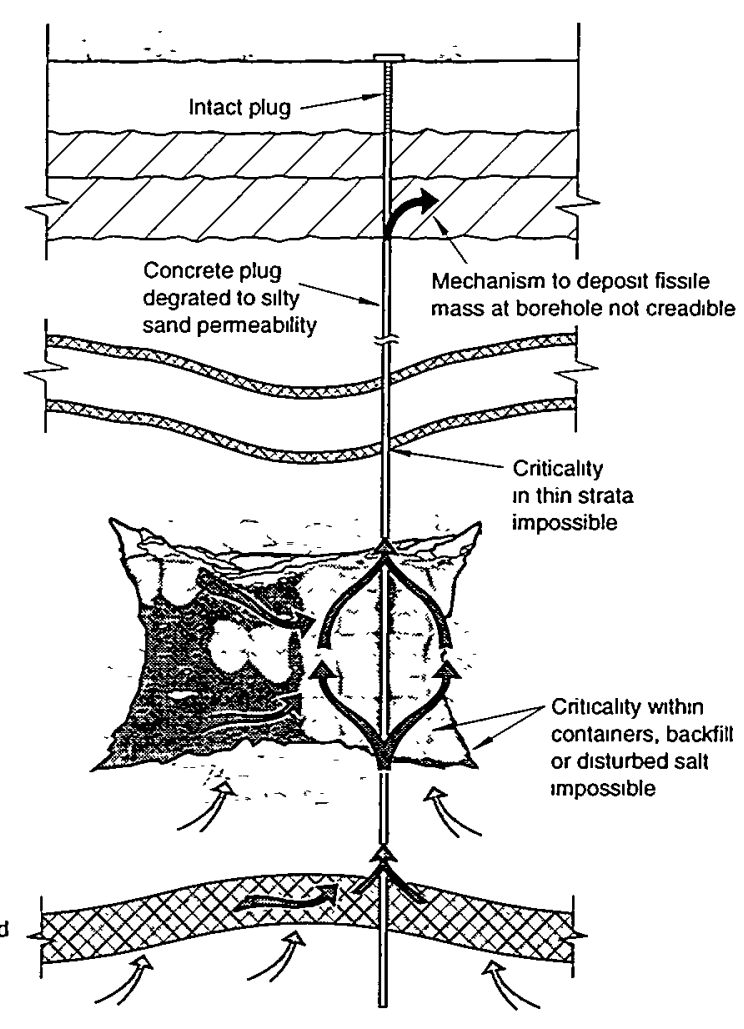

(b)

Figure 13. Hypothesized situation in the disposal area leading to disturbed state of the WIPP (E2 human intrusion scenario) (after Rechard, 1995, Figures 5.1-1, 5.1-2). (a) Room creep closure and brine inflow and (b) brine flow through the borehole to Culebra after concrete plug degrades to silty sand permeability. Although no salt creep or salt precipitation in borehole is conservatively assumed over 10,000-yr simulation, EPA does not require WIPP Project to make the unrealistic assumption that the hypothetical flow system continues beyond 10,000 yr.

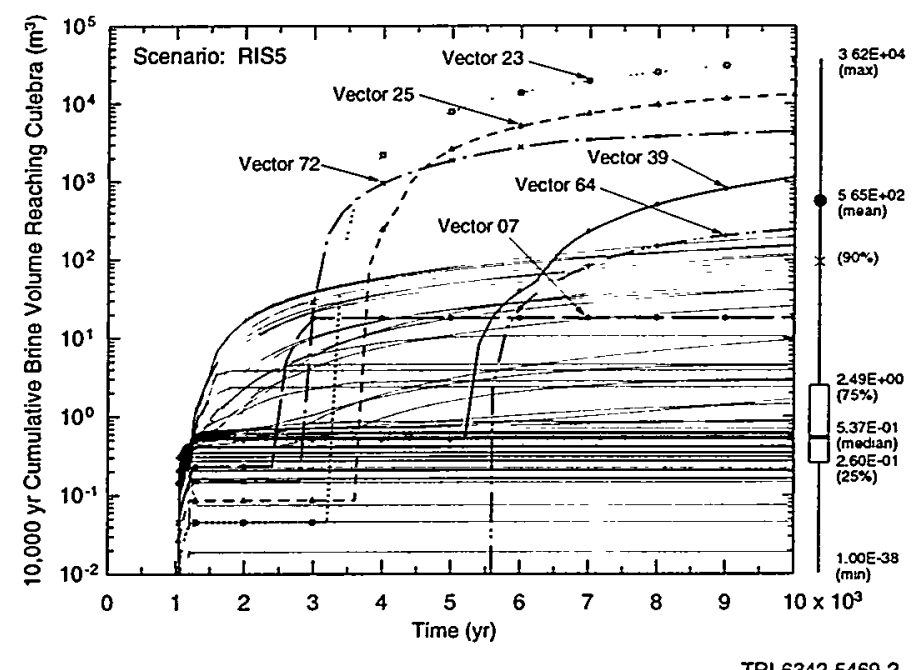

Figure 14. Cumulative brine flow up an intrusion borehole over 10,000 yr after an intrusion that occurs 1000 yr after closure of the repository for the E2 scenario (intrusion without hitting a brine reservoir) in the first replication of the 1996 performance assessment calculation (R1S5) (after Bean et al., 1996, Figure 7.2.2-10). 


\section{Low Probability Based on Physical Constraints on Critical Concentration}

Given that the probability of criticality $(P\{\bar{C}\})$ is composed of four factors, $P\{C\}=P(C \mid p \cap h \cap c) \cdot$ $P\{p\} \cdot P\{h\} \cdot P\{c\}$, where $P(C \mid p \cap h \cap c)$ is the conditional probability of criticality given no obvious physical, hydrologic, or geochemical constraints, $P\{p\}$ is the probability of no physical constraints, $P\{h\}$ is the probability of no hydrologic constraints, and $P\{c\}$ is-the-probability of no geochemical constraints to criticality. In this section, we explore situations where $P\{p\}$ is clearly less than $10^{-4}$ over 10,000 yr such that $P\{C\}$ is also less than $10^{-4}$.

\subsection{Critical Concentration Limit}

A self-sustaining fission chain reaction (i.e., criticality) depends on the chain-carrying neutrons and thereby on the interaction of neutrons with matter; hence a critical condition depends not only on the quantity of fissile material but also on its concentration, shape, and any other material mixed with or surrounding the fissile material either as a solid (e.g., containment vessel), liquid (e.g., solvent), or gas that reflects or absorbs the neutrons. In addition, the temperature of the material has an important influence. As demonstrated by Clayton (1979), the interaction of neutrons with different types, shapes, and masses of material can produce results that are hard to categorize; setting limits for a heterogeneous mixture with specific shapes and masses of fissile and other material is particularly complex. However, standard limits below which criticality is impossible-do-exist-for-homogenous-mixtures of fissile material with one or more other materials, and these limits can provide guidance.

\subsubsection{Uranium- and Plutonium-Water Mixtures}

In describing the possibilities of mixtures of fissile material in the literature, the behavior of fissile material with water is most often presented as the fissile mass versus the fissile concentration (Figure 15). The typical shape of the curve is explained as follows for a ${ }^{235} \mathrm{U} /$ $\mathrm{H}_{2} \mathrm{O}$ mixture. Initially, mixing a small amount of water with $93.2 \%$ wt uranium dilutes the fissile material, which allows more neutrons to escape and thus requires more fissile material to achieve criticality (see Figure 15a, far right). Eventually, however, as more water is added, the ability of the water to moderate the neutrons lowers the amount of fissile material required (see Fig-

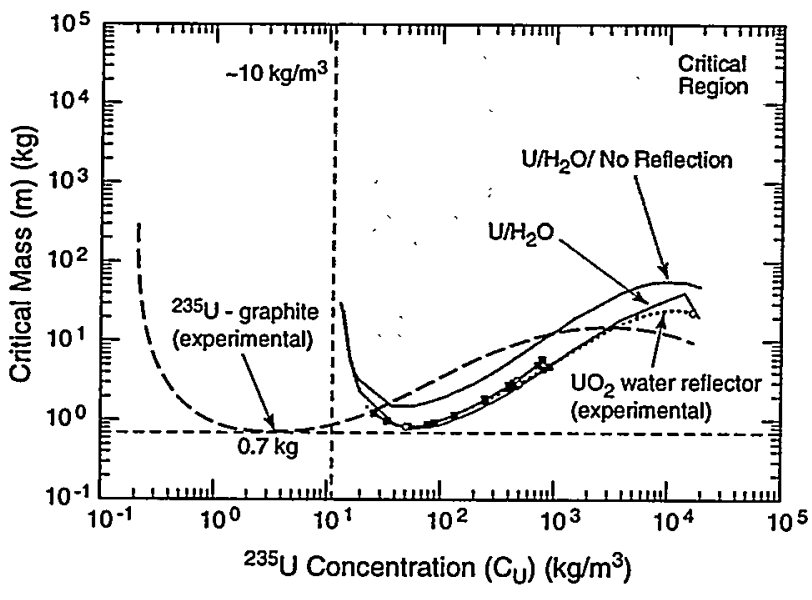

(a)

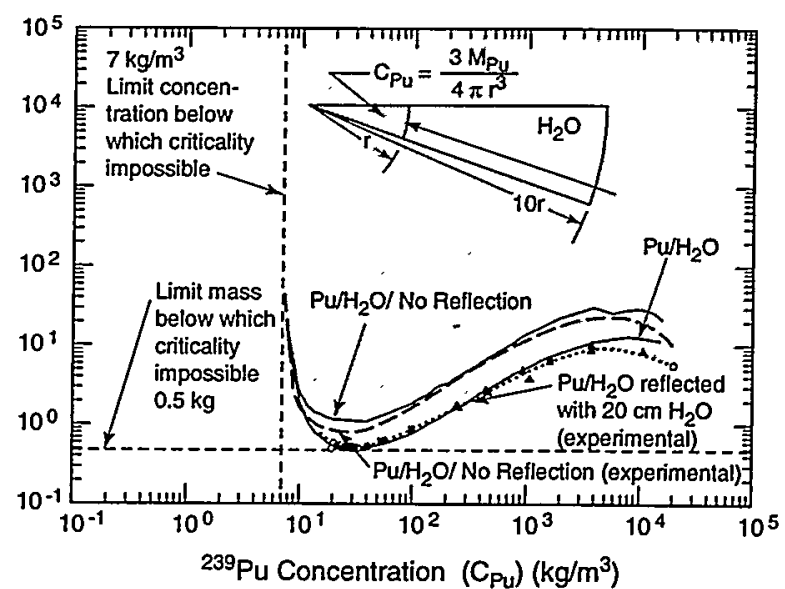

TRI-6342-4833-5

Figure 15. Comparison of calculated and measured critical masses in a homogeneous, spherical shape as a function of fissile solid concentration when mixed and reflected with water. Calculated results from MCNPTM (after Sanchez et al., 1998, Figures E.3-XI, E.3-X2, and E.3-X3), (a) measured data for $93.2 \%$ wt ${ }^{235} U$ from Paxton et al. (1964, Figure 8), and (b) measured data for $100 \% w{ }^{239} \mathrm{Pu}$ from Clayton and Reardon (1980, Figure 27.7) and Paxton et al. (1964, Figure 27). 
ure 15a, midpoint) (i.e., when a compound slows down the neutrons through collisions, for example, hydrogen atoms in water, the probability is increased that the neutron will be absorbed by the fissile material and fission). With more dilution, the amount of neutrons the water absorbs, rather than moderates, becomes so large that the mass again increases until an asymptote is reached in which to go critical the required mass (and volume) is infinite (see Figure 15a, far left). For criticality to occur, the uranium mass must lie to the right and above the curve. For simplicity, the critical region can be expressed as the region with total mass greater than $0.7 \mathrm{~kg}$ and a concentration greater than $10 \mathrm{~kg} / \mathrm{m}^{3}$ of $93.2 \% \mathrm{wt}^{235} \mathrm{U}$.

The same basic shape is observed for a $100 \%$ wt ${ }^{239} \mathrm{Pu} / \mathrm{H}_{2} \mathrm{O}$ mixture. For criticality to occur, the amount of $100 \%$ wt ${ }^{239} \mathrm{Pu}$ mass must be greater than a $0.5 \mathrm{~kg}$ and the ${ }^{239} \mathrm{Pu}$ mass in a unit volume of $\mathrm{H}_{2} \mathrm{O}$ must be greater than $7 \mathrm{~kg} / \mathrm{m}^{3}$ when pure water is the primary interactive (moderating) substance and the other substances are fairly transparent to neutrons (i.e., ideal conditions for criticality) (Figure 15b).

The minimum critical mass (or minimum critical volume) of ${ }^{239} \mathrm{Pu}$ or ${ }^{235} \mathrm{U}$ is a useful limit and is occasionally used in this report. However, the masses and volumes of fissile material collected in a certain region of geologic material can be dependent on time (e.g., flow rates) and thereby depend upon the regulatory period, unless a geometrical constraint on the maximum mass or volume exists. Hence, the concentration limit is applied to the potential solid concentration in or near the repository, because concentration can often be more readily compared to geologic processes such as dissolution, adsorption, and precipitation.

\subsubsection{Computational Tool: MCNP}

Although numerous criticality experiments have been performed in ideal material, criticality experiments with common geologic material have not. Consequently, the work presented here is based on calculations made with MCNPTM (Monte Carlo code for Neutron and Photon transport). MCNPTM is a general purpose, continuous energy, generalized geometry, time dependent coupled neutron/photon transport code that uses a Monte Carlo solution technique (Los Alamos Version 4A, RS ICC version CCC-200) (Briesmeister, 1986). The Monte Carlo solution technique was developed 50 years ago to solve the problem of tracking an individual neutron as it interacts with fissile and other material in a specified region. The distance between interactions, the fissions that occur, the loss by capture or leakage are characterized by parameters such as the reaction cross-sections of the atoms in each material, the mean free paths between interactions, the distribution describing scattering, and the distribution of neutron energy. MCNPTM is currently considered state-of-theart in neutron and photon transport calculations because it uses pointwise continuous-energy cross sections in addition to the multigroup cross sections used by other Monte Carlo neutronic codes (e.g., KENO-V and MORSE [Straker et al., 1970]).

Although the ability to use pointwise continuousenergy cross sections prompted its selection for analysis in this report, MCNPTM cannot easily determine the point of criticality, i.e., the point at which $k_{\text {eff }}$ is exactly equal to one. Other codes, such as ONEDNT in the DANTSYS code system, are able to accomplish this fairly easily by performing a "buckling search" for systems containing fissile material (Alcouffe et al., 1995). With MCNPTM, however, the user must select parameters with a trial-and-error process to discover when $k_{e f f}$ equals one. To aid in this process, a pre-processor for MCNPTM $^{T M}$ was developed to easily generate input files of mixtures of geologic material and a post-processor was developed to estimate conditions for $k_{e f f}=1$ through interpolation of results from previous MCNPTM simulations. Through the use of these pre- and post-processors, a user can more readily generate a criticality curve such as is shown in Figure 15. For ${ }^{235} \mathrm{U}-\mathrm{H}_{2} \mathrm{O}$ and ${ }^{239} \mathrm{Pu}-$ $\mathrm{H}_{2} \mathrm{O}$ mixtures, the calculated criticality curves (using $10^{5}$ histories to evaluate $k_{\text {eff }}$ ) compare quite well with results of experiments compiled by Paxton et al. (1964) and Clayton and Reardon (1980) (Figure 15). Sanchez et al. (1998, pp. 1-14) describe this analysis system in more detail. An example calculation can be found in Rechard et al. (1996b, Appendix A).

\subsection{Criticality Limits Based on Homogeneous Spherical Shapes in Various Materials}

In general, the addition of geologic media, such as Culebra dolomite, to the fissile/water binary system substantially increases the mass and slightly decreases the concentration necessary to go critical. For a mixture of ${ }^{239} \mathrm{PuO}_{2} /$ Culebra dolomite (porosity $[\phi]=16 \%$ ) and brine (based on properties reported in Tables 1, 2, and 3), the concentration limit for criticality is $-3 \mathrm{~kg} / \mathrm{m}^{3}$ (1250 ppm) (Figure 16a) and the mass limit is $2.2 \mathrm{~kg}$ (Rechard et al., 1996a). The concentration limit decreased about a factor of 2.3 , and the mass limit increased by a factor of 4.4 from those values shown for a Pu/ $\mathrm{H}_{2} \mathrm{O}$ binary system (Figure 15 ). The concentration limit for criticality increases to $-10 \mathrm{~kg} / \mathrm{m}^{3}$ when either Salado or Castile brine is the fluid, because of the added 
chlorine and small increases in boron content, which are very effective in absorbing neutrons (Figure 16b). Furthermore, the critical concentration for a ${ }^{239} \mathrm{Pu} /$ halite/ brine mixture is $-53 \mathrm{~kg} / \mathrm{m}^{3}$ and the minimum critical mass is $720 \mathrm{~kg}$, because of the effects from the chlorine in the salt (see Figure 16a).

For uranium as Rutherfordine $\left(\mathrm{UO}_{2} \mathrm{CO}_{3}\right)(5 \%$ ${ }^{235} \mathrm{U}$ ); the limit concentration is $-10 \mathrm{~kg} / \mathrm{m}^{3}$ of ${ }^{235} \mathrm{U}$ and the minimum critical mass is $50 \mathrm{~kg}$ (Rechard et al., 1996a) (Figure 17a). For a system composed of three components (e.g., uranium, water, Culebra dolomite), the critical curve of fissile mass versus fissile concentration can have an asymptote at the right as well as the left of the plot (which, in turn greatly reduces the critical region) when the porosity of the geologic material limits the possible mass of water and fissile material. This effect is also seen for uranium in sandstone with only $10 \%$ porosity (Figure $17 \mathrm{~b}$ ). Here, the ${ }^{235} \mathrm{U}$ enrichment is $3.68 \%$ wt, the same enrichment when the Oklo natural reactors were intermittently operating starting at about $1.97 \mathrm{Ga}$, as described further in Section 4.1.3.

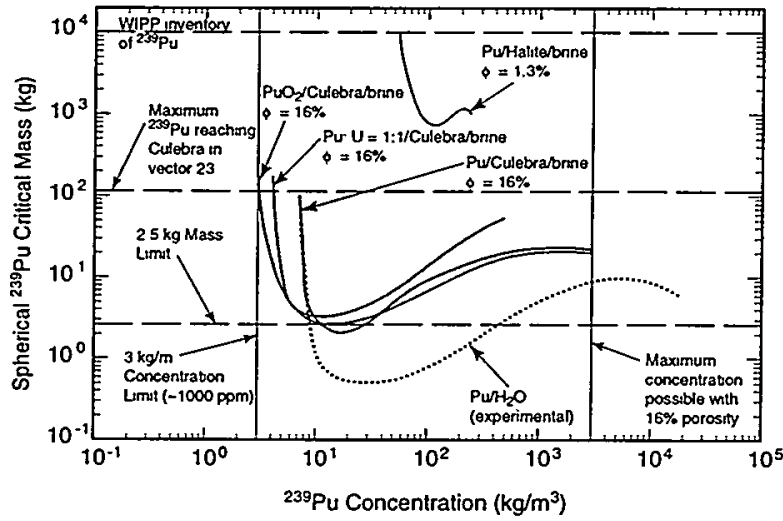

(a)

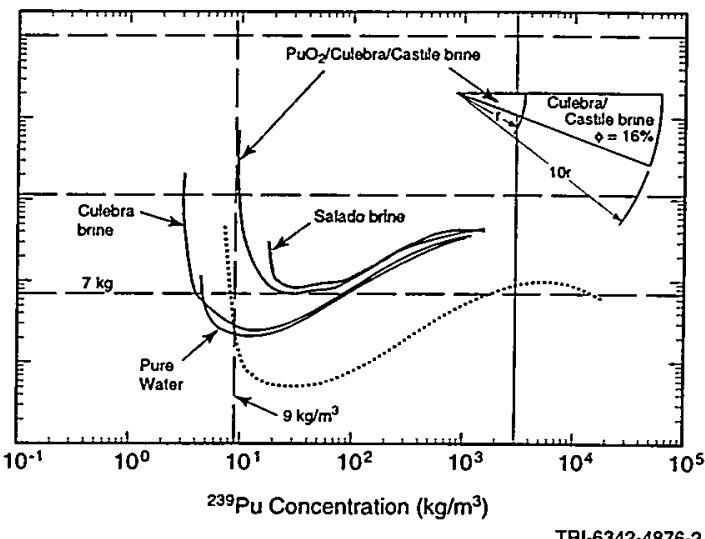

(b)

Figure 16. Calculated critical masses of ${ }^{239} \mathrm{Pu}$ in a spherical shape as a function of ${ }^{239} \mathrm{Pu}$ concentration when mixed with various substances. Results calculated with MCNP ${ }^{\mathrm{TM}}$ (Rechard et al., 1996a, Figure 1): (a) Critical mass of $100 \%$ ot ${ }^{239} \mathrm{Pu}$ or ${ }^{239} \mathrm{PuO}_{2}$ and Culebra brine, and $(b)$ critical mass of ${ }^{239} \mathrm{PuO}_{2}$ for different brines.

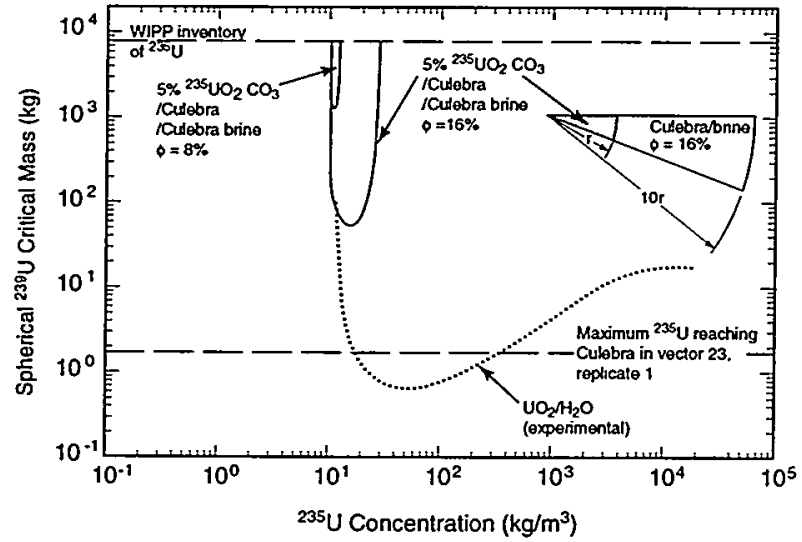

(a)

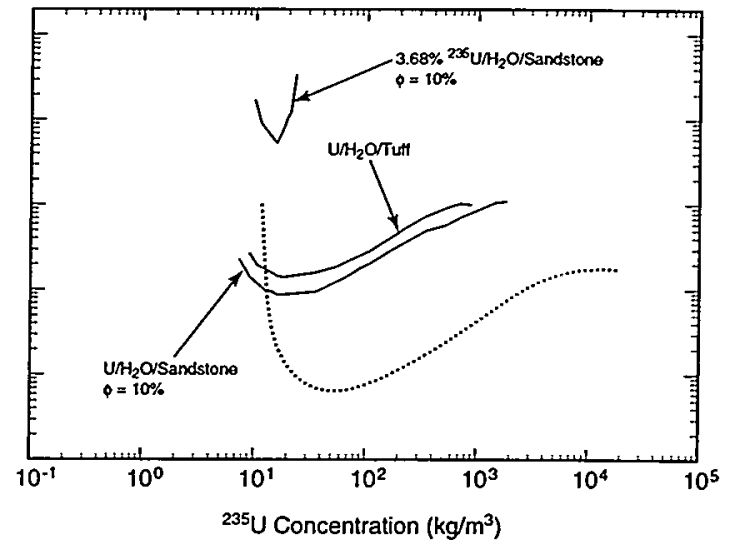

(b)

Figure 17. Critical masses of ${ }^{235} U$ in a spherical shape as a function of ${ }^{235} U$ concentration when mixed with various substances: (a) Culebra dolomite (Rechard et al., 1996a, Figure 1) and (b) Oklo sandstone. Unless otherwise noted, the ${ }^{235} U$ enrichment is $93.2 \%$ wt and the material surrounding the spherical shape is the same as in the sphere but without uranium. 
Comparison of the criticality limit (left asymptote) for $3.68 \%$ wt ${ }^{235} \mathrm{U}$ and $93.2 \%$ wt ${ }^{235} \mathrm{U}$ shows that although there is a large change in required fissile mass to go critical ( $500 \mathrm{~kg} \mathrm{vs.} 9 \mathrm{~kg}$ ), there is only a small sensitivity to fissile content $\left(9 \mathrm{~kg} / \mathrm{m}^{3}\right.$ versus $\left.5 \mathrm{~kg} / \mathrm{m}^{3}\right)$ (Figure 17a). Furthermore, to go critical, the concentration of uranium $(\sim 1000 \mathrm{ppm})$ must reach levels that are considered to be economically mineable ore bodies when located near the surface.

\subsection{Criticality Limits for Adsorption on Rust}

Fissile material can adsorb onto corrosion products of the drums and metals in the waste within the repository, most notably rust. In addition, adsorption on rust represents a reasonable maximum bound for adsorption on other materials within the repository and elsewhere. The initial iron oxide formed is amorphous (such as ferrihydrite $\left[\mathrm{am}-\mathrm{Fe}_{2} \mathrm{O}_{3} \cdot \mathrm{H}_{2} \mathrm{O}\right]$ ) that progresses, through dehydration, to more crystalline phases (first goethite $[\alpha-\mathrm{FeOOH}]$ over $\sim 10 \mathrm{yr}$ and then hematite $\left[\alpha-\mathrm{Fe}_{2} \mathrm{O}_{3}\right]$ over 50,000 yr) (Hsi and Langmuir, 1985; Smith et al., 1994). Because goethite represents the most likely form of rust over the 10,000 -yr regulatory period, the critical limits for homogeneous mixtures of metallic uranium and plutonium with goethite were evaluated for hemispherical shapes (Figure 18). The critical concentration in pure water is about $45 \mathrm{~kg} / \mathrm{m}^{3}$ and $20 \mathrm{~kg} / \mathrm{m}^{3}$ for fissile ${ }^{235} \mathrm{U}$ and ${ }^{239} \mathrm{Pu}$, respectively. ${ }^{11}$

\subsection{Criticality Limits for Planar Shapes in Culebra}

For a planar mixture of ${ }^{239} \mathrm{PuO}_{2} /$ Culebra dolomite $(\phi=16 \%)$ and brine, the concentration limit for criticality is $\sim 5 \mathrm{~kg} / \mathrm{m}^{3}$ (Figure 19), which is very similar to that for a spherical shape (i.e., $3 \mathrm{~kg} / \mathrm{m}^{3}$, Figure 16). Assuming an advective (fracture) porosity of 0.001 , the thickness of the fissile material must exceed $0.45 \mathrm{~m}$, where a 0.001 fracture porosity corresponds to the value evaluated from tracer tests in the Culebra at $\mathrm{H}-3$ and $\mathrm{H}-11$ (WIPP Performance Assessment Division, Vol. 3, 1991); the minimum thickness decreases only slightly to $\sim 0.35 \mathrm{~m}$ for an order of magnitude increase in the advective porosity of 0.04 measured at $\mathrm{H}-19$ (Meigs et al., 1997) (Figure 19).

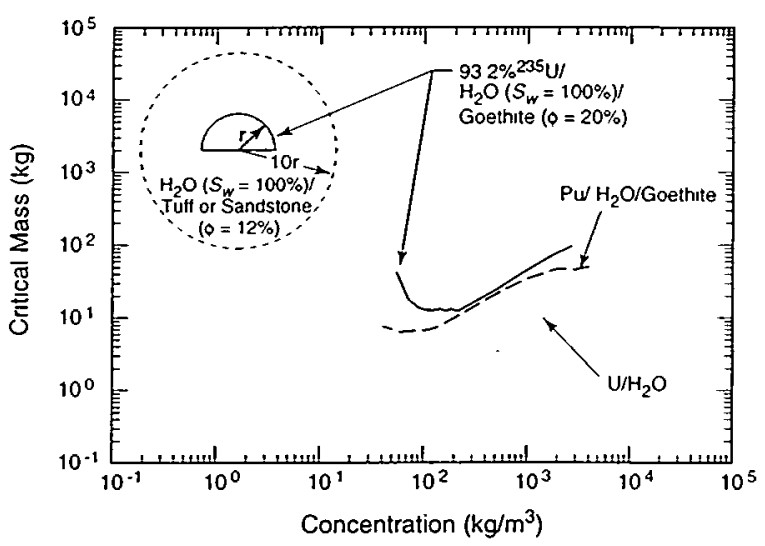

TRI-6342-6228-0

Figure 18. Calculated critical mass versus solid concentration of homogenous solutions of fissile, metallic ${ }^{235} \mathrm{U}$ and ${ }^{239} \mathrm{Pu}$ in hemispherical shape of water and goethite at $20 \%$ porosity (after Sanchez et al., 1998, Figure E.3-26).

\subsection{Physical Constraints on Criticality}

The following discussion primarily uses the limit on homogenous, spherical mixtures because the results are general; however, in the marker beds of the Salado and in the Culebra, plate configurations can be used.

\subsubsection{Compaction in Repository}

The radioactive waste to be emplaced at the WIPP contains very low concentrations of fissile material (primarily ${ }^{239} \mathrm{Pu}$ ); thus, the possibility of criticality is extremely remote prior to closure. Just as important, the possibility of criticality is also remote after closure because criticality requires that this emplaced fissile mass be substantially concentrated. To elaborate, the solid concentration below which an infinite volume of a homogeneous mixture of pure ${ }^{239} \mathrm{PuO}_{2}$, Culebra dolomite, and Culebra brine will not go critical is taken conservatively as $3 \mathrm{~kg} / \mathrm{m}^{3}$. This limit is 30 times larger than the average emplaced density of $0.12 \mathrm{~kg} / \mathrm{m}^{3}\left(\rho_{1}\right)$ with an initial porosity $\left(\phi_{1}\right)$ of 0.848 based on a total Pu FGE mass scheduled to be placed in the WIPP of $21 \mathrm{Mg}$ (Table 4) and a waste volume of $1.756 \times 10^{5} \mathrm{~m}^{3}$ $\left(6.2 \times 10^{6} \mathrm{ft}^{3}\right)$. This density could be increased somewhat through compaction; however, assuming compaction to an average porosity of 0.08 (Figure 20; see also

11 Directly within the repository, the surrounding material would be halite, which greatly increases the required fissile mass and somewhat increases the solid concentration (see Figure 15a). Here, the analysis with rust was intended as a reasonable upper bound on dolomite; however, silica-rich tuff was used so that the analysis could also be used elsewhere. 


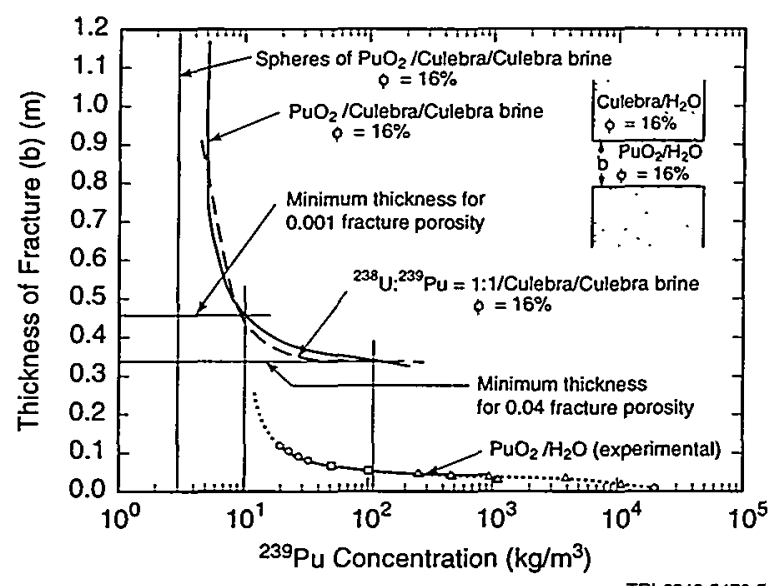

TRI-6342-5479-5

Figure 19. Critical thickness of plates of plutonium and uranium as a function of plutonium solid concentration in the Culebra (Rechard et al., 1996a, Figure 2). Measured data for Pu slabs from Paxton et al. (1964, Figure 30).

WIPP Performance Assessment Division, 1991, Figure 5-20; WIPP Performance Assessment Department, 1993, Vol. 4, Figure 4.2-6) without any salt creep into the waste layer, the fissile mass bulk density $\left(\rho_{\mathrm{f}}\right)$ increases by only a factor of 6 to $0.72 \mathrm{~kg} / \mathrm{m}^{3}$, i.e.,

$$
\rho_{f}=\rho_{i}\left[\frac{1-\phi_{f}}{1-\phi_{i}}\right]=0.72 \mathrm{~kg} / \mathrm{m}^{3} \text {. }
$$

Note that for final porosity values below 0.10 (greater than the mean and median of the final room porosities), the final room height is less than $0.45 \mathrm{~m}$ and the repository cannot go critical (Figure 20). Furthermore, salt creeping or precipitating into pores within the waste as the MgO backfill is dissolved (Bredehoeft and Hall, 1996) makes criticality even more difficult. Finally, if the transportation limit of $0.2 \mathrm{~kg}$ of FGE ${ }^{239} \mathrm{Pu}$ per container is considered, the original $2.68 \mathrm{~m}$ height of the containers would have to be reduced to $0.18 \mathrm{~m}$ to reach the critical concentration-too thin to go critical (Figure 19).

\subsubsection{Criticality in Disturbed Rock Zone and Marker Beds}

If movement of fissile material occurs from the repository into the disturbed halite or marker beds, a mechanism must exist for concentrating the solution. Furthermore, the mass and diameter of a sphere needed to produce criticality are both large and the concentra- tion for plutonium must be about $53 \mathrm{~kg} / \mathrm{m}^{3}$ (Figure 16) and at least as much for uranium. In general, the feasibility of concentrating the fissile material is not credible for two simple reasons: (1) the volume of disturbed halite and marker bed is very large (e.g., the volume of the disturbed rock zone is likely larger than the repository) and (2) no plausible mechanism exists for selective movement of fissile material into only a small portion of the disturbed rock zone or a marker bed. (These reasons consider only physical constraints. Geochemical constraints also exist and are discussed in Section 4.) The mass of plutonium FGEs required for criticality is 4 times greater than will be emplaced in any one room ( 21 MT FGE of ${ }^{239} \mathrm{Pu}$ will be emplaced in the repository, which has 118 equivalent rooms and thus $\sim 178 \mathrm{~kg}$ FGE of plutonium per room). Also, spherical diameters that are the same or greater than the original height of the waste $(2.76 \mathrm{~m})$ are required for criticality in Salado salt (calculated from Figure 16a). These arguments do not consider the ${ }^{238} \mathrm{U}$ also present in the repository $(149 \mathrm{Mg})$, which lowers the possibility of criticality because, when ${ }^{238} \mathrm{U}$ is considered, the total fissile radioisotopes make up less than $14 \%$ of the total radioisotope inventory. (The average uranium enrichment is 5\% $\left[5 \%{ }^{235} \mathrm{U}\right.$ in uranium].)

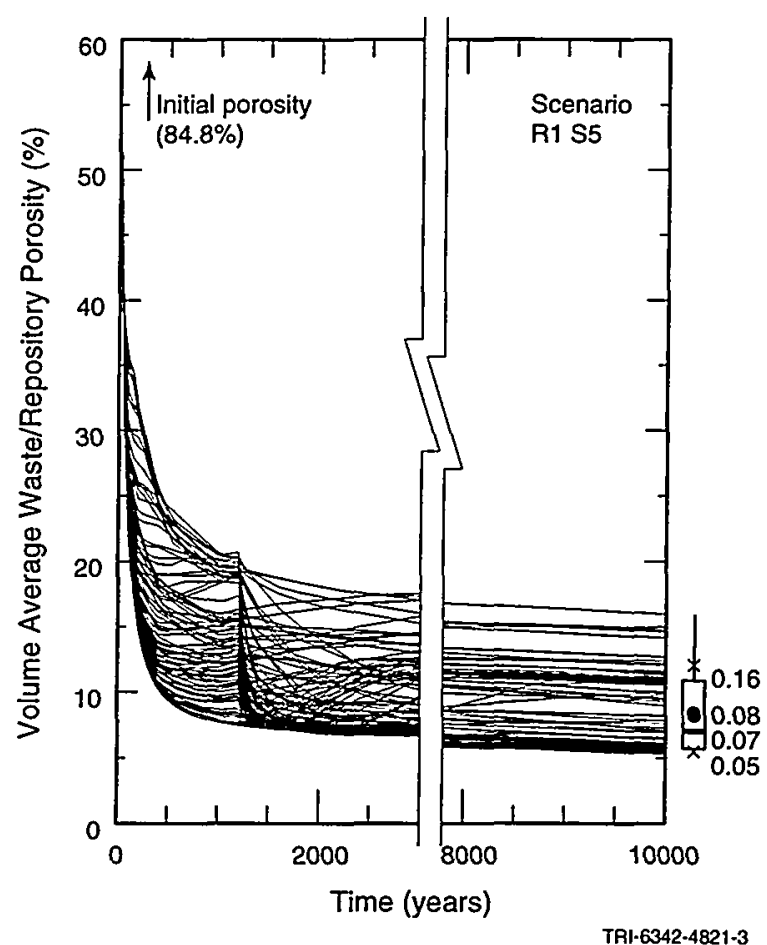

Figure 20. Volume-average porosity in room (waste, any backfill, and empty space) for replication 1 , scenario S5 (Bean et al., 1996, Figure 7.2.1-15). 
The average thickness of many of the anhydrite $\left(\mathrm{CaSO}_{4}\right)$ layers near the repository (anhydrite layers a and $\mathrm{b}$ ) is much less than $0.35 \mathrm{~m}$; hence criticality in these fractured beds is impossible (Figure 19).

\subsubsection{Geometric Constraint on Precipitation}

For those situations where the advective flow porosity is small, most potential deposition through adsorption, colloidal filtering, or precipitation will be along only the advective path, such as along surfaces lining a fracture. This situation places an important constraint on the geometry of the fissile material and eliminates the possibility of criticality in regions with flow predominately in discrete fractures because of the thickness required for the deposited fissile material. As described in Section 2.1.5.4, the advective porosity is 0.001 along the flow path in the Culebra near the repository, as interpreted from tracer tests at the $\mathrm{H}-3$ and $\mathrm{H}-11$ hydropads (Kelley and Pickens, 1986) and 0.4 at H-19 (Meigs et al., 1997). Idealized criticality analysis of flat plates in dolomite show that the deposited thickness of fissile material must exceed $\sim 0.45 \mathrm{~m}$ before criticality is possible, assuming a fracture porosity of 0.001 (Figure 19). Consequently, any change in the water chemistry or dilution of the solution of contaminated brine reaching the Culebra from the repository would occur over volumes larger than those that would permit criticality.

\subsubsection{Deposition Directly in Borehole}

Deposition within the borehole can be eliminated because the diameters used for boreholes are $0.413 \mathrm{~m}$ (16-1/4 in.) or $0.444 \mathrm{~m}$ (17-1/2 in.) for oil and gas wells into the Culebra and $0.311 \mathrm{~m}(12-1 / 4 \mathrm{in}$.) and $0.356 \mathrm{~m}$ (14 in.) into the salt (WIPP Performance Assessment Division, 1991, p. 4-45). All these dimensions are less than the $0.45-\mathrm{m}$ plate thickness required for criticality. (Here the plate is assumed to be oriented vertically.)

\subsubsection{Maximum Fissile Material Reaching Various Strata}

In the 1996 performance assessment, the fissile material reaching the Culebra, using the calculated flow rates (Figure 14) and concentrations of fissile material (Figure 21) are generally quite low (Figure 22). The mass of ${ }^{235} \mathrm{U}$ brought to the Culebra over $10,000 \mathrm{yr}$ remains below the 50-kg mass limit. Only vectors 23

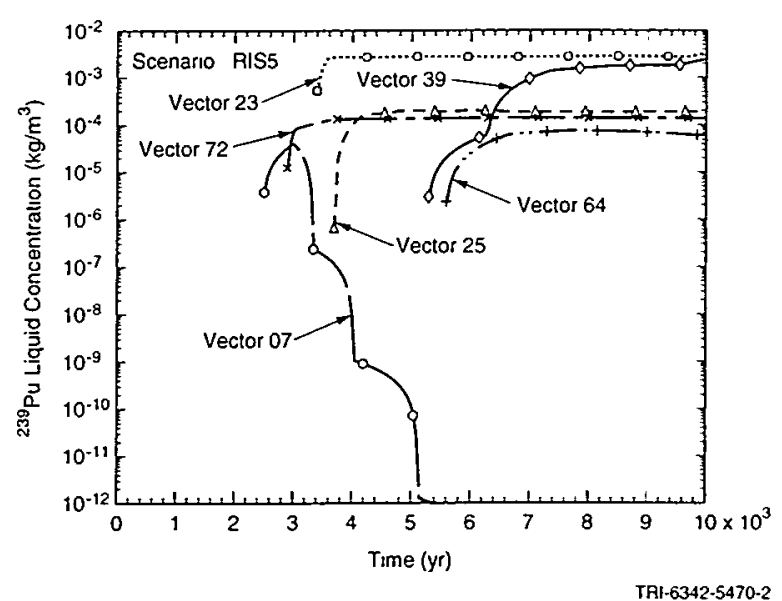

Figure 21. Liquid concentrations of plutonium in brine reaching Culebra in RIS5 (Rechard et al., 1996a, Figure 7).

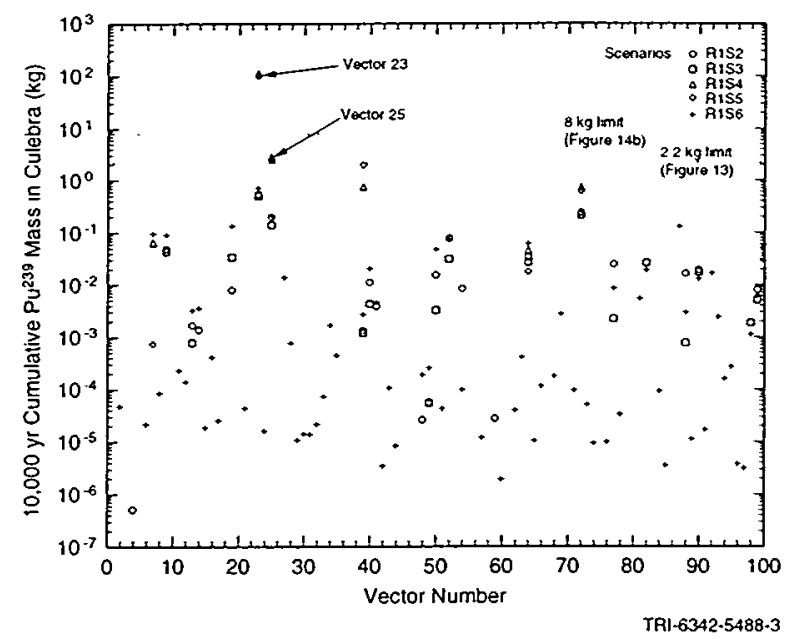

Figure 22. Cumulative mass of ${ }^{239} \mathrm{Pu}$ reaching the Culebra through intrusion borehole over 10,000 yr for RIS2, RIS3, RIS4, RIS5, and RIS6. Vectors 23 and 25 show cumulative masses of 110 and $2.4 \mathrm{~kg}$, respectively, reaching the Culebra (Rechard et al., 1996a. Figure 8).

and 25 exceed the very conservative $2.2-\mathrm{kg}$ mass limit for ${ }^{239} \mathrm{Pu}$ (Figure 16) using the maximum flow rate in replication 1; only vector 23 exceeds the $8-\mathrm{kg}$ mass limit using Castile and Salado brine. ${ }^{12}$

In the 1996 performance assessment, the Culebra is the most likely path for movement of radioisotopes from the borehole to the accessible environment because of

12 The possibly large reduction in solubility for $\mathrm{Pu}^{\mathrm{IV}}$ is sufficient to completely eliminate the possibility of enough plutonium reaching the Culebra in the first $10,000 \mathrm{yr}$. 
its higher permeability relative to other strata in the area. Hence, practically all of the dissolved radioisotopes migrate through this strata with only a maximum of $-5.2 \mathrm{~m}^{3}$ (vector 50, replicate 1) of brine going above the Rustler. Not enough fissile material moves into other strata to exceed the criticality mass limit of $2.2 \mathrm{~kg}$ of ${ }^{239} \mathrm{Pu}$ or $50 \mathrm{~kg}$ of ${ }^{235} \mathrm{U}$.
For Marker Bed 139, the maximum flow is $2225 \mathrm{~m}^{3}$ flowing to the south and $1800 \mathrm{~m}^{3}$ flowing to the north in vector 50 , replicate 1 . The maximum flow of $2225 \mathrm{~m}^{3}$ is not sufficient to move even $2.2 \mathrm{~kg}$ of ${ }^{239} \mathrm{Pu}$ (Figure 16) at the current maximum solubility of $3 \times 10^{-3} \mathrm{mM}$ $\left[\left(3 \times 10^{-3} \mathrm{~mole} / \mathrm{m}^{3}\right) \quad\left(2225 \mathrm{~m}^{3}\right) \quad(0.239 \mathrm{~kg} / \mathrm{mole}=\right.$ $0.16 \mathrm{~kg}<2.2 \mathrm{~kg})]$. 


\section{Low Probability of Criticality in Culebra Based on Information from Ore Deposits}

Because the critical concentration of fissile material is similar to that found in ore deposits (see Section 3), an examination of uranium ore deposits and their genesis provides some insight into the probability of an ore-like concentration of fissile material forming at the WIPP. Another advantage to this approach is that such a comparison is comprehended by a fairly wide scientific audience. In this section, several characteristics of uranium ore deposits (such as indigenous oxidants) are first described, along with the observation that such characteristics are generally absent from the WIPP disposal system. Then the average minimum mass (or the minimum total concentration, given the calculated flow at the WIPP) that would be necessary to exceed a probability of $10^{-8} / \mathrm{yr}$ for an ore-like concentration to be deposited is evaluated; the probability is based on a hypothetical introduction of some agent (such as a strong oxidant) along the contaminant path that would change the brine chemistry in the Culebra.

\subsection{Uranium Ore Deposits}

During the late 1960s, when power utilities were rapidly ordering nuclear power plants, the AEC (in cooperation with the IAEA) seriously explored for uranium ore deposits to meet anticipated demand. In conjunction with this exploration, characteristics of uranium ore deposits were compiled, along with research to explain why the deposits had formed. This section draws upon this literature.

\subsubsection{Uranium Ore Deposits in United States}

Uranium ore typically is formed after oxygenated water leaches uranium from source rocks, such as volcanic tuff, and then deposits it because of favorable water chemistry. Most uranium ore deposits worldwide are in sedimentary rock, with nearly one-third in sandstone. As reported by Adler (1974), more than $95 \%$ of the uranium deposits in the United States that are potentially exploitable reserves are in sandstone. Furthermore, these sandstone deposits, which are found primarily in Wyoming and the Colorado Plateau, represent $\sim 30 \%$ of the world uranium reserves (Brinck, 1974). The more concen- trated portions of these ore deposits in the United States vary between 1 and $5 \mathrm{~kg} / \mathrm{m}^{3}$ (1000 to $2000 \mathrm{ppm}$ ). While deposition of uranium ore has occurred simultaneously with sediments (placer type or syngenetic ore deposits) in the United States, e.g., Ambrosia Lake near Grants, New Mexico (Saucier, 1980, p. 116), and in Canada and South Africa, the uranium ore deposits in the United States were mostly deposited after the formation of the sandstone, i.e., epigenetic ore deposits. The sandstone and other sedimentary rocks usually served as an aquifer that transported soluble $\mathrm{U}^{\mathrm{VI}}$ species to a location, within or adjacent to the aquifer, that contained a chemical environment causing deposition.

Occasionally, a complexing agent such as vanadium is present in the sedimentary rock that produces an insoluble uranium species, such as carnotite and tyuyamunite, which occur in uranium ore deposits in the Colorado Plateau (Shawe, 1956; Langmuir, 1978). More often, the deposition of uranium occurs when soluble $\mathrm{U}^{\mathrm{VI}}$ (e.g., uranium as a uranyl carbonate) is reduced by organic material, pyrite, or $\mathrm{H}_{2} \mathrm{~S}$. This process is readily visualized on an Eh-pH diagram that defines the chemistry of solution, where Eh measures the oxidizing potential of the solution ${ }^{13}$ and $\mathrm{pH}$ the hydronium ion $\left(\mathrm{H}^{+}\right)$ concentration. The diagram shows the predominant location of ore bodies in the reducing environment where the uranium species is $\mathrm{U}^{\mathrm{IV}}$ (Figure 23). However, the uraninite ore $\left(\mathrm{UO}_{2}\right)$ can form and be stable throughout the much larger area where $\mathrm{U}^{\mathrm{IV}}$ dominates, as demonstrated by Langmuir (1978). A similar Eh-pH diagram can be estimated for plutonium (Figure 24); however, it reflects much more speculation because detection and analysis of the low-soluble plutonium species are difficult.

Uranium ore deposits are categorized as either a roll-type or lenticular-type uranium ore deposit. Each of these categories can be classified further with regard to the source of the change in water chemistry, e.g., a reductant is either indigenous to or introduced into the sedimentary aquifer.

The indigenous reducing agent is often derived directly from organic material such as peat bogs and swamps, coal, or oil (Adler, 1974; Granger and Warren, 1974). Yet the indigenous reducing can also be derived indirectly from organic material. For example, sulfate-

13 The oxidizing potential (Eh) of the solution is measured in volts. Eh is formally defined by the Nernst equation (Snoeyink and Jenkins, 1980, pp. 331-332). 


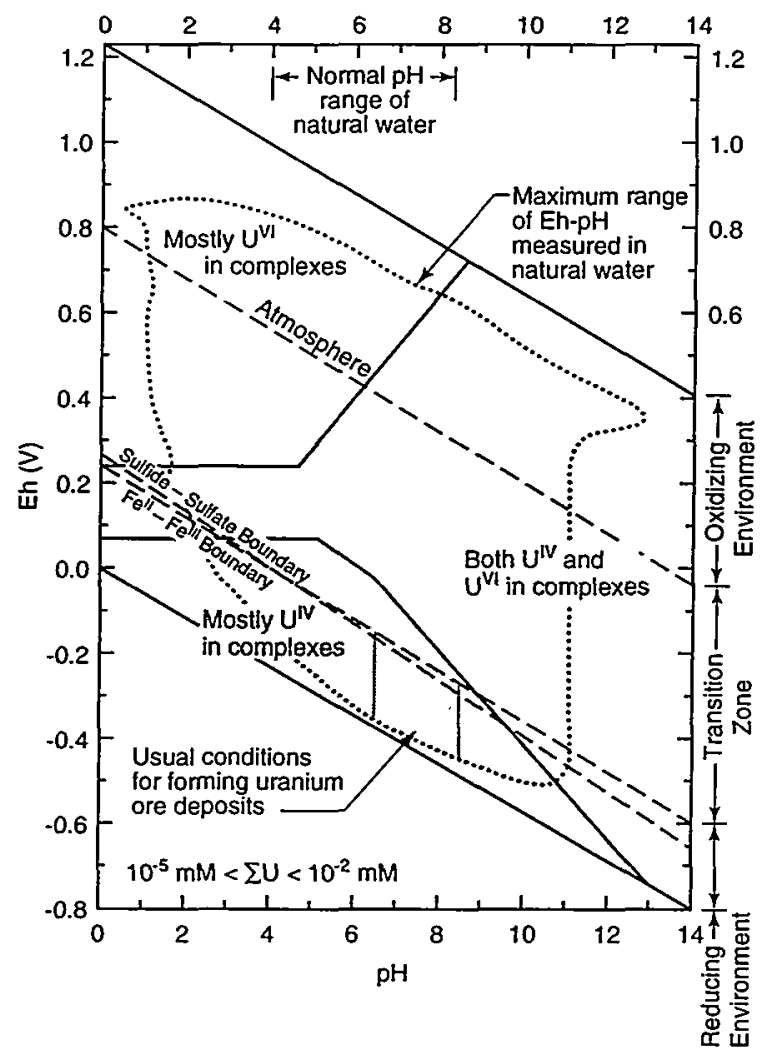

TR1.6342-4599-3

Figure 23. General Eh-pH diagram of uranium formed by superimposing Eh-pH diagrams from several systems (U-C-O-H, U-O-H, U-Si-C-O-H, U-Si-O-H) (after Brookins, 1988, Figures 1, 87, 88, 89, 90, and 91; see also Langmuir, 1997, Figures 13.8, 13.9, and 13.10; WIPP Performance Assessment Division, 1991, Figure 3.3-9). This diagram is only a rough approximation because actually coupling the systems would change the results somewhat. Uranium ore deposits typically form when massive amounts of waters with small amounts of dissolved $U^{V I}$ species encounter a reducing environment (e.g., hydrocarbons) that reduces the uranium to $U^{I V}$ and precipitates uraninite $\left(\mathrm{UO}_{2}\right)$.

reducing bacteria can feed on the organic debris, generating $\mathrm{H}_{2} \mathrm{~S}$ that then diffuses into the sand. If the sand contains some iron minerals, pyrite can form. This pyrite then becomes a means to reduce uranium in solution in groundwater, when the water moves through the channel sand aquifers at a much later time. This phenomenon has been observed in some lenticular uranium ore deposits in ancient fluvial channels in the Colorado Plateau (Adler, 1974).

The introduced reductant can be either a water that carries residues from decaying plant (humic) material, such as occurs in the lenticular deposits near Grants, New Mexico (Adler, 1974; Granger, 1968; Moench and Schlee, 1967), or an inorganic material, such as $\mathrm{H}_{2} \mathrm{~S}$, which is introduced through fault zones and is derived from other organic material or volcanic sources, such as occurs in the coastal uranium ore deposits in Texas.

\subsubsection{Uranium Deposits Adjacent to WIPP}

\subsubsection{Uranium Deposits from Same Period}

In Oklahoma, radioactive anomalies are present throughout several sedimentary sandstone formations deposited during the late Permian Period. (The formations surrounding the WIPP repository are also of the Permian Period, see Section 2.1.) In the 1950s, about 13 tons of uranium ore was mined from the Rush Springs Sandstone of Guadalupian series, which corresponds to Bell Canyon and older formations (Johnson, 1978) ${ }^{14}$. A Doxey shale of Ochoan age, which roughly corresponds to the Dewey Lake Red Beds Formation (Johnson,

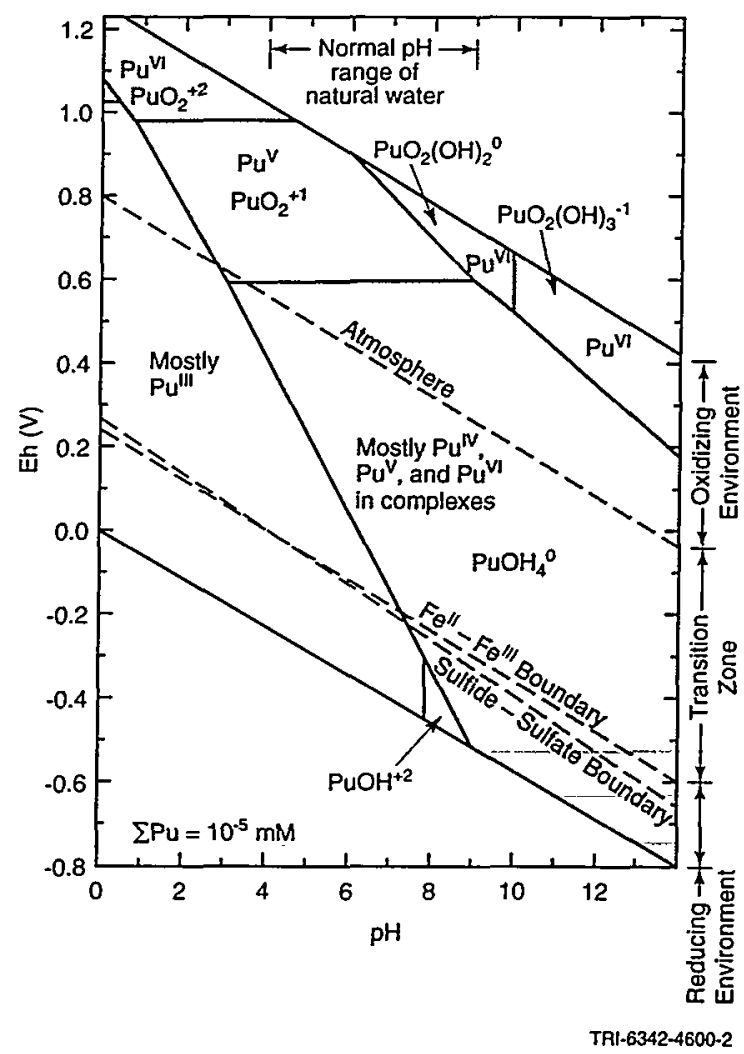

Figure 24. Speculative Eh-pH diagram of plutonium formed by superimposing $E h-p H$ diagrams from several systems (Pu-O-H and Pu-O-H-C system) (after Langmuir, 1997, Figure 13.30; see also Brookins, 1988, Figures 82 and 83; WIPP Performance Assessment Division, 1991, Figure 3.3-9).

I4 Al-Shaieb et al. (1977) correlate the Rush Springs to the older Leonardian series (see Figure 3). 
1978) has anomalous carnotite and tyuyamunite uranium minerals, which formed in the presence of vanadium, in thin interbeds of sandstone and siltstone of the shale. The ore consisted of small lens of carnotite and tyuyamunite deposited a distance of $46 \mathrm{~m}$ (150 ft) along a fracture.

\subsubsection{Uranium Ore Deposit in Similar Media}

As mentioned earlier, uranium ores in sedimentary rocks other than sandstone are uncommon $(<5 \%)$ in the United States. In addition, conditions for the deposition of uranium in carbonate rocks, such as limestone or dolomite, are especially unfavorable because uranyl carbonate complexes are highly soluble; carbonate rocks typically contain no more than $1 \mathrm{ppm}$ uranium (Bell, 1963). However, one small uranium ore deposit of the Jurassic Period occurs near Grants, New Mexico, where the Entrada Sandstone aquifer is overlain by the Todilto Limestone formation (similar to dolomite but lacking magnesium) that produced some oil. Highly fractured areas of the limestone formation allowed water carrying uranium to move into the limestone and deposit local accumulations of uranium in the presence of $\mathrm{H}_{2} \mathrm{~S}$. Conversely, movement of some $\mathrm{H}_{2} \mathrm{~S}$ from the limestone caused pockets of uranium deposition in the sandstone (Bell, 1963; Adler, 1974; Anderson and Kirkland, 1960).

\subsubsection{Oklo Natural Reactors}

The formation of the Oklo uranium ore deposit in Gabon, Africa, began when oxygenated water dissolved uranium in conglomeritic sandstone that had been deposited $\sim 2.06 \mathrm{Ga}$ (summarized in Rechard et al., 1996b; 1997). The dissolved UVI was reduced to $U^{I V}$ through the presence of reducing hydrocarbons in an overlying black shale and sandstone formation. The Oklo ore, which contains $-17,300 \mathrm{Mg}(17,300$ metric tonnes as $\left.\mathrm{U}_{2} \mathrm{O}_{3}\right)$, consists mostly of a low grade ore $(0.2$ to $1 \%$ wt uranium); however, a high grade ore $(>20$ $\%$ wt) is located at faults in the sandstone where greater amounts of hydrocarbons were structurally trapped. The Oklo ore deposit is unique in that about 16 lenticular regions have been identified within the high grade that operated as natural reactors starting about $1.97 \mathrm{Ga}$, when natural uranium had a ${ }^{235} U$ content of $-3.68 \%$ wt. The reactors operated intermittently for about $2 \times 10^{5}$ to $8 \times 10^{5}$ yr (Cowan et al., 1975; Gauthier-Lafaye et al., 1989). The first six natural reactors are typically 10 to $20 \mathrm{~m}$ in length and width, and less than $1 \mathrm{~m}$ thick (Gauthier-Lafaye et al., 1989). Some of the natural reactors are concentrated up to $55 \%$ wt, possibly because of added convective circulation of water heated by each natural reactor, which supplied more uranium solution and dissolved silica in the sandstone to provide more depositional space. The original porosity of the faulted zones is unknown but to provide adequate depositional space and water moderation for criticality, the porosity must have been at least $10 \%$ (see Figure 17b) and was likely between $20 \%$ and $30 \%$.

\subsubsection{Lack of Favorable Depositional Features in WIPP Disposal System}

Several favorable features and conditions prompted the formation of the ore deposits in Gabon, Africa, and in the United States. In general, the deposits were in sandstone that had (1) moderately high porosity for adequate depositional space, (2) high advective porosity to provide high permeability and allow sufficient water circulation, (3) oxygenated water to transport the soluble $\mathrm{U}^{\mathrm{VI}}$, (4) an essentially infinite source of uranium in volcanic tuff or granitic source rocks, and (5) either (a) readily introduced/indigenous reducing material to chemically reduce the uranium to insoluble $\mathrm{U}^{\mathrm{IV}}$ or (b) introduced/indigenous vanadium to form uranyl vanadate minerals, such as carnotite or tyuyamunite.

These favorable features are absent in the WIPP disposal system. First, the pathways to the accessible environment at the WIPP do not pass through sandstone; the Bell Canyon sandstone lies $-590 \mathrm{~m}$ below the repository and the Dewey Lake Red Beds sandstone has a transmissivity too low to measure and possibly is not saturated above the repository (Mercer, 1983). Instead, any potential pathway to the accessible environment must pass through evaporites. Furthermore, no evidence exists to suggest that either vanadium or strong indigenous reductants/oxidants can be found in the evaporites near the WIPP, especially in the Culebra dolomite. More importantly, the ability of fluids to mobilize the uranium and plutonium through oxidation and then concentrate the uranium and plutonium through reduction is not present (Figures 23 and 24). Therefore, we can only speculate about less likely mechanisms for deposition of plutonium and uranium; these hypotheses are discussed in Section 5.

\subsection{Natural Concentration Efficiency Based on Oklo}

Besides demonstrating that the WIPP lacks favorable depositional features, Oklo can also be used to explore the implications of nature's efficiency on what solubility value for ${ }^{239} \mathrm{Pu}$ would be required to collect enough fissile material within $10,000 \mathrm{yr}$, with a probability greater than $10^{-4}$ over that same 10,000 -yr period, to cause criticality. The answer is conditional on the presence of proper geochemical conditions (such as an introduced strong oxidant in the repository and strong reductants at some other location along the flow path; 
few other radioisotopes being coprecipitated with the fissile material), and proper physical conditions (i.e., $P(C l h \cap p \cap c) \cdot P\{h\})$.

Below is an argument similar to Rechard et al. (1996b, 1997) for evaluating maximum total concentrations for the fissile material assuming the probability of $\mathrm{P}\{\mathrm{Cl} h \cap p \cap c\} \cdot P\{h\}$ is $10^{-8} / \mathrm{yr}$ such that $P\{C l\}$ $\leq 10^{-8} / \mathrm{yr}$ when fissile material is transported to the Culebra.

\subsubsection{Required Actinide Concentration Based on Maximum Flow}

Of the 16 natural reactors, data are readily available in the literature for the first six (primarily "reactor 2"). Based on these data, researchers have estimated that $6 \mathrm{Mg}$ (6 MTHM or 6.6 short tons) of ${ }^{235} \mathrm{U}$ were consumed out of $\sim 800 \mathrm{Mg}$ ( 880 short tons) of high grade uranium associated with the six natural reactors. Consumption of $6 \mathrm{Mg}$ corresponds to $\sim 10^{28}$ fissions or $\sim 15,000 \mathrm{MW}$-yr (Gauthier-Lafaye et al., 1989; Cowan and Norris, 1978). Thus, the Oklo natural reactors provide a basis for determining a rate and probability of forming a criticality: Basically, six criticalities occurred per $-800 \mathrm{Mg}$ of uranium, assuming that conditions exist for concentrating fissile material. This rate, in essence, factors in inefficiencies found in nature.

To be consistent with 40 CFR 191, the probability of criticality in the first $10,000 \mathrm{yr}$ must be evaluated, or as done here, the plutonium solubility. evaluated such that the probability of a criticality in the first $10,000 \mathrm{yr}$ is less than $10^{-4}$. The.probability model is based on the failure-rate function, defined by $r(t)=-d \ln [1-F(t)] / d t$ where $t$ is the time elapsed since the disposal system was closed and $F(t)$ denotes the cumulative distribution function for the first time; $T$, when failure occurs (i.e., $F(t)=(T \leq t))$. This expression can be. integrated to give

$$
F(t)=1-\exp \left[-\int r(t) d t\right] .
$$

Over a period of a year, $F(t)$ must be less than $10^{-8}$ (i.e., $P\{c \mid h \cap p \cap c\} \cdot P\{h\}<10^{-8}$ ). This fact, in turn; implies $r(t) \cong 10^{8} / \mathrm{yr}$. Yet the value of $r(t)$ is bound by the product of the "efficiency" of natural concentration processes as estimated from the Oklo natural reactors, $(c=.6$ events $/ 800 \mathrm{Mg}$ ), unknown plutonium concéntration (here assumed to be an unknown total concentration $[s]$, the maximum cumulative flow rate over $10,000 \mathrm{yr}$ through the repository $\left(q_{\max }=3.6 \times 10^{4} \mathrm{~m}^{3} / 10^{4} \mathrm{yr}\right.$ from Figure 14), and the 10,000-yr regulatory time period $(T)$ (i.e., $r(t) \leq c s q_{\max } T$ ). Solving for the apparent plutonium solubility $(s)$ yields a value of $1.55 \times 10^{-21} \mathrm{mM}$, i.e., $r(t)$ $=10^{-8}$ events $/ \mathrm{yr}=6$ events $/ 800 \mathrm{Mg} \cdot \mathrm{s} \cdot 3.6 \times 10^{4} \mathrm{~m}^{3}$.

\subsubsection{Required Actinide Concentration Based on Range of Flows}

The above arguments can be refined because the probability of the high flow rate $\left(q_{\max }\right)$ of $3.6 \times 10^{4}$ $\mathrm{m}^{3} / 10^{4} \mathrm{yr}$ is no more than 0.01 based on the 100 samples (Figure 14).

In the above arguments, the cumulative distribution function is actually conditional on the discharge $(q)$ through the repository, that is,

then

$$
\begin{aligned}
F(t \mid q) & =1-\exp \left[-\int r(t) d t\right] \\
& =1-\exp (-c s q T)
\end{aligned}
$$

$$
\begin{aligned}
F(t) & =\int F(t \mid q) p(q) d q \\
& =\int_{o}^{q} \max (1-\exp (-c s q T)) p(q) d q
\end{aligned}
$$

where, as before

$$
\begin{aligned}
& c=6 \text { events } / 800 \mathrm{mg} \\
& s=\text { total concentration } \\
& q=\text { discharge at time } \mathrm{t} \\
& T=10,000 \mathrm{yr}
\end{aligned}
$$

and, if $p(q)$ is represented by its empirical cumulative distribution function,

$$
F(t) \cong \sum\left(1-\exp \left(-c s q_{i} T\right)\right) p_{i}
$$

In Section 4.2.1, this sum was bound by

$$
F(t)<1-\exp \left(-c s q_{\max } T\right),
$$

yet because the individual $q_{i}$ and $p_{i}$ (frequencies) are available from the 1996 performance assessment calculations' (Figure 14), a better estimate is possible. The distribution of individual $q_{i}$ and $p_{i}$ based on the cumulative discharges at $10,000 \mathrm{yr}$ is shown in Figure 14. Using this distribution, the maximum solubility is $\sim 0.2 \mathrm{mM}=10^{-0.7}$. This maximum solubility bounds the uranium range; it also bounds all but the upper portion of the tail of the distribution for plutonium solubility. Hence, $\dot{P}\{c \mid h \cap p \cap c\} \cdot P\{h\}<10^{-4}$ for the entire range of estimated uranium concentrations, and most of the range of plutonium concentrations. ${ }^{15}$

15 The maximum solubility completely bounds the new solubility values for plutonium (see Section 2.3.7). 


\section{Low Probability Based on Geochemical Constraints on Concentration Mechanisms}

Four geochemical mechanisms could cause a concentration of fissile material in one location: highly concentrated aqueous solution, adsorption on mineral surfaces (e.g., ion exchange or surface complexation), filtration of colloid material, and precipitation. However, in the WIPP repository, no special features exist to make these mechanisms feasible, as discussed below. Furthermore, once the fissile mass leaves the repository, the general tendency is for the radioisotopes to disperse rather than concentrate. In this section, situations are explored where $P\{c\}$ is clearly less than $10^{-4}$ over $10,000 \mathrm{yr}$ such that the probability of criticality, $P\{C\}$, is also less than $10^{-4}$ over $10,000 \mathrm{yr}$.

\subsection{Constraints Posed by Solubility}

\subsubsection{Solubility Constraint on Radioisotope Concentration}

A solution of pure ${ }^{239} \mathrm{PuO}_{2}$ at a concentration of $3 \mathrm{~kg} / \mathrm{m}^{3}$ (Figure 16) corresponds to $12 \mathrm{mM}$, a concentration 30 times greater than the maximum total concentration of $0.4 \mathrm{mM}$ of $\mathrm{Pu}^{\mathrm{IV}}$ predicted in the 1996 performance assessment (Section 2.3.5). Similarly, a solution of pure ${ }^{235} \mathrm{UO}_{2}$ at a concentration of $10 \mathrm{~kg} / \mathrm{m}^{3}$ (Figure 17) corrēsponds to $37 \mathrm{mM}$. Consequently, a solution of either dissolved plutonium $(0.4 \mathrm{mM}$, maximum total concentration) or dissolved uranium (0.23 mM, maximum total concentration) (Figure 10) cannot go critical in the repository or elsewhere. Even maximum solubilities of plutonium and uranium used in other studies (Figure 11) are not critical.

The Individual Protection Requirement in 40 CFR 191 at the accessible environment $(15 \mu \mathrm{Sv} / \mathrm{yr})$ is $\sim 680 \mathrm{pCi} / \ell$ for ${ }^{235} \mathrm{U}$ or $\sim 55 \mathrm{pCi} / \ell$ for ${ }^{239} \mathrm{Pu}$. The Ground Water Requirement in $40 \mathrm{CFR} 191$ at the accessible environment is even more stringent-15 $\mathrm{pCi} / \ell$ (see Section 1.2.3). The equivalent radioisotope concentrations of $15 \mathrm{pCi} / \ell$ for ${ }^{235} \mathrm{U}$ and ${ }^{239} \mathrm{Pu}$ are $3.0 \times 10^{-5} \mathrm{mM}$ and $1.0 \times 10^{-9} \mathrm{mM}$, respectively. Hence the Individual Protection Requirement and Ground Water Requirement for human health adequately protect against criticality at the boundary of the accessible environment (even with ironoxide adsorption as described later in Section 5.2.3).

\subsubsection{Solubility Constraint on Maximum Radioisotope Release}

The solubility of the fissile material places a strict limit on the maximum radioisotope release over 10,000 yr. Although releases above this limit do not necessarily imply a criticality is possible (because the fissile material must be concentrated, as described in the previous section), the maximum release of fissile uranium is very near this limit as seen by comparing the maximum permissible solubility with the upper value for the uranium solubility range. For uranium, the maximum permissible solubility that precludes releasing $50 \mathrm{~kg}$ of fissile uranium in $10,000 \mathrm{yr}$ is $10^{-0.5} \mathrm{mM}$ (i.e., $50 \mathrm{~kg} \cdot 5.1 \% \cdot[\mathrm{mole} / 0.235 \mathrm{~kg}] /\left[3.6 \times 10^{4} \mathrm{~m}^{3} \cdot \mathrm{m}^{3} /\right.$ $\left.\left.10^{3} \ell\right]\right)$. This limit is above the upper range on the uranium concentration of $10^{-1.2}$ for $\mathrm{U}^{\mathrm{IV}}$ and the upper range of $10^{-0.6}$ for $\mathrm{U}^{\mathrm{VI}}{ }^{16}$

\subsection{Adsorption of Plutonium and Uranium}

Because of limitations in surface area in natural geologic systems, adsorption ${ }^{17}$ is an unlikely mechanism for concentrating massive amounts of fissile material to obtain a critical solid concentration, as demonstrated below. As a precursor or catalyst, adsorption, however, can potentially lead to the formation of ore deposits (e.g., Langmuir, 1978; Samama, 1986, pp. 244-249) and is considered in the discussion of precipitation (Section 5.4).

\subsubsection{Adsorption of Fissile Material on Mineral Surfaces in Repository}

Within the repository, conditions that might lead to potential adsorption of plutonium or uranium in a local-

16 The maximum solubility limit for plutonium is below the upper range of the plutonium concentration used in the 1996 performance assessment, but above the currently assumed value discussed in Section 2.3.7.

17 Herein, adsorption refers to the accumulation of material at the interface of another material. Adsorption subsumes several different mechanisms, e.g., surface complexation and ion exchange. Because geochemical adsorption is not strictly a surface phenomenon and because adsorption was attributed initially to only one or a few possible mechanisms-rather than allgeochemists prefer to use the more inclusive term, "sorption." However, the audience of this report includes nuclear engineers who discuss criticality from neutron absorption by the nucleus of an atom. Thus, this report uses the more traditional terms, adsorption and absorption. 
ized area do not exist. Granted, the waste from each storage/generation site contains a wide variety of potentially adsorptive material, such as minerals in soils, glass, waste solidifiers (e.g., bentonite), metals, and corroded surfaces from the steel drums (see Section 2.3); however, from a macroscopic perspective, potentially adsorptive waste - material-is-not-concentrated in - a few drums or from a particular storage or generation site. Hence, adsorptive materials_will_be_fairly_uniformly_distributed throughout the repository and preferential concentration of plutonium in one area is unlikely. Although the formation of biofilms may result in some fissile concentration, the distribution of substrates for biofilm formation is also disseminated throughout the waste in the repository. In addition, growth-limiting or enhancing factors, such as aqueous metal and radioisotope concentrations and nutrients, will be uniformly distributed throughout the repository and will not spatially concentrate the development of biofilms. This assumption of general uniform mixing is consistent with the general conceptual model of the WIPP repository in the 1996 performance assessment.

Even if localized concentration of adsorptive material did occur, separation of plutonium to the exclusion of the-large-amounts of the -other-radioisotopes (e.g., ${ }^{238} \mathrm{U}$ ) is not plausible. If a facile technique through adsorption were known, it would have been used in place of the expensive PUREX method that separates plutonium from other radioisotopes when purifying plutonium for weapons. Likewise a difficulty in proposing an adsorptive backfill as an engineered barrier in the WIPP repository is that the adsorption on proposed backfills is not usually specific and so large masses of different types of material (e.g., nonfissile actinides, iron, nickel, and lead) that are in the TRU waste also adsorb. This situation greatly decreases the likelihood of criticality because these nonfissile actinides can readily absorb neutrons and halt a critical excursion. More specific information on adsorption on rust is provided below, along with several quantitative arguments to support this general reasoned argument.

\subsubsection{Isotherm Adsorption Model}

For modeling, adsorption in geologic media is most often expressed as the distribution of mobile material (here, the mobile uranium and plutonium radioisotopes in the brine) and the immobile rock (here, corrosion products in the repository or dolomite in the Culebra). The distribution coefficient $\left(K_{D}\right)$ in the Freundlich isotherm model (e.g., Jenne, 1998, p. 21; Morel and Her- ing, 1993, p. 516; Freeze and Cherry, 1979, p. 403) is defined as:

$$
x / m=K_{D} C_{e}^{n}
$$

where $x$ is mass of attached adsorbate on the solid, $m$ is the mass of immobile solid, $n$ is nonlinear exponent, and $C_{e}$ is the equilibrium concentration of the adsorbate in the_solution. The_validity_of the_Ereundlich_isotherm can be compromised because kinetics of the reaction are not taken into account (i.e., equilibrium can take hundreds of years) and the character of the minerals can change spatially, i.e., different types of adsorption sites are often available. More importantly, the exponent $n$ is often set to one in the equation, thereby not taking into account the potential to saturate the adsorption sites at high concentrations of radioisotopes. ${ }^{18}$ This situation can be particularly important for criticality calculations where high concentrations are required to cause a criticality event. Hence, the linear form of the Freundlich isotherm is used here only as a screening tool to evaluate whether a problem might exist.

\subsubsection{Nonlinear Isotherm for Iron Oxides} in-Repository

The initial iron corrosion products of the steel within the WIPP repository will be an amorphous ferrihydrite (am- $\mathrm{Fe}_{2} \mathrm{O}_{3} \cdot \mathrm{H}_{2} \mathrm{O}$ ) that will progress, through dehydration, to more crystalline goethite $(\alpha-\mathrm{FeOOH})$ and then hematite $\left(\alpha-\mathrm{Fe}_{2} \mathrm{O}_{3}\right)$. The linear $K_{D}$ for uranium at $\mathrm{pH} 7$, where the maximum adsorption typically occurs, varies from $\sim 100 \mathrm{~kg} / \mathrm{m}^{3}$ for the amorphous phase $\left(\rho_{\mathrm{g}} \cong 3570 \mathrm{~kg} / \mathrm{m}^{3}, \phi \cong 50 \%\right)$ to $\sim 7 \mathrm{~kg} / \mathrm{m}^{3}$ for goethite $\left(\rho_{\mathrm{g}} \cong 4270 \mathrm{~kg} / \mathrm{m}^{3}, \phi \cong 20 \%\right)$ to $\sim 0.500 \mathrm{~kg} / \mathrm{m}^{3}$ for hematite $\left(\rho_{\mathrm{g}} \cong 5270 \mathrm{~kg} / \mathrm{m}^{3}, \phi \cong 10 \%\right)$ (Hsi and Langmuir, 1985; Smith et al., 1994, Figure 2). If the maximum $\mathrm{U}^{\mathrm{VI}}$ solution concentration of $0.23 \mathrm{mM}$ is combined with density of the various polymorphs of iron oxide and their corresponding linear $K_{D}$, only adsorption on hematite is clearly less than the $45 \mathrm{~kg} / \mathrm{m}^{3}$ solid concentration limit (Figure 18) for a half-sphere of rust, assuming $5.1 \%{ }^{235} \mathrm{U}$ enrichment. However, the linear $K_{D}$ values are applicable only at very low solution concentrations.

Payne et al. (1998, Figure 3) experimentally evaluated the adsorption of $\mathrm{U}^{\mathrm{VI}}$ on ferrihydrite (suspended in a solution at $89 \mathrm{mg} / \ell$ ) over a range of $\mathrm{pH}$ and at three initial uranium solution concentrations: $10^{-3} \mathrm{mM}$, $10^{-2} \mathrm{mM}$, and $10^{-1} \mathrm{mM}$. (The latter concentration is very close to the maximum uranium solution concentra-

18 Although the nonlinear Freundlich model does not have an asymptote like the Langmuir model (Langmuir, 1997, p. 362; Jenne, 1998, p. 21), it does allow for greatly reduced adsorption at higher concentrations for $\mathrm{n}<1$. 
tion anticipated at the WIPP.) Because of the saturation of the adsorption sites, the extrapolated concentration in the ferrihydrite colloidal suspension is only $0.05 \mathrm{~kg} / \mathrm{m}^{3}$ at the maximum $\mathrm{U}^{\mathrm{VI}}$ solubility of $10^{-0.6} \mathrm{mM}$ (i.e., 2.0 $\mathrm{mole} / \mathrm{kg} \cdot \mathrm{M}_{\mathrm{w}} \cdot 0.089 \mathrm{~kg} / \mathrm{m}^{3}$ ) (Figure 25); this value is far below the $50 \mathrm{~kg} / \mathrm{m}^{3}$ critical concentration. The ${ }^{235} \mathrm{U}$ concentration on any one ferrihydrite particle could be high $-43 \mathrm{~kg} / \mathrm{m}^{3}$ assuming $5.1 \%{ }^{235} \mathrm{U}$ enrichment (i.e., $\left.2.0 \mathrm{~mole} / \mathrm{kg} \cdot \mathrm{M}_{\mathrm{w}} \bullet \rho_{\mathrm{g}}(1-\phi) \cdot 5.1 \%\right)$ but still not above the critical limit. Furthermore, a critical concentration would require exclusive adsorption of uranium from the contaminated brine in the repository-an unlikely occurrence. Finally, transformation of ferrihydrite to the goethite might be fairly rapid ( $10 \mathrm{yr})$ (Smith et al., 1994) such that pure ferrihydrite might not be present within the repository in large amounts (at least $20 \mathrm{~kg}$ ) in a small area.

Although isotherms of $\mathrm{Pu}^{\mathrm{IV}}$ adsorption on iron oxides at high solution concentrations of plutonium are not available, an extrapolation based on two points at low concentrations (Sanchez et al., 1985, Figure la) shows that a similar situation occurs for plutonium whereby the estimated solid concentration on goethite cannot reach the critical limit assuming a ${ }^{239} \mathrm{Pu}$ FGE of $14 \%$ (i.e., $4 \times 10^{-2} \mathrm{~mole} / \mathrm{kg} \cdot M_{w} \cdot \rho_{g}(1-\phi) \cdot 14 \%=$ $5 \mathrm{~kg} / \mathrm{m}^{3}$ ) (Figure 25). Although this extrapolation has large uncertainty, it is reassuring that the values for $\mathrm{Pu}^{\mathrm{V}}$ adsorption on goethite lie near this same line (Triay et al., 1997, Figure 84) since $\mathrm{Pu}^{\mathrm{V}}$ is thought to be reduced to $\mathrm{Pu}^{\mathrm{IV}}$ when adsorbed on goethite. While use of additional data reported by Sanchez et al. (1985, Figures 1b and $1 c$ ) for $\mathrm{Pu}^{\mathrm{V}}$ results in a new line that predicts a solid concentration on goethite of $26 \mathrm{~kg} / \mathrm{m}^{3}$, it is only slightly above the $20 \mathrm{~kg} / \mathrm{m}^{3}$ limit for rust surrounded by silica rich material ${ }^{19}$ (i.e., $2.3 \times 10^{-1}$ mole $/ \mathrm{kg} \cdot M_{w} \cdot \rho_{g}(1-\phi)$ - $14 \%=26 \mathrm{~kg} / \mathrm{m}^{3}$ ) (Figure 25).

\subsubsection{Adsorption Sites Available on Dolomite}

The adsorption on goethite, as described in the previous section, provides a reasonable upper bound for adsorption on dolomite, where criticality is unlikely for an average $14 \%$ plutonium equivalent enrichment. However, the critical limit for dolomite is much less than for rust; thus, additional arguments based directly on properties of dolomite are presented below to bolster this argument.

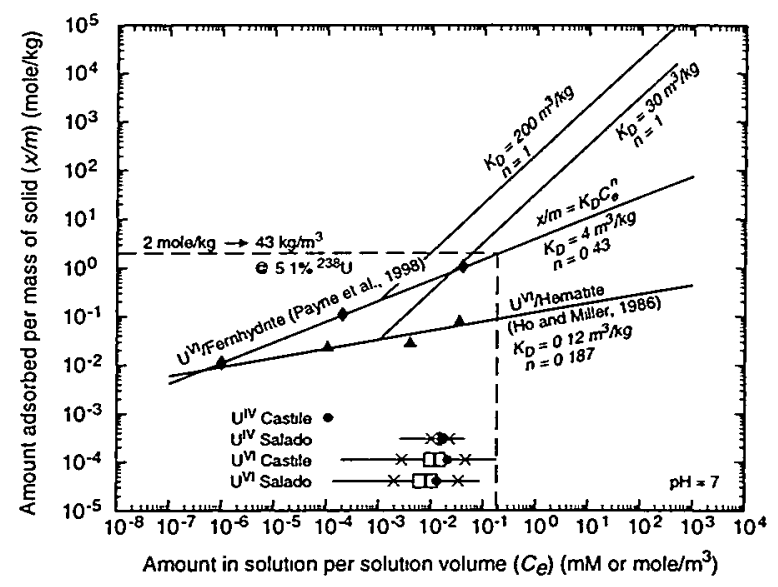

(a) Uranium

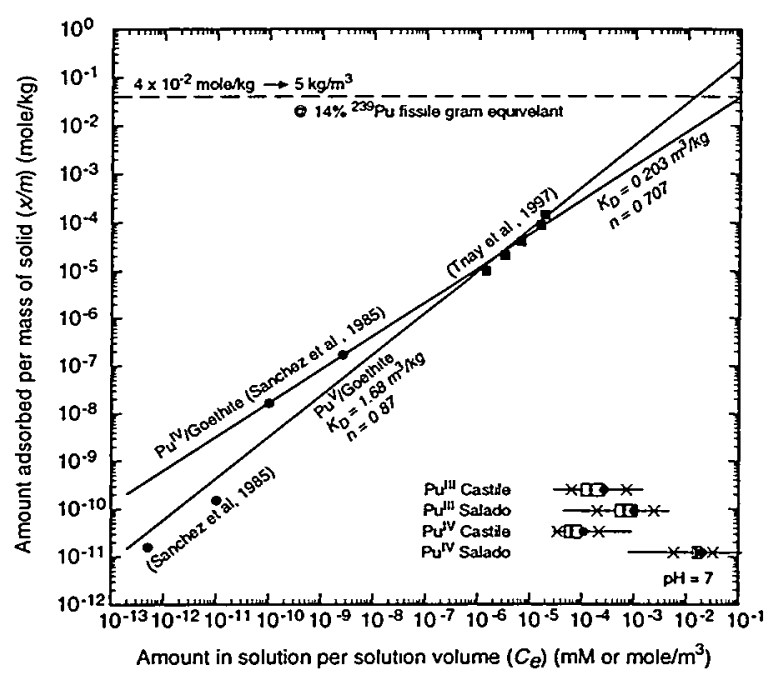

(b) Plutonium

TA1-6342-6225-0

Figure 25. Variation of adsorbed radioisotopes on iron oxides as function of solution concentration at neutral $\mathrm{pH}(\mathrm{a}) \mathrm{U}^{\mathrm{VI}}$ in pure $\mathrm{H}_{2} \mathrm{O}$ on ferrihydrite (Payne et al., 1998, Figure 3) and hematite (Sanchez et al., 1985, Figure 1), (b) $\mathrm{Pu}^{\mathrm{IV}}$ in pure $\mathrm{H}_{2} \mathrm{O}$ (Sanchez et al., 1985, Figure 1), and $\mathrm{Pu}^{V}$ in $\mathrm{J}-13$ well water from Yucca Mountain (Triay et al., 1997, Figure 93) on goethite.

If the maximum solution concentration (Figure 10) is combined with the density of dolomite and maximum $K_{D}$ (Figure 6) for $\mathrm{U}^{\mathrm{VI}},{ }^{20}$ all solid concentrations remain below $10 \mathrm{~kg} / \mathrm{m}^{3}$ because the uranium consists of only $5.1 \%$ fissile ${ }^{235} \mathrm{U}$. For $\mathrm{Pu}^{\mathrm{IV}}$, however, the adsorbed plutonium concentration is greater than $3 \mathrm{~kg} / \mathrm{m}^{3 ; 20}$ the

19 If the current estimated maximum solubility for $\mathrm{Pu}^{\mathrm{IV}}$ is used $\left(3 \times 10^{-4} \mathrm{mM}\right)$, the adsorbed plutonium concentration remains below $20 \mathrm{~kg} / \mathrm{m}^{3}$ even when $100 \%{ }^{239} \mathrm{Pu}$.

20 Even at the maximum solubility, not enough $\mathrm{U}^{\mathrm{IV}}$ can reach the Culebra in $10,000 \mathrm{yr}$ to go critical. 
same is true for $\mathrm{Pu}^{\mathrm{III}}$ but only by a factor of 2 . Yet, when the calculated mobile concentrations of plutonium are combined with the sampled $K_{D}$, the potentially adsorbed plutonium concentrations are less than $3 \mathrm{~kg} / \mathrm{m}^{3}$ in all but two cases (Figure 26).

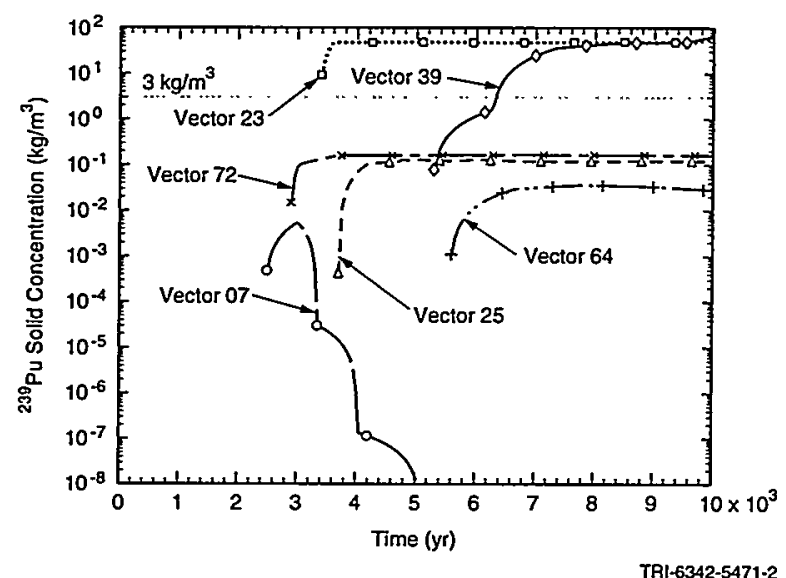

Figure 26. Solid concentration of plutonium from adsorption for RIS5 (replication 1, scenario 5), based on concentrations in Figure $2 I$ (i.e., $C_{T} \cdot K_{D} \cdot \rho_{g}$ $[I-\phi])$.

The two cases showing a potential for criticality with plutonium in the Culebra can be eliminated for three reasons based on geochemical and physical constraints of the system: the density of adsorption sites on dolomite would have to be very large, surface complexation at adsorption sites would not be limited to only ${ }^{239} \mathrm{Pu}$, and the deposition of fissile radioisotopes and thus the geometry of the critical mass must be at the borehole (discussed in Section 5.4, "Precipitation of Fissile Material").

Although for rust, experiments have been conducted up to the adsorption capacity such that the reduced adsorption at high concentrations can be observed, adsorption experiments for radioisotopes at high concentrations are difficult for evaporates and have not been done for dolomite. Hence, a bounding estimate of the required adsorption sites, and thus the maximum amount of fissile material that can adsorb onto a small volume, was made for dolomite and compared to other highly adsorptive natural materials.
The measured mass-specific surface area on carefully crushed and lightly acid-washed samples of dolomite from the Air Intake Shaft, as evaluated by BET surface area analysis (Brunauer et al., 1938), vary from $500 \mathrm{~m}^{3} / \mathrm{kg}$ for indurated dolomite to $2600 \mathrm{~m}^{3} / \mathrm{kg}$ for silty dolomite (Kelly, 1996); these values correspond to between $1 \times 10^{6}$ and $6 \times 10^{6} \mathrm{~m}^{2}$ of surface area per $\mathrm{m}^{3}$ of dolomite (assuming a porosity of $16 \%$ and dolomite grain density of $2850 \mathrm{~kg} / \mathrm{m}^{3}$ ). Dividing the adsorbed plutonium concentration of $3 \mathrm{~kg} / \mathrm{m}^{3}$ (which corresponds to $7.6 \times 10^{24}$ atoms $/ \mathrm{m}^{2}$ of dolomite) by volume-specific surface area gives a site density of between 1 and 7 atoms $/ \mathrm{nm}^{2}$. This range is similar to the observed site density for many highly adsorptive minerals (about 2 sites $/ \mathrm{nm}^{2}$ ) (Davis and Kent, 1990).

Thus, obtaining a critical concentration requires the entire capacity of a highly adsorptive natural material (of which dolomite in the Culebra is reasonably bound). However, the ${ }^{239} \mathrm{Pu}^{\mathrm{IV}}$ would be competing with other plutonium isotopes and other radioisotopes, e.g., $\mathrm{Th}^{\mathrm{IV}}$ and $\mathrm{U}^{\mathrm{IV}}$, which are assumed to behave identically to $\mathrm{Pu}^{\mathrm{IV}}$, for the limited number of sorption sites, thus increasing the required solid concentration limit (Figure 16). More importantly, plutonium would be competing with other metal cations (and even $\mathrm{Ca}$ and $\mathrm{Mg}$, in solution) that are several orders of magnitude more abundant than ${ }^{239} \mathrm{Pu}^{\mathrm{IV}}$ (Figure 10 and Table 5). Hence, the plutonium would need to dislodge already adsorbed material present on the dolomite.

The probability of criticality from adsorption of plutonium becomes unlikely near the intrusion borehole, because the critical concentration increases from $3 \mathrm{~kg} / \mathrm{m}^{3}$ to $\sim 10 \mathrm{~kg} / \mathrm{m}^{3}$ (Figure $16 \mathrm{~b}$ ) or $\sim 17 \mathrm{sites} / \mathrm{nm}^{2}$ as the result of domination of the fluid by the Castile or Salado brine chemistry. (For Salado brine chemistry, it is $\sim 19 \mathrm{~kg} / \mathrm{m}^{3}$ or $\sim 32$ sites $/ \mathrm{nm}^{3}$.) ${ }^{21}$

For uranium, the number of sorption sites is clearly too small. A concentration of $10 \mathrm{~kg} / \mathrm{m}^{3}$ of ${ }^{235} \mathrm{U}$ corresponds to $2.5 \times 10^{7}$ atoms $/ \mathrm{nm}^{3}$, which in turn corresponds to 17 atoms $/ \mathrm{nm}^{2}$. However, the uranium is only $\sim 5 \%$ enriched (initially) and so the available adsorptive sites are much more likely to be filled with ${ }^{238} \mathrm{U}$ than ${ }^{235} \mathrm{U}$. To get $10 \mathrm{~kg} / \mathrm{m}^{3}$ of ${ }^{235} \mathrm{U}$ at $5.1 \%$ enrichment would require 333 sites $/ \mathrm{nm}^{2}$.

21 Synthetically prepared goethite $(\alpha-\mathrm{FeOOH})$, a very effective adsorbent, has a site density of $\sim 17 \mathrm{sites} / \mathrm{nm}^{2}(\mathrm{Kent}$ et al., 1988 , Table 3-1). Although Brady et al. (1.999) report that if all the $\mathrm{Mg}$ and $\mathrm{Ca}$ ions present in an altered layer of dolomite were available for ion exchange, the maximum site density would be 30 sites/nm ${ }^{2}$, not all $\mathrm{Mg}$ and Ca ions are available for ion exchange and so the density is better represented by $\sim 2$ sites $/ \mathrm{nm}^{2}$ of many highly adsorptive minerals. 


\subsection{Concentration of Colloid Material in the WIPP Disposal System}

\subsubsection{Colloidal Concentration in Repository}

Similar to adsorption, the uptake of fissile actinides by the various types of colloidal particles is governed by a complex equilibrium among dissolved fissile actinides, solid phases, and the colloidal particles. The behavior of the colloidal particles themselves, however, is best described as a steady-state process, in which new particles are continuously generated and dispersed in the liquid phase but are gradually destabilized through a variety of processes. The concern in terms of nuclear criticality is whether the concentration of colloids is critical or whether there is a mechanism by which actinide-bearing colloidal particles can be locally concentrated either while they are dispersed in the fluid or as a result of destabilization.

\subsubsection{Limits on Colloidal Concentration}

The concentration of mobile (i.e., dispersed) colloidal actinides (mineral fragment colloids, actinide intrinsic colloids, humic substances, and microbes) is limited by themodynamic equilibria. Results from experiments with WIPP-relevant microbes (Papenguth, 1996a,b,c; Papenguth and Aguilar, 1996; Papenguth and Behl, 1996b; Papenguth and Moore, 1996) suggest that microbes do not actively bioaccumulate actinides (i.e., move actinides through the cell membrane), but instead passively bioaccumulate actinides extracellularly, a process that is similar to adsorption. Similarly, humic substances, some mineral fragment particles, and microbes act as substrates for adsorption of actinides. $\mathrm{Pu}^{\mathrm{IV}}$-polymer, the only form of actinide intrinsic colloid present in the WIPP disposal system, and colloidal-sized actinide coprecipitates (i.e., mineral fragment type colloidal particles) have actinides incorporated into the structure of the colloid itself. However, the link between intrinsic colloidal actinide concentration and equilibrium thermodynamics produces a limit on the concentration of colloidal actinides that cannot reasonably exceed by 30 times the dissolved concentration of fissile actinides and thereby go critical. For example, the total uranium and plutonium concentration of the adsorption experiments discussed in Section 5.2.3 and plotted in Figure 25 includes the colloidal suspension and is not critical. For example, the colloidal suspension of uranium and ferrihydrite was only $0.05 \mathrm{~km} / \mathrm{m}^{3}$.

\subsubsection{Fate of Colloids prior to Intrusion}

Destabilization of mobile colloidal fissile actinides, followed primarily by gravitational settling, could conceivably concentrate fissile material, but the mechanism is limited to local microenvironments that are likely to be centimeter-sized or even smaller within the repository. After closure of the WIPP repository, salt creep will crush the waste containers and compact waste material (Figure 13). After closure and salt creep, one can envision complex geometries of pores within the waste. Colloidal particles could form throughout the waste matrix; however, the fluid columns in which agglomerated colloidal particles will settle are likely to be short and poorly connected. Consequently, the local concentrations of colloidal agglomerates that develop in the WIPP will remain uniformly distributed in the waste throughout the repository and will not concentrate in a single location. By analogy, in a closed house, dust (i.e., aerosols) settles on the horizontal surfaces in the house. The dust does not, however, concentrate at any single location.

\subsubsection{Fate of Colloids after Intrusion}

In a disturbed repository, turbulence created by flowing brine could result in filtration of any dispersed colloidal actinides, but concentration of colloidal actinides will again be localized in small microenvironments. As described above, the waste will contain many centimeter-sized microenvironments of small poorly connected pores. Filtration will take place in crevices and interstices at the boundaries of those small pores, resulting in small concentrations of colloidal actinides in those localized small areas.

Again, considering the dusty house, an air stream flowing through an open house is similar in concept to brine flowing through the repository. In the dusty house, dust that has settled on horizontal surfaces is stirred up and concentrated in local environments, such as corners or other areas where turbulence is less. In the repository, local accumulations will develop in a similar fashion. However, the tight packing of the waste will provide local filtration of colloidal particles. Hence, the fissile actinides associated with colloidal particles will remain fairly uniformly distributed within the repository on a macroscopic scale. More importantly, the perfect filtration of iron oxides with adsorbed uranium cannot go critical and iron oxides with adsorbed plutonium probably will not go critical, as discussed in Section 5.2.3. 


\subsubsection{Colloidal Concentration in Culebra}

Because the total mobile concentration of $\mathrm{Pu}^{\mathrm{IV}}$ is due partially to association with microbes and mineral colloids, filtering of colloids could lead to a possible means of plutonium deposition in the Culebra. As argued above, it is probable that colloids susceptible to filtering would be filtered during transit through waste within the repository (as described above in Section 5.3.1) or in the borehole backfill material (Section 3.5.4); however, to be consistent with the assumptions for the 1996 performance assessment, colloids were assumed to have escaped the repository and borehole and then be filtered in the Culebra. For the cases in which large releases of plutonium are calculated, high $\mathrm{Pu}^{\mathrm{IV}}$ total concentrations in Salado brine were used. In these cases, plutonium associated with mineral colloids and microbes accounts for only $7 \%$ of the total concentration (Table 5). Perfect filtering of $7 \%$ of the maximum $110 \mathrm{~kg}$ released in simulation 23 results in $7.7 \mathrm{~kg}$ that must be filtered in less than $0.46 \mathrm{~m}^{3}$ from the borehole (e.g., sphere of radius $0.46 \mathrm{~m}$ ) to obtain a minimum concentration of $19 \mathrm{~kg} / \mathrm{m}^{3}$ for Salado brine (Figure 16). More importantly, the $7.7 \mathrm{~kg}$ is for spheres and is smaller than the $8-\mathrm{kg}$ to $10-\mathrm{kg}$ minimum required (see Figure 16) and is smaller than the 13.4-kg limit suggested by the arguments based on Oklo reactors, as presented in Section 4.1.3. Therefore, colloidal filtering of plutonium cannot cause criticality by itself.

The total concentration of $\mathrm{U}^{\mathrm{IV}}$ in Salado brine is partially due to filterable colloids (37\%) (Table 5) but the mass of $U^{I V}$ brought to the Culebra in the 1996 performance assessment is insufficient material to cause criticality. While the mass of $\mathrm{U}^{\mathrm{VI}}$ brought to the Culebra is higher, no portion of the solubility is due to colloids.

\subsection{Precipitation of Fissile Material}

A necessary condition for precipitation of fissile material and other major components of the brine is a change in the brine chemistry (i.e., the redox state and buffer capacity, $\mathrm{pH}$, ionic strength, or solute concentrations) such that the solubility of a component is reduced. As previously described, the deposition of uranium generally occurs when soluble fissile material, e.g., $\mathrm{U}^{\mathrm{VI}}$ as a uranyl carbonate, is reduced by organic material, pyrite, or $\mathrm{H}_{2} \mathrm{~S}$ (Figure 22). Because this particular mechanism is not feasible in the WIPP disposal system, as described below, several other speculative mechanisms are proposed in the following discussion but were found to be improbable.

\subsubsection{Precipitation in Repository}

The effective redox state of the repository will be reducing to extremely reducing, depending on the kinetics of the redox reactions within the repository (i.e., the brine redox state will lie near the lower diagonal line defining the stability of water in Figure 23). The main determinant of oxidation states within the repository will be the rate of interaction with elemental iron, $\mathrm{Fe}^{0}$, and the rate of microbe-facilitated reduction of oxidized species, such as nitrate and sulfate. The resulting repository waters are expected to have relatively high concentrations of reducing redox-active species such as $\mathrm{Fe}^{+\mathrm{HI}}$ and $\mathrm{S}^{-\mathrm{II}}$. Hence, the most likely oxidation states are the insoluble $\mathrm{Pu}^{\mathrm{III}}$ and $\mathrm{U}^{\mathrm{IV}}$; however, there is some possibility of more soluble $\mathrm{Pu}^{\mathrm{IV}}$ and $\mathrm{U}^{\mathrm{VI}}$. Because iron and organic waste are present throughout the waste, there is little chance of great variation in the redox state of the brine from one place to another, and thus no driving force for dissolution and precipitation to redistribute the fissile materials. Again, one of the main assumptions used in the 1996 performance assessment is that microenvironments within the repository are small or short-lived enough that the macroscopic brine chemistry within the repository can be treated as if it were uniform (WIPP Performance Assessment Department, 1996).

\subsubsection{Precipitation in Culebra}

Provided some brine contaminated with radioisotopes reaches the Culebra, changes in the chemistry of contaminated brine are likely as it mixes with brine within the Culebra. However, these changes in brine chemistry will likely occur over a wide area, because the amount of injected brine varies over time and would eventually cease as the borehole creeps shut or precipitates plug the porosity. Hence, precipitation of fissile material is not possible in a region small enough to cause criticality as demonstrated by examining the influence of three factors - changes in ionic strength, in $\mathrm{pH}$, and in redox state-on the brine chemistry.

\subsubsection{Simulation of Mixing Zone}

The calculated flow fields for radioisotopes migrating through the Culebra over $10,000 \mathrm{yr}$ do not show a tendency to concentrate into a small area except at the intrusion borehole. Hence, similar to adsorption and colloidal filtering, the most likely area to precipitate the fissile material in sufficient concentration is at the borehole. A simulation was run to evaluate the size of the zone in which dilution and potential precipitation might occur because of changes in ionic strength, $\mathrm{pH}$, or redox state. 
Simulation (or "vector") 23, replicate 1 was rerun using SECOFL2D (version 3.01ZO) with a steady state injection of $3.62 \times 10^{4} \mathrm{~m}^{3}$ of Castile brine over $10,000 \mathrm{yr}$. This injection caused the regional flow direction to shift from the south to the southwest since a low permeability zone lay to the east. For transport calculations with SECOTP2D (version 1.41), a small local grid, $26 \mathrm{~m} \times 26 \mathrm{~m}$ with 961 cells, was centered over a hypothetical borehole penetrating the center of the repository. Similar to the original CCA calculations, boundary conditions for the hydraulic head $(\mathrm{H})$ around the grid were interpolated from the regional flow grid (Figure 27a). Because the transport model lay directly over the repository, it was modeled as a single porosity medium (see Section 2.1.5.3).

For the sake of the following arguments, adsorption in vector 23 was ignored, and deposition of fissile material was assumed to occur in the mixing zone between the injected brine and Culebra brine because of the change in ionic strength, $\mathrm{pH}$, or redox state. However, it is instructive to briefly describe the adsorption results. The linear adsorption distribution coefficient for vector 23 was $6.8 \mathrm{~m}^{3} / \mathrm{kg}$ (less than the mean and median of $10 \mathrm{~m}^{3} / \mathrm{kg}$ for the sampled distribution), and the linear Freundlich model predicted the entire $110 \mathrm{~kg}$ was adsorbed within $0.5 \mathrm{~m}$ of the borehole, using the same fluid flow conditions and plutonium concentration as in vector 23 (Figure 27c). The average fissile density was greater than $9 \mathrm{~kg} / \mathrm{m}^{3}$ (but by only a factor of 1.2 assuming $14 \% \mathrm{FGE}$ of ${ }^{239} \mathrm{Pu}$ ). Furthermore, the average fissile density was less than $9 \mathrm{~kg} / \mathrm{m}^{3}$ using the minimum linear adsorption of $0.7 \mathrm{~kg} / \mathrm{m}^{3}$. More importantly, the same is true of the nonlinear adsorption model for goethite.

\subsubsection{Change in Ionic Strength}

Although the repository brines are saturated with $\mathrm{NaCl}$, the ionic strength varies due to the amount of dissolved $\mathrm{MgCl}_{2}$. As a repository brine enters and mixes with Culebra brine, the ionic strength will drop.

Solubility may be ionic-strength dependent; for example, most highly negatively charged species are stabilized by high ionic strength so that any mineral whose solubility is controlled by highly charged species in solution will have a higher solubility in high ionic strength brines. However, as the brine is diluted and the solubility decreased, the concentration is also reduced by the dilution, so precipitation will occur only if the change in solubility is greater than the change in concentration. The model of IV actinide solubility used in the 1996 performance assessment showed the minus six charged pentacarbonate species dominating the solubility, and thus the solubility could be dependent on the

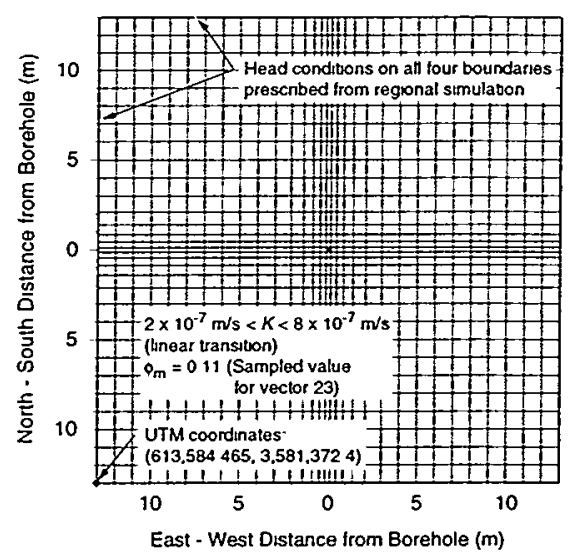

(a) Computational mesh

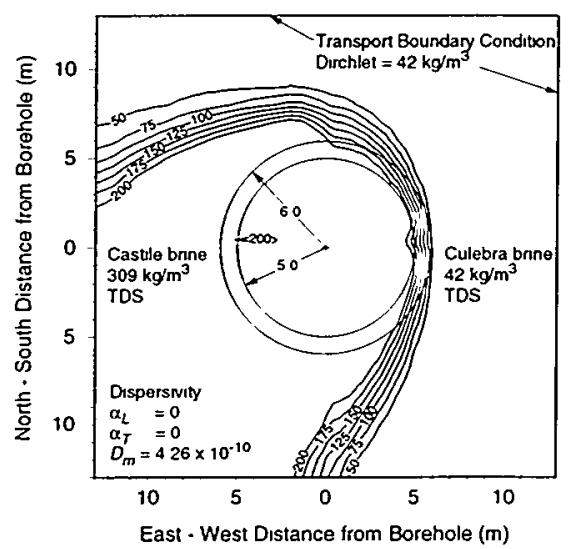

(b) Brine mixing zone

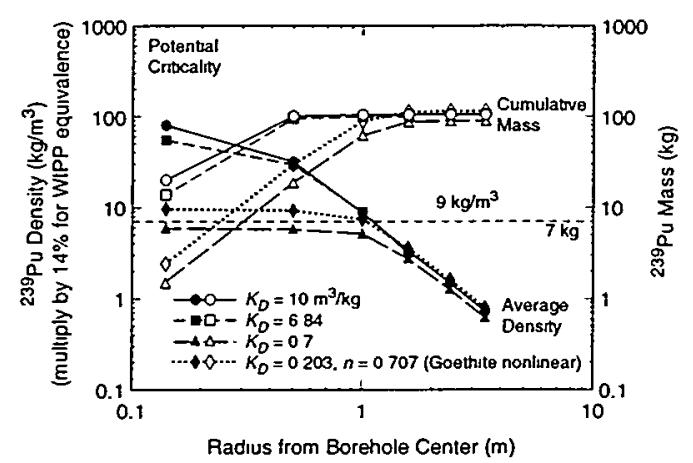

(c) Average adsorption on dolomite

TRI-6342-6231-1

Figure 27. Calculated mixing of Castile $\left(309 \mathrm{~kg} / \mathrm{m}^{3}\right)$ minor discrepancy with Table 1) brine in Culebra with liquid injected from intrusion borehole using discharge and flow field from vector 23 , replicate 1 , shows that mixing zone area is too large to cause solid concentration at critical limit. (a) Numerical mesh (after Wallace, 1999, Figure 1) and (b) concentration contours assuming background concentration in Culebra of 42 $\mathrm{kg} / \mathrm{m}^{3}$ brine at $100 \mathrm{yr}$ (after Wallace, 1999, Figure 2), and $(c)$ distribution of mass and average density around the intrusion borehole using various adsorption assumptions. 
ionic strength of the brine. Similarly, the model of III actinide solubility shows the plus 2 charged hydroxy complex dominating the solubility and decreasing by an order of magnitude as the ionic strength decreases from 7.4 in synthetic Salado brine to 6.66 in Castile brine. Hence, if these models are accurate, they predict some precipitation on dilution. ${ }^{22}$

Consequently, a possible situation is the dilution of $\mathrm{Pu}^{\mathrm{IV}}$ in a Salado-dominated brine to a Culebra-dominated brine (Figure 10). (Because insufficient $\mathrm{Pu}^{\mathrm{III}}$ reaches the Culebra in $10,000 \mathrm{yr}$, it is not considered here.) The maximum calculated discharge of ${ }^{239} \mathrm{Pu}^{\mathrm{IV}}$ over $10,000 \mathrm{yr}$ as calculated in the 1996 performance assessment is considered, which is about $110 \mathrm{~kg}$ (simulation 23 in Figure 21). To obtain a plutonium concentration of $3 \mathrm{~kg} / \mathrm{m}^{3}$ or greater (see Figure 16), assuming a single porosity medium, the volume of deposition of all the plutonium reaching the Culebra in 10,000 yr must be less than $37 \mathrm{~m}^{3}$ (a sphere of about 2-m radius or a cylinder of $1.7-\mathrm{m}$ radius, assuming deposition throughout the 4-m thickness of the Culebra dolomite). When the Culebra is represented as a fractured medium, a similarly small area is required because the fracture space available for precipitation of fissile radioisotopes in the Culebra is limited near the WIPP repository. Assuming a fracture zone $0.45 \mathrm{~m}$ thick corresponding to the interpreted 0.001 fracture porosity, the area must be less than $24.4 \mathrm{~m}^{2}$ to obtain a plutonium concentration of $10 \mathrm{~kg} / \mathrm{m}^{3}$ or greater (Figure 19).

At $100 \mathrm{yr}^{23}$, a simple estimate of the volume of the dilution zone as the annulus between two concentric cylinders (Figure 27) results in a solid concentration four times lower than the $3 \mathrm{~kg} / \mathrm{m}^{3}$ limit even for a total of $110 \mathrm{~kg}$ in vector 23 (which takes $10,000 \mathrm{yr}$ to occur).

\subsubsection{Changes in $\mathrm{pH}$}

The $\mathrm{pH}$ and $\mathrm{CO}_{2}$ concentration in the repository will be controlled by the addition of excess $\mathrm{MgO}$. Contaminated brines entering the Culebra will carry significant dissolved $\mathrm{Mg}(\mathrm{OH})_{2}$, but little solid $\mathrm{Mg}(\mathrm{OH})_{2}$, so the $\mathrm{pH}$ is expected to drop from alkaline to near neutral, and the $\mathrm{CO}_{2}$ concentration is expected to rise, as the $\mathrm{Mg}(\mathrm{OH})_{2}$ is consumed by the Culebra $\mathrm{CO}_{2}$. The change in $\mathrm{pH}$ and $\mathrm{CO}_{2}$ concentration could cause coprecipita- tion of plutonium or uranium with $\mathrm{MgCO}_{3}$ within the Culebra pore space; however, changes in $\mathrm{pH}$ and availability of $\mathrm{CO}_{2}$ will be dependent on sufficient mixing of the two brines which, as shown in Figure 27, does not occur in a small enough region to obtain a critical concentration.

\subsubsection{Change in Redox State (Eh)}

The Culebra brine has low concentrations of active reduction or oxidation species (Brush, 1998). Oxidized Culebra solids such as sulfate are relatively redox inactive without major microbial intervention, and the reduced solids ( $2 \% \mathrm{Fe}^{\mathrm{II}}$ in the dolomite, and pyrite) are relatively inaccessible or small in concentration. Consequently, the redox state of the deep brine as it moves through the Culebra will change little, even up to 100 fold dilution (Brush, 1998). Therefore, reduction of the $\mathrm{U}^{\mathrm{VI}}$ to $\mathrm{U}^{\mathrm{IV}}$ will not occur (i.e., the normal situation in which a uranium deposit is formed by means of reduction of soluble species does not apply). Likewise, the reduction of $\mathrm{Pu}^{\mathrm{IV}}$ to $\mathrm{Pu}^{\mathrm{III}}$ will not occur.

With oxidation, there are two possible precipitation reactions that may deposit actinides: the oxidation of $\mathrm{Pu}^{\mathrm{III}}$ to $\mathrm{Pu}^{\mathrm{IV}}$, and the oxidation of $\mathrm{Fe}^{\mathrm{II}}$ to $\mathrm{Fe}^{\mathrm{III}}$ and coprecipitation with $\mathrm{Pu}^{\mathrm{IV}}$. Because $\mathrm{Pu}^{\mathrm{III}}$ is extremely reduced, it requires the presence of $\mathrm{Fe}^{0}$, other reducing metals, or applied voltage to persist for long periods in the laboratory. $\mathrm{As} \mathrm{Pu}^{\mathrm{III}}$ is removed from the $\mathrm{Fe}^{0}$ in the repository, it may slowly oxidize to $\mathrm{Pu}^{\mathrm{IV}}$. In the 1996 performance assessment, these conditions do not cause precipitation because $\mathrm{Pu}^{\mathrm{IV}}$ is more soluble than $\mathrm{Pu}^{\mathrm{III}}$ in Salado brine. $^{24}$

Concerning iron oxidation, $\mathrm{Fe}^{\mathrm{III}}$ is less soluble than $\mathrm{Fe}^{\mathrm{II}}$, so any oxidation occurring at the borehole could cause precipitation of amorphous iron oxyhydroxides. Freshly precipitated iron oxyhydroxides have a very high adsorption capacity, and actinides may be sorbed or coprecipitated during their formation. But the only mechanism for major change in the redox state of the brine directly at the borehole is oxidation by means of an injection of oxygen down the borehole. Because the borehole is assumed to be plugged (or degraded to the permeability of silty sand), the availability of sufficient oxygen is unlikely.

22 Recent calculations concerning the solubility of $\mathrm{Pu}^{\mathrm{IV}}$ show the neutral tetra hydroxide species dominates the solubility. Thus the solubility should be relatively independent of ionic strength and not affected by dilution of the injected brine (see Section 2.3.7).

23 It takes more than 130 yr to release more than $2.2 \mathrm{~kg}$ of ${ }^{239} \mathrm{Pu}^{\mathrm{IV}}$ in vector 23 for replication 1, with the solubility distribution used in the 1996 performance assessment.

24 This precipitation mechanism is indeed possible with the more recent estimates of $\mathrm{Pu}^{\mathrm{IV}}$ solubility because $\mathrm{Pu}^{\mathrm{III}}$ is now more soluble. However, the solubility of $\mathrm{Pu}^{\mathrm{II}}$ (for which the oxidation mechanism applies) is sufficiently low that a critical mass never reaches the Culebra in 10,000 yr in any of the vectors in replicate 1 (Figure 22). 


\section{Consequences of a Criticality}

Criticality at the surface in a facility handling fissile radioisotopes is normally prevented because of the potential exposure of workers to radiation either directly during criticality or later if decontamination of the facility is necessary. However, it is of less importance after closure of a repository, assuming that criticality could occur, because criticality would have to either (1) generate significant amounts of fission products above those already present or being released from the repository, or (2) degrade the ability of the disposal system to contain nuclear waste, before criticality would have even the potential to affect human health. The potential for an observable consequence from criticality in these two categories is examined below.

\subsection{Criticality Description}

\subsubsection{Categories of Criticality}

When evaluating consequences, categorization of the criticality event is helpful. Rechard et al. (1996b; 1997) group the criticality event into six main types for which a consequence can be estimated based on two basic conditions: (a) moderation, i.e., whether there is sufficient water to effectively moderate (slow down neutrons) and thereby promote fissions and (b) assembly, i.e., whether the assembly is slow, fast, or explosive, where slow refers to a process occurring over geologic time, fast refers to events over seconds, and explosive refers to processes over microseconds. The six main criticality types (Figure 28 ) then, are

1. high moderation, slow rate of assembly, e.g., Oklo natural thermal reactors

2. high moderation, fast rate of assembly, e.g., aqueous solution accidents

3. high moderation, explosive rate of assembly, e.g., Bowman-Venneri hypothesis

4. low moderation, slow rate of assembly, e.g., fast breeder reactor

5. low moderation, fast rate of assembly, e.g., experiments/accidents with fissionable materials (BetheTait bounding analysis) (Bethe and Tait, 1956)

6. low moderation, explosive rate of assembly, e.g., weapons.

Based on recent arguments (Canavan et al., 1995; Van Konynenburg, 1996; Sanchez et al., 1995; Kimpland, 1996; Kastenberg et al., 1996; and Rechard et al.,

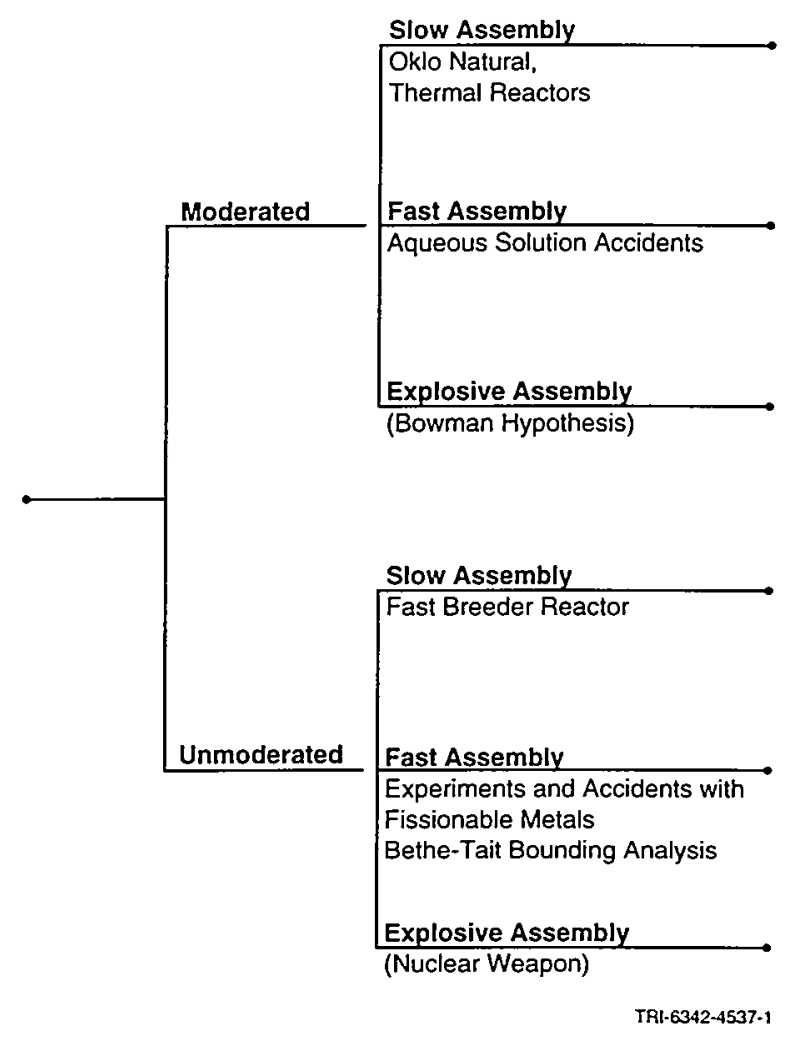

Figure 28. Six basic types of criticality events. Similarities with natural or engineered systems are noted (Rechard et al., 1996b, Fig. 7).

1996b; 1997), the Bowman-Venneri hypothesis (Category 3 ) and weapon assembly (Category 6) can be given a negligible probability. In addition, the average enrichment of fissile material is less than $14 \%$, so theoretical reasons also support the improbability of an explosion (Murray, 1957, p. 182). Fast rates of assembly are less probable for the WIPP because of the diffuse distribution of fissile particles throughout TRU waste as described in Section 2 (rather than as in fuel rods), which gives Categories 2 and 5 a negligible probability. Also in a natural setting, a credible method of slowly assembling the fissile materials without water or human intervention is unknown; thus Category 4's probability is near zero. After assembly, the consequences for Categories 1, 2, 4, and 5 are similar (Rechard et al., 1996b; 1997). Therefore, in determining probability and consequences over the long term, Category 1, high moderation and a slow rate of assembly, receives the most emphasis below. 


\subsubsection{Character of the Criticality Event}

In describing the consequences of a criticality in a geologic repository, the event is analyzed as a series of criticality excursions on a small time scale that occur within a large time scale that can be described as steady state. Although a nuclear reactor routinely runs at steady-state power levels, it is an engineered system in which the coolant is maintained at constant temperature and pressure conditions. Even in this environment, controlling the power level is a dynamic process; to achieve this steady-state power level, the operating parameters, such as removing or inserting neutron absorbers in the control rods, are constantly changed. Specifically, the power is directly related to the neutron population in the assembly; yet, in a critical assembly, the neutron population is never truly steady-state because any small perturbation in the neutron population causes it to deviate from a steady-state situation. To elaborate, the neutron population can be described as

$$
\mathrm{d} n / \mathrm{d} t=\eta \Delta k / \ell
$$

where

$$
\begin{aligned}
\eta= & \text { neutron population } \\
l= & \text { mean neutron lifetime } \\
\Delta k= & k_{e f f}-1=\text { excess multiplication factor } \\
k_{e f f}= & \text { multiplication factor (ratio of the popu- } \\
& \begin{array}{l}
\text { lation of neutrons during one generation } \\
\text { to the previous population) }
\end{array}
\end{aligned}
$$

Assuming that $\Delta k$ is constant, then

$$
\eta=\eta_{o} e^{(\Delta \mathrm{kt}) / \ell}
$$

This solution indicates that neutron population changes at an exponential rate, and thus the criticality event is inherently unstable. Any small perturbations in the system will cause it to experience a rapid power decline or increase. In the latter case, the power increases until a negative feedback effect occurs.

\subsection{Generation of Fission Products}

\subsubsection{Burnup of Plutonium}

As previously argued in Rechard et al. (1997), about 100 years after criticality, fissioning of ${ }^{239} \mathrm{Pu}$ produces radioisotopes with fewer EPA units (and thus fewer health hazards) than those present prior to criticality, as described below. The EPA unit performance measure $(R)$ for a radioisotope is the quotient of the activity (in curies) of that radioisotope divided by the regulatory release limit (in curies) specified in 40 CFR 191, Appendix A (Rechard, 1995).

$$
\begin{aligned}
R & =\frac{1}{f_{w}}\left(\frac{Q_{1}}{L_{1}}+\frac{Q_{2}}{L_{2}}+\cdots+\frac{Q_{n R}}{L_{n R}}\right) \\
& =\sum_{i=1}^{n R} \frac{Q_{i}}{f_{w} L_{i}} \leq 1(\text { or } 10)
\end{aligned}
$$

where

$$
f_{w}=\text { waste unit factor }=\frac{\sum W_{i}}{10^{6} C i}
$$

$W_{i}=$ activity in curies for $\alpha$-emitting TRU repository radioisotope $i$ with half-life $\left(\tau_{1 / 2}\right) \geq 20$ years

$L_{i}=$ the EPA release limit for radioisotope $i$ (see EPA, 1993)

$n R=$ number of radioisotopes contributing to the release

$Q_{i}=$ cumulative release for radioisotope $i$ beyond a specified boundary,

$$
\begin{aligned}
&= \int_{0}^{10,000 y r} q_{i} d t \\
& q_{i} \quad=\quad \begin{array}{l}
\text { release rate into accessible environment } \\
\text { at time } t \text { for radioisotope } i \text { and scenario } j \\
\text { calculated from consequence model(s) }
\end{array}
\end{aligned}
$$

Since the EPA unit is a surrogate for health risk, it is a metric for identifying the consequences of fissioning ${ }^{239} \mathrm{Pu}$ within a geologic repository (should a nuclear reaction occur). For waste consisting only of ${ }^{239} \mathrm{Pu}$ (and assuming a unit value for the waste unit factor, i.e., $f_{w}=1$ ), we have an EPA release limit of $100 \mathrm{Ci}=4.0537 \times 10^{24}$ atoms $=1.6091 \mathrm{~kg}$. To identify the consequences of fissioning of ${ }^{239} \mathrm{Pu}$, at time $=0 \mathrm{yr}$ all $1.6091 \mathrm{~kg}$ of ${ }^{239} \mathrm{Pu}$ was converted to its fission yield products (Walker et al., 1989, pp. 21-49). As a function of time, each fission yield product was decayed and the sum of its contribution to the EPA unit $(R)$ assessed (Table 7). One hundred ten years after fissioning, the cumulative EPA unit contributions from all the fission yield products are less than unity (i.e., the initial source term). Thus, if a subsurface criticality excursion of a unit amount of ${ }^{239} \mathrm{Pu}$ takes place in a repository and the fission yield products are not released in quantities greater than ${ }^{239} \mathrm{Pu}$, then the source term health hazard is less than before criticality. A similar benefit occurs when using plutonium in nuclear reactors (or the proposal to transmute by means of particle accelerators) but the possibility of human exposure during the process or during dismantlement of the facility is much greater. 
Table 7. Summed EPA Units Versus Time (Rechard et al., 1997, Table II)

\begin{tabular}{|c|c|c|}
\hline & $\begin{array}{l}\text { Time } \\
(\mathrm{yr})\end{array}$ & $\begin{array}{l}\text { Summed EPA Units of } \\
\text { Fission Products }\end{array}$ \\
\hline & 0 & 1.000 \\
\hline & 0.003 & 11.1790 \\
\hline & 10 & 8.8538 \\
\hline & 100 & 1.1047 \\
\hline & 110 & 0.8794 \\
\hline & 1000 & 0.0004 \\
\hline & 10000 & 0.0003 \\
\hline b & \multicolumn{2}{|c|}{$\begin{array}{l}\text { Based on release limits (surrogate of health } \\
\text { risk) in } 40 \mathrm{CFR} 191 \mathrm{f} \text { fr fission products of one } \\
\text { initial EPA unit of } 23 \mathrm{~g}_{\mathrm{Pu}} \\
\text { Release limit is } 100 \mathrm{Ci} \\
\text { Half-life is } 7.594 \times 10^{11} \mathrm{~s} \\
\text { Mass is } 1.60091 \mathrm{~kg}\end{array}$} \\
\hline
\end{tabular}

\subsubsection{Fission Products Generated from Uranium Fission in the Repository}

The reduction in potential health effects, as measured by the EPA units, from uranium fissioning are not as dramatic as for plutonium, but neither are the effects significantly detrimental. As noted earlier, the placement of CH- and RH-TRU waste in the WIPP has an initial (and maximum) heat power output of $136 \mathrm{~kW}$ (Figure 9), of which about $3 \%$ or $4 \%$ is from decay of fission products that have contaminated the RH-TRU waste (Section 2.3.2). This $5.4 \mathrm{~kW}(4 \%$ of $136 \mathrm{~kW})$ from fission product decay is quite small; to provide perspective, it is equivalent to 0.4 container out of more than 7679 containers of commercial spent fuel planned for disposal at Yucca Mountain, Nevada, assuming that each container holds 21 pressure water reactor (PWR) spent fuel assemblies $(\sim 8.2 \mathrm{MTHM} /$ container; $\sim 10 \mathrm{~kW} /$ container) (Rechard, ed., 1998, Table 3-3; Wilson et al., 1994).

The $5.4 \mathrm{~kW}$ from fission products at the WIPP represents $\sim 10^{26.6}$ fissions, assuming a burn-up of $40 \mathrm{GWd} /$ MTHM, is $3.6 \times 10^{26}$ fissions. In comparison, the maximum number of fissions possible from the $8 \mathrm{Mg}$ of ${ }^{235} \mathrm{U}$ (Table 4) at the WIPP, also assuming a $40 \mathrm{GWd} / \mathrm{MTHM}$ burnup (consumption of about $4 \%$ of the fissile mass) with $2.8 \times 10^{24}$ fissions/GWd, is $9 \times 10^{26}\left(\sim 10^{27}\right)^{25}$ fissions-less than one-half order of magnitude greater than the already small number of fission products represented in the repository. ${ }^{26}$

\subsection{Heat Potentially Generated}

\subsubsection{Heat Present in Repository}

As noted earlier, the average estimated initial heat power from radioactive decay of radioisotopes in the CH-TRU waste is $136 \mathrm{~kW}$ (Figure 9). In addition, knowing that ${ }^{239} \mathrm{Pu}$ produces heat at $2.4 \mathrm{~W} / \mathrm{kg}$, a maximum heat power of $197 \mathrm{~kW}$ from radioactive decay can be estimated assuming (a) the maximum $0.2 \mathrm{~kg}$ of FGEs of plutonium is placed in each $0.21-\mathrm{m}^{3}$ drum and $0.35 \mathrm{~kg}$ is placed in each $1.8-\mathrm{m}^{3}$ box and (b) the repository contains $3.7 \times 10^{5}$ drums and $2.3 \times 10^{4}$ boxes. The original Environmental Impact Statement on the WIPP (DOE, 1980) made a similar estimate, but because at that time the repository was assumed to be larger $\left(3.7 \times 10^{5} \mathrm{~m}^{3}\right.$ versus current $1.76 \times 10^{5} \mathrm{~m}^{3}$ volume) (Rechard, 1999), the DOE assumed $9 \times 10^{5}$ drums and $10^{5}$ boxes. Thus, its calculation of total initial power was $538 \mathrm{~kW}$. In a thermal analysis in which the latter heat power was spread over $7.3 \times 10^{5} \mathrm{~m}^{2}$ (current area is $5.1 \times 10^{5} \mathrm{~m}^{2}$ ), Thorne and Rudeen (1981) estimated the maximum rise in temperature at the center of the repository to be $1.6^{\circ} \mathrm{C} 80$ years after emplacement. ${ }^{27}$

\subsubsection{Criticality Heat in Repository}

The indefinite geometry of criticality in the salt after transport and precipitation of plutonium (or uranium) makes estimating the potential steady-state power of numerous critical excursions difficult without some arbitrary but reasonable assumptions. Here we assume a point power source in a water-saturated geologic medium. For steady-state, the power is determined primarily by the assumed operating temperature of the natural reactor and, secondarily, on the radial distance from the source to where ambient temperatures are assumed. If a distance to the ambient temperature of $10 \mathrm{~m}$ is assumed (10 times the typical thickness of the lenticular natural reactors at Oklo) with a critical zone temperature

25 The $9 \times 10^{26}$ fissions are similar to a bound on the daily power from a critical excursion, which is $\sim 10^{21}$ fissions/day or $3.6 \times 10^{27}\left(10^{27.6}\right)$ fissions over $10,000 \mathrm{yr}$, as argued in Section 6.3 , based on heat generating constraints.

26 The comparison is more favorable when the entire heat power is assumed to be caused by the decay of fission products, rather than just $4 \%$. The heat power represented by $136 \mathrm{~kW}$ in the WIPP is equivalent to 111 MTHM or 13.6 containers of spent nuclear fuel in a commercial repository. Again assuming a current average of $40 \mathrm{GWd} / \mathrm{MTHM}$ of fuel for a pressurized water reactor, the 13.6 containers represent $-10^{28}$ fissions. Hence, the maximum fission products after average burnup of the fissile material in the repository would be an order of magnitude less than those initially placed at the WIPP.

27 The $1.6^{\circ} \mathrm{C}$ temperature rise at the WIPP from radioactive decay is less than the $6^{\circ} \mathrm{C}$ temperature rise potentially caused by the exothermic corrosion, over $2 \mathrm{yr}$, of aluminum waste should sufficient brine be present in the repository (Bennett et al., 1996). 
of $\sim 700 \mathrm{~K}^{28}$, then the steady-state power is $\sim 40 \mathrm{~kW}$ $\left(-10^{20}\right.$ fissions/day) (Carslaw and Jaeger, 1959, p. 248): by a similar critical assembly in the Culebra would amount to only $3.6 \mathrm{~kW}$.

$$
\begin{aligned}
& \Delta T=T_{a}-T_{r} \simeq \frac{Q_{a}}{4 \pi K}\left(\frac{1}{a}-\frac{1}{r} \operatorname{erfc} \frac{r-a}{(4 \alpha t)^{1 / 2}}\right) \\
& Q_{a} \simeq 4 \pi K \Delta T\left(\frac{a r}{r-a}\right) \simeq 40 \mathrm{~kW}
\end{aligned}
$$

where

$$
\begin{aligned}
& Q_{a}=\text { power at source } \\
& r=\text { radial distance to ambient temperature } \\
& \alpha=\text { thermal diffusivity }=K / \rho C_{p} \\
& K=\text { thermal conductivity }(5.4 \mathrm{~W} / \mathrm{m} \cdot \mathrm{K}) \text { for }
\end{aligned}
$$

$a=$ diameter of critical sphere $(0.75 \mathrm{~m})$

The estimate of $40 \mathrm{~kW}$ for a 0.75 -m-diameter sphere (compaction of room from $84.8 \%$ porosity to $16 \%$ porosity [Figure 19]) or $23 \mathrm{~kW} / \mathrm{m}^{2}$ is 2.5 orders of magnitude greater than the estimated power density of $\sim 0.1 \mathrm{~kW} / \mathrm{m}^{2}$ at Oklo (Cowan and Norris, 1978) and thus likely very conservative. This conservative estimate of heat power is much less than the $538 \mathrm{~kW}$ that results in a $1.6^{\circ} \mathrm{C}$ rise in temperature at the center of the repository and thus of no consequence.

\subsubsection{Criticality Heat in Culebra}

The maximum amount of plutonium carried to the Culebra in the 1996 performance assessment is $110 \mathrm{~kg}$ (Figure 22). The volume occupied by $110 \mathrm{~kg}$ of plutonium at a concentration of $3 \mathrm{~kg} / \mathrm{m}^{3}$ is $-37 \mathrm{~m}^{3}$. As noted above, the amount of heat generated at Oklo has been estimated as $0.1 \mathrm{~kW} / \mathrm{m}^{3}$ in the natural reactors (Cowan and Norris, 1978). Consequently, the power produced

\subsection{Potential Damage to Geologic Media}

\subsubsection{Disruption to-Salt}

In 1961, the AEC detonated a 3.1-kiloton nuclear explosive $361 \mathrm{~m}$ below the surface in the Salado near Carlsbad, New Mexico (Rawson et al., 1965) (for reference, the WIPP is located at $655 \mathrm{~m}$ ). An approximately hemispherical cavity of $22.6-\mathrm{m}$ radius was_created_and increased the permeability in the salt about $100 \mathrm{~m}$ above the cavity. The explosion disrupted a tunnel plug such that gaseous fission products and steam vented to the atmosphere by means of the open shaft. (Most solid fission products were trapped within $38 \mathrm{~m}$ of the detonation in the melted salt.) Such damage from criticality is not likely at the WIPP, because of the nearly zero probability of a nuclear explosion being produced. The average fissile material enrichment of WIPP TRU waste is only $14 \%$, far below the theoretical minimum of $35 \%$ enrichment required for an explosion ${ }^{29}$ (Murray, 1957, p. 182).

By analogy to criticality accidents, the potential damage to the salt from a fast assembly of fissile material is negligible. Specifically, the maximum energy release from prompt neutrons for accidents is $\leq 10^{20}$ fissions (either moderated accidents from fissile solutions [Table 8] or unmoderated accidents with fissile metal [Table 9]). This small amount of rapidly produced energy release per event would be unlikely to cause any significant damage to the immediate rock situated $655 \mathrm{~m}$ $(2100 \mathrm{ft})$ below the surface at the repository horizon. In rock of any type, the potential void created would have a small radius. The true radius of a potential spherical void (or camouflet) formed beneath the surface (the apparent void plus the debris) from an explosion is roughly (Baker et al., 1980)

$$
R_{T}=1.1053(w)^{0.252} d^{0.135}
$$

where $R_{T}$ is the radius $(\mathrm{ft}), d$ is depth below surface $(\mathrm{ft})$, and $w$ is weight of explosive (lbs). The explosive weight rather than the energy from the explosive is used in the

This temperature is similar to the temperature for fluids circulating through the Oklo natural reactors based on the study of fluid inclusions showing temperatures between 650 to $695 \mathrm{~K}$. This assumption is also supported by the Lu and Gd isotope analysis showing temperatures between 525 and $725 \mathrm{~K}$, and by the mineral composition of clays, which indicates temperatures between 575 to $625 \mathrm{~K}$ (Gauthier-Lafaye et al., 1989; Oversby, 1996). feedback to the system and automatically prevents an explosion. 
Table 8. Criticality Accidents in Processing Plants

\begin{tabular}{|c|c|c|c|c|c|}
\hline Date & Plant & $\begin{array}{l}\text { Total } \\
\text { Fissions }\end{array}$ & $\begin{array}{l}\text { Prompt } \\
\text { Fissions }\end{array}$ & $\begin{array}{l}\text { Doses } \\
\text { (Rads) }\end{array}$ & Cause \\
\hline $3 / 15 / 53^{a}$ & $\begin{array}{l}\text { Mayak Enterprises, } \\
\text { the Urals }\end{array}$ & $2.5 \times 10^{17}$ & N/A & 100 and 1000 & $\begin{array}{l}\text { Radioactive solution leaked from } \\
\text { vessel during transfer within con- } \\
\text { crete cell }\end{array}$ \\
\hline $4 / 21 / 57^{a}$ & $\begin{array}{l}\text { Mayak Enterprises, } \\
\text { the Urals }\end{array}$ & $2 \times 10^{17}$ & N/A & $\begin{array}{l}\text { One fatal, five } \\
\text { debilitating }\end{array}$ & $\begin{array}{l}\text { Uranium solution leaked from cham- } \\
\text { ber }\end{array}$ \\
\hline $1 / 2 / 58^{a}$ & $\begin{array}{l}\text { Mayak Enterprises, } \\
\text { the Urals }\end{array}$ & $2.3 \times 10^{17}$ & N/A & $\begin{array}{l}\text { Four fatal, one } \\
\text { debilitating }\end{array}$ & HEUs ejected from holding tank \\
\hline $6 / 16 / 58^{b}$ & $\mathrm{Y}-12, \mathrm{TN}$ & $1.3 \times 10^{18}$ & $7 \times 10^{16}$ & $\begin{array}{l}365,339,327,270 \\
236,69,69, \text { and } 23\end{array}$ & ${ }^{235} \mathrm{U}$ solution washed into drum \\
\hline $12 / 30 / 58^{b}$ & LANL, NM & $1.5 \times 10^{17}$ & $1.5 \times 10^{17}$ & $\begin{array}{l}4400 \text { (fatal), } 135 \text {, } \\
\text { and } 3\end{array}$ & $\begin{array}{l}\text { Plutonium concentrated in solvent } \\
\text { layer }\end{array}$ \\
\hline $10 / 16 / 59^{b}$ & ICPP, ID & $4 \times 10^{17}$ & $10^{17}$ & $\begin{array}{l}50 \text { and } 32 \\
\text { (primarily beta) }\end{array}$ & ${ }^{235} \mathrm{U}$ solution siphoned into tank \\
\hline $12 / 5 / 60^{\mathrm{a}}$ & $\begin{array}{l}\text { Mayak Enterprises, } \\
\text { the Urals }\end{array}$ & $10^{19}$ & N/A & 5 & $\begin{array}{l}\text { Plutonium concentration too high in } \\
\text { solution }\end{array}$ \\
\hline $1 / 25 / 61^{b}$ & ICPP, ID & $6 \times 10^{17}$ & $6 \times 10^{17}$ & None & $\begin{array}{l}{ }^{235} \mathrm{U} \text { solution forced into cylinder by } \\
\text { air }\end{array}$ \\
\hline $8 / 14 / 61^{\mathrm{a}}$ & $\begin{array}{l}\text { Siberian Chemical } \\
\text { Combine }\end{array}$ & $\begin{array}{c}5 \times 10^{15} \\
10^{17}\end{array}$ & $\mathrm{~N} / \mathrm{A}$ & 200 & $\begin{array}{l}\text { Increase in temperature and equip- } \\
\text { ment malfunction }\end{array}$ \\
\hline $4 / 7 / 62^{b}$ & $\begin{array}{l}\text { Hanford } \\
\text { Recuplex, WA }\end{array}$ & $8.2 \times 10^{17}$ & $10^{16}$ & 87,33 , and 16 & $\begin{array}{l}\text { Plutonium solution in sump sucked } \\
\text { into tank }\end{array}$ \\
\hline $9 / 7 / 62^{a}$ & $\begin{array}{l}\text { Mayak Enterprises, } \\
\text { the Urals }\end{array}$ & $2 \times 10^{17}$ & N/A & Insignificant & Plutonium left undissolved \\
\hline $1 / 30 / 63^{\mathrm{a}}$ & $\begin{array}{l}\text { Siberian Chemical } \\
\text { Combine }\end{array}$ & $7.9 \times 10^{17}$ & N/A & Four 6 to 17 & $\begin{array}{l}\text { HEU solution was divided and trans- } \\
\text { ferred to different vessels }\end{array}$ \\
\hline $12 / 13 / 63^{\mathrm{a}}$ & $\begin{array}{l}\text { Siberian Chemical } \\
\text { Combine }\end{array}$ & $2.7 \times 10^{17}$ & N/A & Insignificant & $\begin{array}{l}\text { Vacuum valve to the trap was shut } \\
\text { off }\end{array}$ \\
\hline $7 / 24 / 64^{b}$ & $\begin{array}{l}\text { Wood River } \\
\text { Junction }\end{array}$ & $1.3 \times 10^{17}$ & $10^{17}$ & $\begin{array}{l}10,000 \text { (fatal), } \\
\text { Two } 60 \text { to } 100\end{array}$ & ${ }^{235} \mathrm{U}$ solution poured into tank \\
\hline $11 / 13 / 65^{a}$ & $\begin{array}{l}\text { Electrostal Fuel } \\
\text { Fabrication Plant }\end{array}$ & $10^{15}$ & N/A & 3.5 & $\begin{array}{l}\text { Power accumulation in water reser- } \\
\text { voir }\end{array}$ \\
\hline $12 / 16 / 65^{\mathrm{a}}$ & $\begin{array}{l}\text { Mayak Enterprises, } \\
\text { the Urals }\end{array}$ & $7 \times 10^{17}$ & N/A & $\leq 0.03$ & $\begin{array}{l}\text { Uranium mass exceeded safety Mar- } \\
\text { gin }\end{array}$ \\
\hline $12 / 10 / 68^{\mathrm{a}}$ & $\begin{array}{l}\text { Mayak Enterprises, } \\
\text { the Urals }\end{array}$ & $5 \times 10^{17}$ & N/A & $\begin{array}{l}\text { One fatal, one } \\
\text { debilitating }\end{array}$ & Plutonium concentration too high \\
\hline $8 / 24 / 70^{\mathrm{b}}$ & Windscale, UK & $10^{15}$ & $10^{15}$ & Negligible & $\begin{array}{l}\text { Plutonium concentrated in trapped } \\
\text { solution }\end{array}$ \\
\hline $10 / 17 / 78^{b}$ & ICPP, ID & $3 \times 10^{18}$ & Unknown & None & $\begin{array}{l}{ }^{235} \mathrm{U} \text { buildup due to diluted scrub } \\
\text { solution }\end{array}$ \\
\hline $12 / 13 / 78^{\mathrm{a}}$ & $\begin{array}{l}\text { Siberian Chemical } \\
\text { Combine }\end{array}$ & $3 \times 10^{18}$ & N/A & $\begin{array}{l}\text { One } 250 \text { to } 200 \\
\text { Seven } 5 \text { to } 60\end{array}$ & $\begin{array}{l}\text { Plutonium mass in containers too } \\
\text { high }\end{array}$ \\
\hline \multicolumn{6}{|c|}{$\begin{array}{l}\text { a Taken from Frolov et al. (1995). } \\
\text { b Taken from Knief (1985, Chapter 3, pp. 17-28), original reference, Paxton (1983). (Data values shown here agree with those in Stratton and } \\
\text { Smith, 1989.) }\end{array}$} \\
\hline
\end{tabular}


Table 9. Criticality Accidents Involving Moderated Metal and Oxide Systems (after Stratton and Smith, 1989)

\begin{tabular}{|c|c|c|c|c|c|}
\hline Date & Plant & $\begin{array}{l}\text { Total } \\
\text { Fissions }\end{array}$ & $\begin{array}{l}\text { Prompt } \\
\text { Fissions }\end{array}$ & $\begin{array}{l}\text { Doses } \\
\text { (Rads) }\end{array}$ & Cause \\
\hline $6 / 06 / 45$ & Los Alamos & $4 \times 10^{16}$ & $3 \times 10^{15}$ & 66,66 , and 7.4 & Water leaked into assembly \\
\hline 1950 & Chalk River & Unknown & NA & NA & Excess moderator added \\
\hline $6 / 02 / 52$ & $\begin{array}{l}\text { Argonne National } \\
\text { Lab }\end{array}$ & $1.22 \times 10^{17}$ & NA & $136,127,60$, and 9 & $\begin{array}{l}\text { Control removed, water not } \\
\text { removed }\end{array}$ \\
\hline $12 / 12 / 52$ & Chalk River & $1.2 \times 10^{20}$ & NA & low & Positive void coefficient \\
\hline $7 / 22 / 54$ & Idaho National Lab & $4.68 \times 10^{18}$ & NA & NA & Planned transient extended \\
\hline $10 / 15 / 58$ & $\begin{array}{l}\text { Vinca, } \\
\text { Yugoslavia }\end{array}$ & $2.6 \times 10^{18}$ & NA & $\begin{array}{c}205,320,410,415 \\
422, \text { and } 433\end{array}$ & Faulty power monitoring \\
\hline $3 / 15 / 60$ & Saclay, France & $3 \times 10^{18}$ & NA & NA & Removal of absorber rod \\
\hline $1 / 03 / 61$ & Idaho National Lab & $4.4 \times 10^{18}$ & NA & 3 fatalities & Removal of control rod \\
\hline $11 / 05 / 62$ & Idaho National Lab & $1 \times 10^{18}$ & NA & NA & Planned transient exceeded \\
\hline $12 / 30 / 65$ & Mol, Belgium & $4.3 \times 10^{17}$ & NA & $\mathrm{NA}$ & $\begin{array}{l}\text { Mis-operation plus not } \\
\text { draining tank }\end{array}$ \\
\hline $9 / 23 / 83$ & $\begin{array}{l}\text { Buenos Aires, } \\
\text { Argentina }\end{array}$ & $4 \times 10^{17}$ & NA & low & Failure to drain tank \\
\hline
\end{tabular}

empirical expression because the exponent is so small $(\sim 1 / 4)$; the type of rock is not used for rough estimates because it has a secondary effect. At most, potential voids (camouflets) of $<1.3 \mathrm{~m}$ radius would occur in the salt (Rechard et al., 1996b; 1997), assuming the average accident energy release of $10^{18}$ fissions $(\sim 4.5 \mathrm{~kg}$ TNT $[10 \mathrm{lbs}])^{30}$.

The validity of the use of criticality accidents as an analogy for energy release from a criticality in or near a geologic repository was checked through two types of calculations. First, a BetheTait analysis of an unmoderated accident suggests a bound of $6 \times 10^{17}$ fissions or 18.7 MJ (Rechard et al., 1996b; 1997), which is approximately equal to the maximum number of fissions seen in accidents in processing plants and laboratories throughout the world. Second, a detailed nuclear dynamics analysis of a criticality in geologic media shows that the energy releases from a nuclear criticality are minimized because the reaction is quickly stopped by near instantaneous negative feedback (Sanchez et al., 1998, Figures 4.3-1 and 4.3-2; Rechard, ed., 1995, p. 10-41) (Figure 29). The feedback is from the simple heating of the fissile mass, which changes the resonance band (i.e., Doppler effects) of the system; the negative feedback is not dependent upon the slower, thermally driven changes of the overall assembly, such as evaporation of a water moderator. The maximum number of integrated fissions $(E)$ varied between $10^{16}$ and $5.6 \times 10^{19}$ during any one critical event and lasted between $3.6 \times 10^{3}$ and $3.6 \times 10^{5} \mathrm{~s}$ (Sanchez et al., 1998, p. 4-15). The maximum number could be expressed by the empirical equation (Sanchez et al., 1998, Figure 4.4-5):

$$
E=2.73 \times 10^{17} \varepsilon^{1.003}
$$

where

$$
\begin{aligned}
\varepsilon= & \delta_{o} m /\left|\alpha_{\mathrm{T}}\right| \\
\delta_{o}= & \text { initial reactivity } \\
\delta= & (\Delta k) / k=\left(k_{e f}^{-1}\right) / k_{e f f}=\text { reactivity (ratio of } \\
& \text { excess multiplication factor to multipli- } \\
& \text { cation factor) } \\
m= & \text { fissile mass }(\mathrm{kg}) \\
\alpha_{\mathrm{T}}= & \text { feedback coefficient }\left(\mathrm{k}^{-1}\right)
\end{aligned}
$$

30 The release of kinetic energy from rapid thermal heating would be slower than in a chemical explosion, and so the conversion to TNT represents an upper bound. 


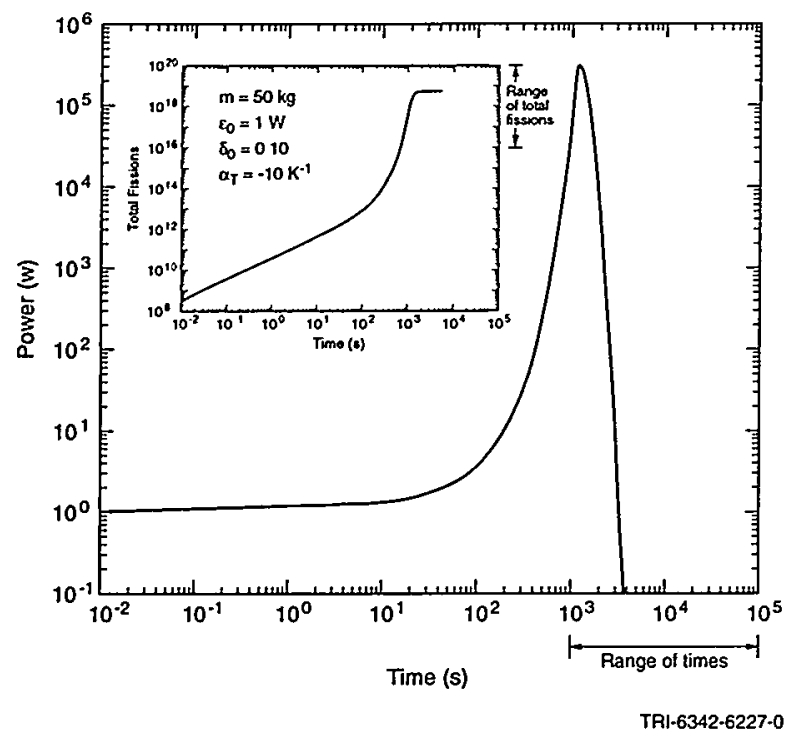

Figure 29. Typical result of nuclear excursion using point reactor kinetics model (after Sanchez et al., 1998, Figures 4.3-I and 4.3-2).

\subsubsection{Disruption to Dolomite}

If the average fissile content in the repository is less than $14 \%$, then in order for the percentage to approach the theoretical minimum of $35 \%$ required for an explosion, as discussed in the previous section, the fissile content must more than double between the repository and its entry into the Culebra dolomite. Consequently, a nuclear explosion is not feasible in the Culebra either. Furthermore, the potential damage to the dolomite from a sudden assembly of fissile material is minor. As noted above, the maximum energy release from prompt neutrons for aqueous accidents, as calculated by BetheTait analysis, is $6 \times 10^{17}$ fissions or $18.7 \mathrm{MJ}$ (Rechard et al., 1996b). Again, this small amount of rapidly produced energy release per event would be unlikely to cause any significant damage to the dolomite $300 \mathrm{~m}$ below the surface in the Culebra. For $4.5-\mathrm{kg}$ TNT, the potential void radius is only slightly larger $(1.4 \mathrm{~m}[4.8 \mathrm{ft}])$ at the shallower depth. 


\section{Summary and Conclusions}

Based on this evaluation of both probability and consequences of criticality, a critical event (or processes leading up to criticality) was omitted from direct consideration in the 1996 performance assessment. The arguments concerning criticality have been organized according to the two main aspects of risk (probability and consequences). Probability has been further categorized by its components, based on pertinent phenomena as follows:

$$
\operatorname{Risk}\{C\}=P\{C\} \cdot C\{C\}
$$

where

$$
\mathrm{P}\{C\}=(P\{C \mid p \cap h \cap \mathrm{c}\} \cdot P\{p\} \cdot P\{h\} \cdot \mathrm{P}\{\mathrm{c}\})
$$

These components were then grouped with regard to disposal system location, i.e., within the repository and in the far field. This simple approach is useful primarily because the scientific disciplines necessary to examine the criticality issue are easily distinguished. Note, however, that the distinction between physical, hydrologic, and geochemical constraints is somewhat arbitrary. For example, once the geochemical mechanism is understood, the process can be explained by microscopic physical limits. Thus, the division here is on a macroscopic scale.

\subsection{Use of Critical Concentration of Plutonium in Evaluating Probabilities}

In this report, constraints on the physical and geochemical_conditions_were_evaluated_by_examining fissile limits on criticality based on static neutronic calculations. Both critical mass limits of fissile material and the critical concentration limits of plutonium or uranium for various mixtures of geologic material, fissile material, and fluid were calculated. These limits were then_compared_to_solid_concentrations_possible_through natural phenomena such as dissolution, adsorption, and precipitation. Using critical concentration is an advantage because the critical concentration (1) is more clearly dependent on geochemical processes than the absolute mass of fissile material and (2) is less sensitive to variations in geologic properties than critical mass.

The criticality limits for a mixture of $\mathrm{PuO}_{2}$, Culebra dolomite_with_porosity_of_16\%,_and_Culebra_brine_is_a minimum mass of $2.2 \mathrm{~kg}$ and minimum concentration of
$3 \mathrm{~kg} / \mathrm{m}^{3}$ (Figure 16). For Castile or Salado brine, the limits increase to $7 \mathrm{~kg}$ mass and $10 \mathrm{~kg} / \mathrm{m}^{3}$ concentration. For $\mathrm{PuO}_{2}$, Salado salt with a porosity of $1.3 \%$, and Salado brine, the minimum mass is $700 \mathrm{~kg}$ and minimum concentration is $55 \mathrm{~kg} / \mathrm{m}^{3}$. For most arguments, the $3 \mathrm{~kg} / \mathrm{m}^{3}$ concentration limit is used, as a conservative value.

\subsection{Probabilities of Criticality}

In all cases that were examined, either a physical, geochemical, or hydrologic constraint exists to reduce the chance of criticality at the WIPP to a vanishingly small probability. Physical constraints include original distribution of fissile material, mass of fissile material transported, and physical processes such as compaction; hydrologic constraints refer to zone of mixing; and geochemical constraints refer to processes such as adsorption and precipitation.

\subsubsection{Physical Constraints}

On a macroscopic scale, the fissile mass at the WIPP is emplaced fairly uniformly (Figure 8) at a concentration far below critical. In addition, the compaction of the repository through salt creep is not sufficient to reach the minimum critical concentration of $3 \mathrm{~kg} / \mathrm{m}^{3}$ (compaction from an initial waste room porosity of $84 \%$ to a final porosity of $10 \%$ corresponds to a concentration of $0.3 \mathrm{~kg} / \mathrm{m}^{3}$ ) (Table 10 ).

\subsubsection{Hydrologic Constraints}

-Prior-to-intrusion,-a-hydrologic-constraint-exists-inthat the resaturation of the WIPP repository is not sufficient to move and assemble enough fissile material for criticality.

After intrusion, two hydrologic constraints exist in the_Culebra_Eirst,_the_dispersion_that-normally_occurs while contaminants move through the Culebra aquifer suggests that the small amount of material brought to the aquifer can reach a critical concentration only near the intrusion borehole. (The fact that the amount of material in the aquifer is small is the result of actinide solubility, as described below.) Second, the zone of mixing fluid from the intrusion borehole and the Culebra is such that at a minimum $1000 \mathrm{~kg}$ must reach the Culebra.to-provide_conditions-for-criticality. 
Table 10. Summary of Geophysical Arguments Supporting Low Probability of Criticality from Plutonium at WIPP

\begin{tabular}{ll}
\hline $\begin{array}{c}\text { Scenario } \\
\text { Geophysical Mechanism } \\
\text { Location }\end{array}$ & Argument \\
\hline $\begin{array}{c}\text { No Intrusion }\left(\mathrm{S}_{\mathrm{o}}\right) \\
\text { Compaction } \\
\text { Repository }\end{array}$ & $\begin{array}{l}\text { Physical constraint: Compacted porosity }\left(0=0.10 \Rightarrow 0.3 \mathrm{~kg} / \mathrm{m}^{3}\right) \\
\text { gives solid concentration }\left(0.3 \mathrm{~kg} / \mathrm{m}^{3}\right) \text { much less than critical concen- } \\
\text { tration }\left(3 \mathrm{~kg} / \mathrm{m}^{3}\right)\end{array}$ \\
$\begin{array}{l}\text { Geochemical constraint: Required concentration }\left(3 \mathrm{~kg} / \mathrm{m}^{3} \cong 12 \mathrm{mM}\right) \\
\text { much greater than fissile solubility }\end{array}$ \\
Concentration mechanisms & $\begin{array}{l}\text { Without intrusion, no long-term gradient for brine movement whereby } \\
\text { fissile material can be moved and then concentrated. }\end{array}$
\end{tabular}

\begin{tabular}{l}
\hline Intrusion $\left(\mathrm{S}_{\mathrm{i}}\right)$ \\
Adsorption \\
Repository \\
Culebra \\
\\
Precipitation \\
Repository \\
(Redox, ionic strength, \\
and pH variation) \\
Culebra \\
(Redox, ionic strength, \\
and pH variation)
\end{tabular}

\section{Colloidal Filtering Repository}

Culebra

Geochemical constraint: Adsorptive material such as rust well distributed through repository and any adsorption not exclusive to fissile material

Geochemical constraint: Cannot occur throughout, must occur at borehole since insufficient material reaches Culebra in $10^{-1} \mathrm{yr}$ because of solubility limit

Physical constraint: Not enough Pulll reaches Culebra in $10^{4} \mathrm{yr}$.

Geochemical constraint: Iron, brine, and MgO, which control brine chemistry, well distributed throughout repository

Physical constraint: Questionable in locations with discrete fractures since deposition thickness must exceed $0.45 \mathrm{~m}$; also, for advective fracture porosities of $0.001,44 \%$ of all minerals deposited must be $\mathrm{PuO}_{2}$

Hydrologic constraints: Zone of mixing too large, need $>1100 \mathrm{~kg}$ which requires $\sim 10^{5} \mathrm{yr}$ at high flow rate $\left(>10^{4} \mathrm{yr}\right)$ to get $3 \mathrm{~kg} / \mathrm{m}^{3}$ solid concentration

Geochemical constraint: (a) Fissile material already reduced, thus traditional mechanism not applicable, (b) no strong oxidant known in Culebra $\left(\mathrm{O}_{2}\right.$ from surface unlikely through sand-filled borehole), and (c) precipitation with other materials fills pores and reduces porosity available for water and fissile material

Geochemical constraint: (a) Fissile concentration on colloidals controlled by thermodynamics, (b) distribution of colloidal substrates uniformly distributed throughout repository, and (c) no bioaccumulation by microbes

Geochemical constraint: Not enough Pu ${ }^{\text {III }}$ reaches Culebra in $10,000 \mathrm{yr}$, filterable colloids only $7 \%$ of $\mathrm{Pu}^{\mathrm{IV}}$, and thus insufficient fissile mass 


\subsubsection{Geochemical Constraints}

Solubility of the fissile material is insufficient to cause criticality. The low solubility also implies that vast amounts of brine are required to transport a sufficient quantity of fissile material to cause criticality. In the simulation for the 1996 performance assessment of the WIPP, only one case out of 100 showed enough material reaching the Culebra that exceeded the minimum fissile mass, and even then, the fissile material must be concentrated. The uniform distribution, on a macroscopic scale, of material in the WIPP repository implies that fissile material is not present in sufficient amounts in any one location to reach critical concentrations through adsorption on, for example, rust from corrosion of steel drums. Furthermore, the uniform distribution of material such as organics and rust means that the brine chemistry is also fairly uniform such that changes in $\mathrm{pH}$, ionic strength, or reduction-oxidation potential do not vary, on a macroscopic scale, and thus cannot promote preferential precipitation or colloidal filtering at only one or a few locations. Rather, these changes in geochemical conditions, if they do occur, would occur throughout the repository.

Several geochemical constraints exist to prevent criticality within the disposal system at the WIPP (though outside the repository itself). First, adsorption on dolomite or any other material must exceed the adsorptive capacity of synthetically prepared goethite $\left(-17\right.$ sites $\left./ \mathrm{nm}^{2}\right)$ in order to provide sufficient adsorptive capacity for plutonium and similar actinides such as thorium and uranium. This adsorptive capacity for a natural material is unlikely. Second, the fissile material will be highly reduced within the repository. Hence, the traditional mechanism of forming uranium ore bodies through precipitation by reduction of the more soluble high-oxidation-state actinides cannot occur. Precipitation mechanisms such as oxidation of $\mathrm{Pu}^{\mathrm{III}}$ to $\mathrm{Pu}^{\mathrm{IV}}$ and direct or coprecipitation of $\mathrm{Pu}^{\mathrm{IV}}$ with $\mathrm{Fe}^{\mathrm{III}}$ would be gradual and diffuse over an area too large to cause criticality. However, neither a strong reductant nor oxidant in a localized area has been discovered within the Culebra; thus, a sudden change in the reduction-oxidation potential is unlikely. Precipitation through changes in ionic strength or $\mathrm{pH}$ could be brought about by a Castile- or Salado-dominated brine mixing with the Culebra brine. However, as discussed in the previous section, the zone of mixing requires at least an order of magnitude more plutonium than is calculated to reach the Culebra over 10,000 yr. Furthermore, the transport- ing fluid (Salado or Castile brine) has many dissolved solids and would contain other actinides; thus several constituents other than fissile material will also be deposited since a method to fractionalize the fissile material is not evident.

In addition, the minimum solubility of fissile material was evaluated based on requirements given the rough natural inefficiencies observed for the natural reactors at Oklo. For sufficient material to move to the Culebra in 10,000 yr, solubilities in excess of those anticipated for uranium, and all but a small portion of the tail of the distribution for plutonium, are required. Specifically, the required plutonium solubility, assuming a similar efficiency of nature at the WIPP that occurred at Oklo, is quite high (i.e., $0.2 \mathrm{mM}$ in the Culebra).

\subsection{Consequences of Criticality}

For criticality to be detrimental to a deep geologic repository, criticality must either (1) generate significant amounts of fission products above those already present or being released from the repository or (2) degrade the ability of the disposal system to contain nuclear waste. Neither occurs should criticality be present in the WIPP disposal system. Criticality involving the most abundant fissile material, ${ }^{239} \mathrm{Pu}$, decreases the health hazards after $110 \mathrm{yr}$, based on the Containment Requirements criterion of EPA's standard, 40 CFR 191. Although the effects of criticality for ${ }^{235} \mathrm{U}$ do not immediately reduce health hazards, neither are they significantly increased. The maximum number of fissions possible from uranium disposed of at the WIPP, and thus fission products, is $\sim 10^{27}$ fissions. This value is less than one-half of that represented by one large container of spent nuclear fuel and is less than one-half order of magnitude greater than the small amount of fission products already present in the repository. Because of the small number of fissions possible, the heat power from the fissions themselves is not greater than the heat power already present. Furthermore, the amount of heat power generated by decay of fission products from both plutonium and uranium fissions is also less (by an order of magnitude) than the heat power initially present in the repository. Finally, the physical damage to the salt or dolomite is negligible, because the heat generation rates are so low. Even if the average power released in a day were to be converted to an equivalent explosive release, the damage to geologic media would not be significant. 


\section{References}

Adler, H.H. 1974. "Concepts of Uranium-Ore Formation in Reducing Environments in Sandstones and Other Sediments," Formation of Uranium Ore Deposits, Proceedings of a Symposium on the Formation of Uranium Ore Deposits, Athens, Greece, May 6-10, 1974. STI/PUB/ 374. Vienna, Austria: International Atomic Energy Agency. 141-168.

Alcouffe, R.E., R.S. Baker, F.W. Brinkley, D.R. Marr, R.D. O'Dell, and W.F. Walters. 1995. DANTSYS: A Diffusion Accelerated Neutral Particle Transport Code System. LA-12969-M. Los Alamos, NM: Los Alamos National Laboratory.

Allen, E.J. 1978. Criticality Analysis of Aggregations of Actinides from Commercial Nuclear Waste in Geological Storage. ORNL/TM-6458. Oak Ridge, TN: Oak Ridge National Laboratory.

Al-Shaieb, Z., R.W. Olmsted, J.W. Shelton, R.T. May, R.T. Owens, and R.E. Hanson. 1977. "Uranium Potential of Permian and Pennsylvanian Sandstones in Oklahoma," The American Association of Petroleum Geologists Bulletin. Vol. 61, no. 3, 360-375.

Anderson, R.Y., and D.W. Kirkland. 1960. "Origen, Varves, and Cycles of Jurassic Todilto Formation, New Mexico," Bulletin of the American Association of Petroleum Geologists. Vol. 44, no. 1, 37-52.

Andersson, K. 1988. SKI Project-90: Chemical Data. SKITR-91-21. Stockholm, Sweden: Swedish Nuclear Power Inspectorate.

Babb, S.C., and C.F. Novak. 1995. "User's Manual for FMT, Version 2.0." Albuquerque, NM: Sandia National Laboratories. (On file in Sandia WIPP Central Files [SWCF] as WPO\#28119.)

Baker, W.E., J.J. Kulesz, P.S. Westine, P.A. Cox, and J.S. Wilbeck. 1980. Manual for the Prediction of Blast and Fragment Loadings on Structures. DOE/TIC-11268. San Antonio, TX: Southwest Research Center for Albuquerque Operations Office, U.S. Department of Energy, Albuquerque, NM.

Bean, J.E., M.E. Lord, D.A. McArthur, R.J. MacKinnon, J.D. Miller, and J.D. Schreiber. 1996. "Analysis Package for Salado Flow Calculations (Task 1) of the Performance Assessment Analysis Supporting the Compliance Certification Application (CCA)." Albuquerque, NM: Sandia National Laboratories. (On file in SWCF as WPO\#40514.)

Beauheim, R.L. 1987. Interpretations of Single-Well Hydraulic Tests Conducted At and Near the Waste Isolation Pilot
Plant (WIPP) Site, 1983-1987. SAND87-0039. Albuquerque, NM: Sandia National Laboratories.

Beauheim, R.L., and R.M. Holt. 1990. "Hydrogeology of the WIPP Site," Geological and Hydrological Studies of Evaporites in the Northern Delaware Basin for the Waste Isolation Pilot Plant (WIPP), New Mexico, Field Trip \#14 Guidebook, November 1-4, 1990. Leaders D. Powers, R. Holt, R.L. Beauheim, and N. Rempe. SAND90-2035J. Dallas, TX: Dallas Geological Society. 131-179.

Bell, K.G. 1963. Uranium in Carbonate Rocks. Professional Paper 474-A. Washington, DC: United States Government Printing Office.

Bennett, D., Y. Wang, and T.W. Hicks. 1996. "An Evaluation of Heat Generation Processes for the WIPP." Memorandum to Distribution, August 20, 1996. Albuquerque, NM: Sandia National Laboratories. (On file in SWCF as WPO\#40635.)

Bethe, H.A., and J.H. Tait. 1956. "An Estimate of the Order of Magnitude of the Explosion When the Core of a Fast Reactor Collapses," U.S.-U.K. Reactor Hazard Meeting, 1956. RHM(56)/113. Harwell, Berks, England: Atomic Energy Research Establishment. 22 pp.

Bingham, F.W., and G.E. Barr. 1979. Scenarios for LongTerm Release of Radionuclides from a Nuclear-Waste Repository in the Los Medaños Region of New Mexico. SAND78-1730. Albuquerque, NM: Sandia National Laboratories.

Bingham, F.W., and G.E. Barr. 1980. "Development of Scenarios for the Long-Term Release of Radionuclides from the Proposed Waste Isolation Pilot Plant in Southeastern New Mexico," Scientific Basis for Nuclear Waste Management, Proceedings of the International Symposium, Boston, MA, November 27-30, 1979. Ed. C.J.M. Northrup, Jr. SAND79-0955C. New York, NY: Plenum Press. Vol. 2, 771-778.

Blyckert, W.A., and R.D. Carter. 1980. Criticality Parameters of 55-Gallon Waste Drum Arrays. RHO-SA-183; CONF801107-58. Richland, WA: Rockwell International Corporation, Rockwell Hanford Operations.

Bowman, C.D., and F. Venneri. 1996. "Underground Supercriticality from Plutonium and Other Fissile Material," Science \& Global Security. Vol. 5, 279-302.

Brady, P.V., H.W. Papenguth, and J.W. Kelly. 1999. "Metal Sorption to Dolomite Surfaces," Applied Geochemistry. Vol. 14, no. 5, 569-579.

Bredehoeft, J., and P. Hall. 1996. "WIPP with Magnesium Oxide Backfill." Version 1.2. Report Prepared for New 
Mexico Attorney General. La Honda, CA: The Hydrodynamics Group. (On file in SWCF as ERMS\#500165.)

Briesmeister, J.F., ed. 1986. MCNP: A General Monte Carlo Code for Neutron and Photon Transport. Version 3a. LA-7396-M, Rev. 2 Manual. Los Alamos, NM: Los Alamos National Laboratory.

Brinck, J.W. 1974. "The Geochemical Distribution of Uranium as a Primary Criterion for the Formation of Ore Deposits," Formation of Uranium Ore Deposits, Proceedings of a Symposium on the Formation of Uranium Ore Deposits, Athens, Greece, May 6-10, 1974. STI/PUB/ 374. Vienna, Austria: International Atomic Energy Agency. 21-32.

Brookins, D.G. 1978. Geochemical Constraints on Accumulation of Actinide Critical Masses from Stored Nuclear Waste in Natural Rock Repositories. ONWI-17. Columbus, $\mathrm{OH}$ : Office of Nuclear Waste Isolation (ONWI), Battelle Memorial Institute.

Brookins, D.G. 1988. Eh-pH Diagrams for Geochemistry. New York, NY: Springer-Verlag.

Brunauer, S., P.H. Emmett, and E. Teller. 1938. "Adsorption of Gases in Multimolecular Layers," Journal of the American Chemical Society: Vol. 60,309-319.

Bruno, J., and P. Sellin. 1992. Radionuclide Solubilities to be Used in SKB 91. SKB Technical Report 92-13. Stockholm, Sweden: Swedish Nuclear Fuel and Waste Management Co.

Brush, L.H. 1990. Test Plan for Laboratory and Modeling Studies of Repository and Radionuclide Chemistry for the Waste Isolation Pilot Plant. SAND90-0266. Albuquerque, NM: Sandia National Laboratories.

Brush, L.H. 1998. "Ranges and Probability Distributions of Kds for Dissolved Pu, Am, U, Th, and Np in the Culebra for the PA Calculations to Support the WIPP CCA," Laboratory Column Experiments for Radionuclide Adsorption Studies of the Culebra Dolomite Member of the Rustler Formation. D.A. Lucero, G.O. Brown, and C.E. Heath. SAND97-1763. Albuquerque, NM: Sandia National Laboratories. D-11 through D-108.

Brush, L.H., and L.J. Storz. 1996. "Revised Ranges and Probability Distributions of $K_{d} s$ for Dissolved Pu, Am, U, Th, and $\mathrm{Np}$ in the Culebra for the PA Calculations to Support the WIPP CCA." Memorandum to M.S. Tierney, July 24, 1996. Albuquerque, NM: Sandia National Laboratories. (On file in SWCF as WPO\#41561.)

Canavan, G.H., S.A. Colgate, O.P. Judd, G.H. McCall, A.G. Petschek, J.C. Solem, T.F. Stratton, W.R. Stratton, and P.P. Whalen. 1995. Comments on "Nuclear Excursions" and "Criticality' Issues." LA-UR-95-0851. Los Alamos, NM: Los Alamos National Laboratory.
Carslaw, H.S., and J.C. Jaeger. 1959. Conduction of Heat in Solids. $2^{\text {nd }}$ ed. Oxford: Clarendon Press; New York, NY: Oxford University Press. 248.

Carter, R.D. 1973. “Appendix N, Criticality Calculations," Nuclear Reactivity Evaluations of 216-Z-9 Enclosed Trench. Ed. A.E. Smith. ARH-2915. Richland, WA: Atlantic Richfield Hanford Company.

Clayton, E.D. 1979. Anomalies of Nuclear Criticality. PNLSA-4868, Rev. 5; CONF-791103-114, Rev. 5. Richland, WA: Pacific Northwest Laboratory.

Clayton, E.D., and W.A. Reardon. 1980. "Chapter 27: Nuclear Safety and Criticality of Plutonium," Plutonium Handbook: A Guide to the Technology: Ed. O.J. Wick. La Grange Park, IL: American Nuclear Society. Vol. 1, 875-919.

Cohen, S.C. 1996a. "Supplement 2: Criticality Review for the Waste Isolation Pilot Plant," Review of the WIPP Draft Application to Show Compliance with EPA Transuranic Waste Disposal Standards. EEG-61; DOE/AL/ 58309-61. Albuquerque, NM: Environmental Evaluation Group. S2-1 through S2-26.

Cohen, S.C. 1996b. "Supplement 3: Reviews of WAESDTR-83-0015 and TME-3025 Rev. 1," Review of the WIPP Draft Application to Show Compliance with EPA Transtlranic Waste Disposal Standards. EEG-61; DOE/AL/ 58309-61. Albuquerque, NM: Environmental Evaluation Group. S3-1 through S3-3.

Cohen, S.C. 1996c. "Supplement 4: Letter Dated January 18, 1984 to Environmental Evaluation Group on Postulated WIPP Reconcentration Criticality," Review of the WIPP Draft Application to Show Compliance with EPA Transuranic Waste Disposal Standards. EEG-61; DOE/AL/ 58309-61. Albuquerque, NM: Environmental Evaluation Group. S4-1 through S4-10.

Cowan, G.A. 1976. “A Natural Fission Reactor," Scientific American. Vol. 235, no. 1, 36-47.

Cowan, G.A., and A.E. Norris, eds. 1978. Investigations of the Natural Fission Reactor Program: October 1977September 1978. LA-7536-PR. Los Alamos, NM: Los Alamos Scientific Laboratory.

Cowan, G.A., E.A. Bryant, and W.R. Daniels. 1975. "Some United States Studies of the Oklo Phenomenon," Le Phenomene d'Oklo/The Oklo Phenomenon, Proceedings of a Symposium, Libreville, Gabon, June 23-27, 1975. STIPUB-405. Vienna: International Alomic Energy Agency. 341-356.

Cramer, J.J., and J.A.T. Smellie, eds. 1994. Final Report of the AECL/SKB Cigar Lake Analog Study: AECL-10851, COG-93-147, SKB TR 94-04. Pinawa, Manitoba: 
Atomic Energy of Canada Limited, Whiteshell Nuclear Research Establishment.

Davis, J.A., and D.B. Kent. 1990. "Surface Complexation Modeling in Aqueous Geochemistry," Mineral-Water Interface Geochemistry. Eds. M.F. Hochella, Jr. and A.F. White. Reviews in Mineralogy Vol. 23. Washington, DC: Mineralogical Society of America. 177-260.

DOE (U.S. Department of Energy). 1979. Draft Environmental Impact Statement, Waste Isolation Pilot Plant. DOE/ EIS-0026-D. Washington, DC: U.S. Department of Energy. Vols. 1-2.

DOE (U.S. Department of Energy). 1980. Final Environmental Impact Statement, Waste Isolation Pilot Plant. DOE/ EIS-0026. Washington, DC: U.S. Department of Energy. Vols. 1-2.

DOE (U.S. Department of Energy). 1995. Transuranic Waste Baseline Inventory Report (Revision 2). DOE/CAO-951121. Carlsbad, NM: U.S. Department of Energy, Carlsbad Area Office.

DOE (U.S. Department of Energy). 1996. Title 40 CFR Part 191 Compliance Certification Application for the Waste Isolation Pilot Plant. DOE/CAO-1996-2184. Carlsbad, NM: United States Department of Energy, Waste Isolation Pilot Plant, Carlsbad Area Office. Vols. I-XXI.

Energy Policy Act of 1992. 1992. Public Law 102-486, 106 Stat. 2776,42 U.S.C. 13201 et seq.

EPA (U.S. Environmental Protection Agency). 1985a. "40 CFR Part 191: Environmental Standards for the Management and Disposal of Spent Nuclear Fuel, High-Level and Transuranic Radioactive Wastes; Final Rule," Federal Register. Vol. 50, no. 182, 38066-38089.

EPA (U.S. Environmental Protection Agency). 1985b. Background Information Document: Final Rule for HighLevel and Transuranic Radioactive Wastes. EPA 520/185-023. Washington, DC: Environmental Protection Agency, Office of Radiation Programs.

EPA (U.S. Environmental Protection Agency). 1993. “40 CFR Part 191: Environmental Radiation Protection Standards for the Management and Disposal of Spent Nuclear Fuel, High-Level and Transuranic Radioactive Wastes; Final Rule," Federal Register. Vol. 58, no. 242, 6639866416.

EPA (U.S. Environmental Protection Agency). 1996. "40 CFR Part 194: Criteria for the Certification and Re-Certification of the Waste Isolation Pilot Plant's Compliance With the 40 CFR Part 191 Disposal Regulations; Final Rule," Federal Register. Vol. 61, no. 28, 5224-5245.

Freeze, R.A., and J.A. Cherry. 1979. Groundwater. Englewood Cliffs, NJ: Prentice-Hall, Inc. 403.
Frolov, V.V., B.G. Ryazanov, V.I. Sviridov, and G.S. Starodubtsev. 1995. "A Review of Criticality Accidents Which Occurred in the Russian Industry," ICNC '95: The Fifth International Conference on Nuclear Criticality Safety, Albuquerque, NM, September 17-21, 1995. Albuquerque, NM: University of New Mexico, Department of Chemical and Nuclear Engineering. Vol. 1, 23-30.

Galson, D.A., and P.N. Swift. 1995. "Recent Progress in Scenario Development for the WIPP," High Level Radioactive Waste Management 1995, Proceedings of the Sixth Annual International Conference, Las Vegas, NV, April 30-May 5, 1995. SAND95-0117C. La Grange Park, IL: American Nuclear Society; New York, NY: American Society of Civil Engineers. 391-396.

Gauthier-Lafaye, F., and F. Weber. 1989. "The Francevillian (Lower Proterozoic) Uranium Ore Deposits of Gabon," Economic Geology and the Bulletin of the Society of Economic Geologists. Vol. 84, no. 8, 2267-2285.

Gauthier-Lafaye, F., F. Weber, and H. Ohmoto. 1989. "Natural Fission Reactors of Oklo," Economic Geology and the Bulletin of the Society of Economic Geologists. Vol. 84, no. 8, 2286-2295.

Granger, H.C. 1968. "Localization and Control of Uranium Deposits in the Southern San Juan Basin Mineral Belt, New Mexico-An Hypothesis," Geological Survey Research 1968. U.S. Geological Survey Professional Paper 600-B. Washington: U.S. Government Printing Office. B60-B70.

Granger, H.C., and C.G. Warren. 1974. "Zoning in the Altered Tongue Associated with Roll-Type Uranium Deposits," Formation of Uranium Ore Deposits, Proceedings of a Symposium on the Formation of Uranium Ore Deposits, Athens, Greece, May 6-10, 1974. STIPUB/ 374. Vienna, Austria: International Atomic Energy Agency. 185-200.

Hacking, I. 1975. The Emergence of Probability: A Philosophical Study of Early Ideas About Probability Induction and Statistical Inference. London; New York: Cambridge University Press. 77.

Helton, J.C., M.G. Marietta, and R.P. Rechard. 1993. "Conceptual Structure of Performance Assessments Conducted for the Waste Isolation Pilot Plant," Scientific Basis for Nuclear Waste Management XVI, Materials Research Society Symposium Proceedings, Boston, MA, November 30-December 4, 1992. Eds. C.G. Interrante and R.T. Pabalan. Pittsburgh, PA: Materials Research Society. Vol. 294, 885-898.

Helton, J.C., J.E. Bean, J.W. Berglund, F.J. Davis, K. Economy, J.W. Garner, J.D. Johnson, R.J. MacKinnon, J. Miller, D.G. O'Brien, J.L. Ramsey, J.D. Schreiber, A. Shinta, L.N. Smith, D.M. Stoelzel, C. Stockman, and P. Vaughn. 1998. Uncertainty and Sensitivity Analysis 
Results Obtained in the 1996 Performance Assessment for the Waste Isolation Pilot Plant. SAND98-0365. Albuquerque, NM: Sandia National Laboratories.

Hill, C. [1996]. Geology of the Delaware Basin: Guadalupe, Apache, and Glass Mountains, New Mexico and West Texas. Eds. R.F. Lindsay and R.A. Garber. Publication No. 96-39. [Midland, TX]: Permian Basin Section SEPM (Society for Sedimentary Geology).

Ho, C.H., and N.H. Miller. 1986. "Absorption of Uranyl Species from Bicarbonate Solution onto Hematite Particles," Journal of Colloid and Interface Science. Vol. 110, no. 1, 165-171.

Holt, R.M. 1997. Conceptual Model for Transport Processes in the Culebra Dolomite Member, Rustler Formation. SAND97-0194. Albuquerque, NM: Sandia National Laboratories.

Holt, R.M., and D.W. Powers. 1990. Geologic Mapping of the Air Intake Shaft at the Waste Isolation Pilot Plant. DOE-WIPP 90-051. Carlsbad, NM: Westinghouse Electric Corporation.

Hsi, C-K.D., and D. Langmuir. 1985. "Adsorption of Uranyl onto Ferric Oxyhydroxides: Application of the Complexation Site-Binding Model," Geochimica et Cosmochimica Acta. Vol. 49, no. 9, 1931-1941.

Hunter, R.L. 1989. Events and Processes for Constructing Scenarios for the Release of Transuranic Waste from the Waste Isolation Pilot Plant, Southeastern New Mexico. SAND89-2546. Albuquerque, NM: Sandia National Laboratories.

IAEA (International Atomic Energy Agency). 1981. Safety Assessment for the Underground Disposal of Radioactive Wastes. Safety Series No. 56. Vienna, Austria: International Atomic Energy Agency.

Iman, R.L., and W.J. Conover. 1980. "Small Sample Sensitivity Analysis Techniques for Computer Models, With an Application to Risk Assessment," Communications in Statistics. Vol. A9, no. 17, 1749-1842.

Jenne, E.A. 1998. "Chapter 1 Adsorption of Metals by Geomedia: Data Analysis, Modeling, Controlling Factors, and Related Issues," Adsorption of Metals by Geomedia: Variables, Mechanisms, and Model Applications. Ed. E.A. Jenne. San Diego, CA: Academic Press. 2-73.

Johnson, K.S. 1978. "Stratigraphy and Mineral Resources of Guadalupian and Ochoan Rocks in the Texas Panhandle and Westem Oklahoma," Geology and Mineral Deposits of Ochoan Rocks in Delaware Basin and Adjacent Areas. Comp. G.S. Austin. Circular 159. Socorro, NM: New Mexico Bureau of Mines \& Mineral Resources. 57-62.
Kaplan, S., and B.J. Garrick. 1981. "On the Quantitative Definition of Risk," Risk Analysis. Vol. 1, no. 1, 11-27.

Kastenberg, W.E., P.F. Peterson, J. Ahn, J. Burch, G. Casher, P.L. Chambré, E. Greenspan, D.R. Olander, J.L. Vujic, B. Bessinger, N.G.W. Cook, F.M. Doyle, and L.B. Hilbert, Jr. 1996. "Considerations of Autocatalytic Criticality of Fissile Materials in Geologic Repositories," Nuclear Technology. Vol. 115, no. 3, 298-310.

Kelley, V.A., and J.F. Pickens. 1986. Interpretation of the Convergent-Flow Tracer Tests Conducted in the Culebra Dolomite at the H-3 and H-4 Hydropads at the Waste lsolation Pilot Plant (WIPP) Site. SAND86-7161. Albuquerque, NM: Sandia National Laboratories.

Kelley, V.A., and G.J. Saulnier, Jr. 1990. Core Analyses for Selected Samples from the Culebra Dolomite at the Waste Isolation Pilot Plant Site. SAND90-7011. Albuquerque, NM: Sandia National Laboratories.

Kelly, J.W. 1996. "Surface Area Analysis Results," Conceptual Model for Transport Processes in the Culebra Dolomite Member, Rustler Formation. R.M. Holt. SAND970194. Albuquerque, NM: Sandia National Laboratories. C-4 through C-5.

Kent, D.B., V.S. Tripathi, N.B. Ball, J.O. Leckie, and M.D. Siegel. 1988. Surface-Complexation Modeling of Radionuclide Adsorption in Subsurface Environments. SAND86-7175; NUREG/CR-4807. Albuquerque, NM: Sandia National Laboratories.

Kimpland, R.H. 1996. "Dynamic Analysis of Nuclear Excursions in Underground Repositories Containing Plutonium," Science and Global Security. Vol. 5, no. 3, 323332.

Knief, R.A. 1985. Nuclear Criticality Safety: Theory and Practice. La Grange Park, IL: American Nuclear Society. 17-28.

Langmuir, D. 1978. "Uranium Solution-Mineral Equilibria at Low Temperatures with Applications to Sedimentary Ore Deposits," Geochimica et Cosmochimica Acta. Vol. 42, no. 6, 547-569.

Langmuir, D.L. 1997. Aqueous Environmental Geochemistry. Upper Saddle River, NJ: Prentice Hall. 536.

Lappin, A.R., R.L. Hunter, D.P. Garber, and P.B. Davies, eds. 1989. Systems Analysis, Long-Term Radionuclide Transport, and Dose Assessments, Waste Isolation Pilot Plant (WIPP), Southeastern New Mexico; March 1989. SAND89-0462. Albuquerque, NM: Sandia National Laboratories.

Lemire, R.J., and F. Garisto. 1989. The Solubility of $U, N p$, $P u, T h$ and Tc in a Geological Disposal Vault for Used Nuclear Fuel. AECL-10009. Pinawa, Manitoba: Atomic 
Energy of Canada Limited, Whiteshell Nuclear Research Establishment.

Leslie, B.W., E.C. Pearcy, and J.D. Prikryl. 1993. "Oxidative Alteration of Uraninite at Nopal I Deposit, Mexico: Possible Contaminant Transport and Source Term Constraints for the Proposed Repository at Yucca Mountain," Scientific Basis for Nuclear Waste Management XVI, Materials Research Society Symposium Proceedings, Boston, MA, November 30-December 4, 1992. Eds. C.G. Interrante and R.T. Pabalan. Pittsburgh, PA: Materials Research Society. Vol. 294, 505-512.

Lipner, M.H., and J.M. Ravets. 1980. Nuclear Criticality Safety Analyses for the Waste Isolation Pilot Plant Project. WAES-TME-3025. Pittsburgh, PA: Westinghouse Electric Corporation, Advanced Energy Systems Division.

Meigs, L., and J. McCord. 1996. "Letter Report: Physical Transport in the Culebra Dolomite." July 11, 1996. Albuquerque, NM: Sandia National Laboratories. (On file in SWCF as WPO\#39167.)

Meigs, L.C., R.L. Beauheim, J.T. McCord, Y.W. Tsang, and R. Haggerty. 1997. "Design, Modelling, and Current Interpretations of the $\mathrm{H}-19$ and $\mathrm{H}-11$ Tracer Tests at the WIPP Site," Field Tracer Experiments: Role in the Prediction of Radionuclide Migration: Synthesis and Proceeding of an NEA/EC GEOTRAP Workshop, Cologne, Germany, August 28-30, 1996. SAND96-2796C. Paris: Nuclear Energy Agency, Organisation for Economic Co-Operation and Development. 157-169.

Mercer, J.W. 1983. Geohydrology of the Proposed Waste Isolation Pilot Plant Site, Los Medaños Area, Southeastern New Mexico. Water-Resources Investigations Report 834016. Albuquerque, NM: U.S. Geological Survey.

Mercer, J.W., and B.R. Orr. 1979. Interim Data Report on the Geohydrology of the Proposed Waste Isolation Pilot Plant Site, Southeast New Mexico. Water-Resources Investigations Report 79-98. Albuquerque, NM: U.S. Geological Survey. 92.

Moench, R.H., and J.S. Schlee. 1967. Geology and Uranium Deposits of the Laguna District, New Mexico. Geological Survey Professional Paper 519. Washington: U.S. Government Printing Office.

Morel, F.M.M., and J.G. Hering. 1993. Principles and Applications of Aquatic Chemistry. New York, NY: John Wiley \& Sons, Inc. 516.

Murray, R.L. 1957. Nuclear Reactor Physics. Englewood Cliffs, NJ: Prentice-Hall, Inc. 182.

NAS/NRC (National Academy of Sciences/National Research Council). 1995. Technical Bases for Yucca Mountain Standards. Committee on Technical Bases for Yucca
Mountain Standards, Board on Radioactive Waste Management, Commission on Geosciences, Environment, and Resources. Washington, DC: National Academy Press.

NAS/NRC (National Academy of Sciences/National Research Council). 1996. The Waste Isolation Pilot Plant: A Potential Solution for the Disposal of Transuranic Waste. Committee on the Waste Isolation Pilot Plant, Board on Radioactive Waste Management, Commission on Geosciences, Environment, and Resources. Washington, DC: National Academy Press.

Novak, C.F. 1995. "The WIPP Actinide Source Term: Test Plan for the Conceptual Model and the Dissolved Submodel." SAND95-1985. Albuquerque, NM: Sandia National Laboratories. (September 21, 1995 Draft on file in SWCF as WPO\#27860 and WPO\#31162.)

NWPA. 1983. Nuclear Waste Policy Act of 1982. Public Law 97-425, 96 Stat. 2201, 42 U.S.C. 10101 et seq.

Oversby, V.O. 1996. Oklo: Des Reacteurs Nucleaires Fossiles (Oklo: The Fossil Nuclear Reactors). Physics Study (R. Naudet, CEA): Translation of Chapters 6, 13, and Conclusions. SKB Technical Report 96-14. Stockholm, Sweden: Swedish Nuclear Fuel and Waste Management Co.

Papenguth, H.W. 1996a. "Addendum to Colloidal Actinide Source Term Parameter Record Packages." Albuquerque, NM: Sandia National Laboratories. (In Parameter Record Package WPO\#35855: Mobile-ColloidalActinide Source Term. 3. Humic Substances.)

Papenguth, H.W. 1996b. "Attachment A: Rationale for Definition of Parameter Values for Actinide Intrinsic Colloids." Albuquerque, NM: Sandia National Laboratories. (In Parameter Record Package WPO\#35852: MobileColloidal-Actinide Source Term. 2. Actinide Intrinsic Colloids.)

Papenguth, H. W. 1996c. "Attachment A: Rationale for Definition of Parameter Values for Microbes." Albuquerque, NM: Sandia National Laboratories. (In Parameter Record Package WPO\#35856: Mobile-ColloidalActinide Source Term. 4. Microbes.)

Papenguth, H.W., and R. Aguilar. 1996. "Attachment A: Rationale for Definition of Parameter Values for Mineral Fragment Type Colloids." Albuquerque, NM: Sandia National Laboratories. (In Parameter Record Package WPO\#35850: Mobile-Colloidal-Actinide Source Term Parameters. 1. Mineral Fragment Colloids.)

Papenguth, H.W., and Y.K. Behl. 1996a. "Test Plan: Evaluation of Dissolved Actinide Retardation at the Waste Isolation Pilot Plant." TP 96-02. Albuquerque, NM: Sandia National Laboratories. (On file in SWCF as WPO\#31336.) 
Papenguth, H.W., and Y.K. Behl. 1996b. "Test Plan: For Evaluation of Colloid Facilitated Actinide Transport." TP 96-01. Albuquerque, NM: Sandia National Laboratories. (On file in SWCF as WPO\#31337.)

Papenguth, H.W., and R.C. Moore. 1996. "Attachment A: Rationale for Definition of Parameter Values for Humic Substances." Albuquerque, NM: Sandia National Laboratories. (In Parameter Record Package WPO\#35855: Mobile-Colloidal-Actinide Source Term. 3. Humic Substances.)

Paxton, H.C. 1983. A History of Critical Experiments at Pajarito Site. LA-9685-H. Los Alamos, NM: Los Alamos National Laboratory.

Paxton, H.C., J.T. Thomas, D. Callihan, and E.B. Johnson. 1964. Critical Dimensions of Systems Containing ${ }^{235} U$, ${ }^{239} \mathrm{Pu}$, and ${ }^{233} U$. TID-7028. Los Alamos, NM: Los Alamos Scientific Laboratory.

Payne, T.E., G.R. Lumpkin, and T.D. Waite. 1998. "Chapter 2 Uranium $^{\mathrm{VI}}$ Adsorption on Model Minerals: Controlling Factors and Surface Complexation Modeling," Adsorption of Metals by Geomedia: Variables, Mechanisms, and Model Applications. Ed. E.A. Jenne. San Diego, CA: Academic Press. 75-97.

Rawson, D., C. Boardman, and N. Jaffe-Chazan. 1965. Project Gnome: The. Environment Created by a Nuclear Explosion in Salt. PNE-107F. Livermore, CA: Lawrence Radiation Laboratory, University of California.

Rechard, R.P. 1991. “CAMCON: Computer System for Assessing Regulatory Compliance of the Waste Isolation Pilot Plant," Probabilistic Safety Assessment and Management, Proceedings of the International Conference on Probabilistic Safety Assessment and Management (PSAM), Beverly Hills, CA, February 4-7, 1991. Ed. G. Apostolakis. SAND90-2094C. New York, NY: Elsevier Science Publishers. Vol. 2, 899-904.

Rechard, R.P. 1995. An Introduction to the Mechanics of Performance Assessment Using Examples of Calculations Done for the Waste Isolation Pilot Plant Between 1990 and 1992. SAND93-1378. Albuquerque, NM: Sandia National Laboratories.

Rechard, R.P. 1999. Historical Background on Assessing the Performance of the Waste Isolation Pilot Plant. SAND98-2708. Albuquerque, NM: Sandia National Laboratories.

Rechard, R.P., ed. 1992. User's Reference Manual for CAMCON: Compliance Assessment Methodology Controller, Version 3.0. SAND90-1983. Albuquerque, NM: Sandia National Laboratories.

Rechard, R.P., ed. 1995. Performance Assessment of the Direct Disposal in Unsaturated Tuff of Spent Nuclear
Fuel and High-Level Waste Owned by U.S. Department of Energy. Volume 2: Methodology and Results. SAND952563/2. Albuquerque, NM: Sandia National Laboratories.

Rechard, R.P., ed. 1998. Update to Assessment of Direct Disposal in Unsaturated Tuff of Spent Nuclear Fuel and High-Level Waste Owned by U.S. Department of Energy. SAND98-0795; DOE/SNF/REP-015; INEEL/EXT-9800185. Idaho Falls, ID: U.S. Department of Energy, Assistant Secretary for Environmental Management under DOE Idaho Operations Office.

Rechard, R.P., W. Beyeler, R.D. McCurley, D.K. Rudeen, J.E. Bean, and J.D. Schreiber. 1990. Parameter Sensitivity Studies of Selected Components of the Waste Isolation Pilot Plant Repository/Shaft System. SAND89-2030. Albuquerque, NM: Sandia National Laboratories. II-30.

Rechard, R.P., C.T. Stockman, L.C. Sanchez, H.R. Trellue, J.S. Rath, and J. Liscum-Powell. 1996a. RNT-1: Nuclear Criticality in Near Field and Far Field. FEP Screening Argument. Albuquerque, NM: Sandia National Laboratories. (On file in SWCF as WPO\#40818.)

Rechard, R.P., M.S. Tierney, L.C. Sanchez, and M.A. Martell. 1996b. Consideration of Criticality when Directly Disposing Highly Enriched Spent Nuclear Fuel in Unsaturated Tuff: Bounding Estimates. SAND96-0866. Albuquerque, NM: Sandia National Laboratories.

Rechard, R.P., M.S. Tierney, L.C. Sanchez, and M-A. Martell. 1997. "Bounding Estimates for Critical Events when Directly Disposing Highly Enriched Spent Nuclear Fuel in Unsaturated Tuff," Risk Analysis. Vol. 17, no. 1, 19-35.

Sabins, F.F., Jr. 1978. Remote Sensing: Principals and Interpretation. San Francisco, CA: W.H. Freeman and Company.

Samama, J-C. 1986. Ore Fields and Continental Weathering. New York, NY: Van Nostrand Reinhold Company. 244 249.

Sanchez, A.L., J.W. Murray, and T.H. Sibley. 1985. "The Adsorption of Plutonium IV and V on Goethite," Geochimica et Cosmochimica Acta. Vol. 49, no. 11, 2297-2307.

Sanchez, L.C. 1996. "Identification of Important Radionuclides Used in 1996 CCA WIPP Performance Assessment." Memorandum to Distribution, April 25, 1996. Albuquerque, NM: Sandia National Laboratories. (On file in SWCF as WPO\#37431.)

Sanchez, L.C., J. Liscum-Powell, J.S. Rath, and H.R. Trellue. 1997. “EPAUNI: Analysis Package for Estimating Probability Distribution of EPA Unit Loading in the WIPP Repository for Performance Assessment Calculations." 
Albuquerque, NM: Sandia National Laboratories. (On file in SWCF as WPO\#43898.)

Sanchez, L.C., J.S. Rath, R. Aguilar, H.R. Trellue, K. Cochrane, L.L. Taylor, and J.R. Wilson. 1998. Nuclear Dynamics Consequence Analysis (NDCA) for the Disposal of Spent Nuclear Fuel in an Underground Geologic Repository, Volume 2: Methodology and Results, Volume 3: Appendices. SAND98-2208/3; INEEL/EXT-09800996; DOE/SNF/REP-0033. Idaho Falls, ID: Assistant Secretary for Environmental Management, U.S. Department of Energy.

Sanchez, R., W. Myers, D. Hayes, R. Kimpland, P. Jaegers, P. Paternoster, S. Rojas, R. Anderson, and W. Stratton. 1995. Criticality Characteristics of Mixtures of Plutonium, Silicon Dioxide, Nevada Tuff, and Water. LA-UR95-2130. Los Alamos, NM: Los Alamos National Laboratory. (November 3, 1995 Draft Received from Authors, WPO\#31283.)

Saucier, A.E. 1980. "Tertiary Oxidation in the Westwater Canyon Member of Morrison Formation," Geology and Mineral Technology of the Grants Uranium Region 1979. Comp. C.A. Rautman. Memoir 38. Socorro, NM: New Mexico Bureau of Mines \& Mineral Resources. 116-121.

Sewards, T., A. Brearley, R. Glenn, I.D.R. MacKinnon, and M.D. Siegel. 1992. Nature and Genesis of Clay Minerals of the Rustler Formation in the Vicinity of the Waste Isolation Pilot Plant in Southeastern New Mexico. SAND90-2569. Albuquerque, NM: Sandia National Laboratories.

Shawe, D.R. 1956. "Significance of Roll Ore Bodies in Genesis of Uranium-Vanadium Deposits on the Colorado Plateau," Proceedings of the International Conference on the Peaceful Uses of Atomic Energy, Geneva, August 8-20, 1955. Volume 6: Geology of Uranium and Thorium. New York, NY: United Nations. 335-337.

Siegel, M.D., S.J. Lambert, and K.L. Robinson, eds. 1991. Hydrogeochemical Studies of the Rustler Formation and Related Rocks in the Waste Isolation Pilot Plant Area, Southeastern New Mexico. SAND88-0196. Albuquerque, NM: Sandia National Laboratories.

Smith, R.W., J.C. Walton, and M. Rahman. 1994. "Effects of Recrystallization on Time Variant Sorption of Radionuclides onto Steel Corrosion Products," Scientific Basis for Nuclear Waste Management XVII, Materials Research Society Symposium Proceedings, Boston, MA, November 29-December 3, 1993. Eds. A. Barkatt and R.A. Van Konynenburg. Pittsburgh, PA: Materials Research Society. Vol. 333, 713-718.

Snoeyink, V.L., and D. Jenkins. 1980. Water Chemistry. New York, NY: John Wiley \& Sons, Inc. 331-332.
Stein, C.L., and J.L. Krumhansl. 1988. "A Model for the Evolution of Brines in Salt from the Lower Salado Formation, Southeastern New Mexico," Geochimica et Cosmochimica Acta. Vol. 52, 1037-1046.

Straker, E.A., P.N. Stevens, D.C. Irving, and V.R. Cain. 1970. Morse Code - A Multigroup Neutron and Gamma-Ray Monte Carlo Transport Code. ORNL-4585. Oak Ridge, TN: Oak Ridge National Laboratory.

Stratton, W.R. 1967. A Review of Criticality Accidents. LA3611. Los Alamos, NM: Los Alamos Scientific Laboratory.

Stratton, W.R. 1983. The Myth of Nuclear Explosions at Waste Disposal Sites. LA-9360. Los Alamos, NM: Los Alamos National Laboratory.

Stratton, W.R., and D.R. Smith. 1989. A Review of Criticality Accidents. DOE/NCT-04. Washington, DC: U.S. Department of Energy.

Sweet, J.N., and J.E. McCreight. 1980. Thermal Conductivity of Rocksalt and Other Geologic Materials from the Site of the Proposed Waste Isolation Pilot Plant. SAND791665. Albuquerque, NM: Sandia National Laboratories.

Taubes, G. 1995. "Blowup at Yucca Mountain," Science. Vol. 268 , no. $5219,1836-1839$.

Thorne, B.J., and D.K. Rudeen. 1981. Regional Effects of TRU Repository Heat. SAND79-7161. Albuquerque, NM: Sandia National Laboratories.

Trauth, K.M., S.C. Hora, R.P. Rechard, and D.R. Anderson. 1992. The Use of Expert Judgment to Quantify Uncertainty in Solubility and Sorption Parameters for Waste Isolation Pilot Plant Performance Assessment. SAND920479. Albuquerque, NM: Sandia National Laboratories.

Triay, I.R., A. Meijer, J.L. Conca, K.S. Kung, R.S. Rundberg, B.A. Strietelmeier, and C.D. Tait. 1997. Summary and Synthesis Report on Radionuclide Retardation for the Yucca Mountain Site Characterization Project. Yucca Mountain Site Characterization Program Milestone 3784M. LA-13262-MS. Los Alamos, NM: Los Alamos National Laboratory.

Van Konynenburg, R.A., comp. 1996. "Comments on the Draft Paper 'Underground Supercriticality from Plutonium and Other Fissile Material,' written by C.D. Bowman and F. Venneri (LANL)," Science and Global Security. Vol. 5, no. 3, 303-322.

Walker, F.W., J.R. Parrington, and F. Feiner. 1989. Nuclides and Isotopes: Chart of the Nuclides. 14th ed. San Jose, CA: General Electric Company.

Wallace, M. 1999. "Disposition of Culebra Criticality Modeling," Memorandum to Rob Rechard, August 16, 1999. 
Albuquerque, NM: Sandia National Laboratories. (On file in SWCF as Records Package ERMS\#507679; item ERMS\#507680.)

Weast, R.C., ed. 1974. CRC Handbook of Chemistry and Physics. 55th ed. Cleveland, OH: CRC Press. B-193 - B-195.

Weiner, R. 1996. "Documentation Package for Oxidation State Distribution of Actinides in the Repository." SNL Technical Memorandum, March 27, 1996. Albuquerque, NM: Sandia National Laboratories. (On file in SWCF as WPO\#35194.)

Whipple, C.G. 1996. "Can Nuclear Waste Be Stored Safely at Yucca Mountain?," Scientific American. Vol. 274, no. $6,72-79$.

Wilson, M.L., J.H. Gauthier, R.W. Barnard, G.E. Barr, H.A. Dockery, E. Dunn, R.R. Eaton, D.C. Guerin, N. Lu, M.J. Martinez, R. Nilson, C.A. Rautman, T.H. Robey, B. Ross, E.E. Ryder, A.R. Schenker, S.A. Shannon, L.H. Skinner, W.G. Halsey, J.D. Gansemer, L.C. Lewis, A.D. Lamont, I.R. Triay, and A.S. Meijer. 1994. Total-System Performance Assessment for Yucca Mountain-SNL Second Iteration (TSPA-1993). SAND93-2675. Albuquerque, NM: Sandia National Laboratories. Executive Summary, Vols. 1-2.
Winchester, J.W. 1979. "Long Term Geochemical Interactions of High Active Waste with Crystalline Rock Repository Media," Scientific Basis for Nuclear Waste Management, Proceedings of the Symposium on "Science Underlying Radioactive Waste Management," Materials Research Society Annual Meeting, Boston, MA, November 28-December 1, 1978. Ed. G.J. McCarthy. New York, NY: Plenum Press. Vol. 1, 345-347.

WIPP LWA. 1992. Waste Isolation Pilot Plant Land Withdrawal Act. Public Law 102-579, 106 Stat. 4777.

WIPP Performance Assessment Department. 1993. Preliminary Performance Assessment for the Waste Isolation Pilot Plant, December 1992. Volume 4: Uncertainty and Sensitivity Analyses for 40 CFR 191, Subpart B. SAND92-0700/4. Albuquerque, NM: Sandia National Laboratories.

WIPP Performance Assessment Department. 1996. "PANEL, Version 3.60, User's Manual." Albuquerque, NM: Sandia National Laboratories. (On file in SWCF as WPO\#37361.)

WIPP Performance Assessment Division. 1991. Preliminary Comparison with 40 CFR Part 191, Subpart B for the Waste Isolation Pilot Plant, December 1991. Volume 3: Reference Data. Eds. R.P. Rechard, A.C. Peterson, J.D. Schreiber, H.J. Iuzzolino, M.S. Tierney, and J.S. Sandha. SAND91-0893/3. Albuquerque, NM: Sandia National Laboratories. 


\section{Distribution \\ SAND99-2898}

\section{Federal Agencies}

US Department of Energy (4)

Office of Civilian Radioactive Waste Mgmt.

Attn: Deputy Director, RW-2

Director, RW-10

Office of Human Resources \& Admin.

Director, RW-30

Office of Program Mgmt. \& Integ.

Director, RW-40

Office of Waste Accept., Stor., \& Tran.

Forrestal Building

Washington, DC 20585

U. S. Department of Energy (2)

Yucca Mountain Site Characterization Office

Attn: Project Director RW-3

A. Van Luik

P. O. Box 30307

Las Vegas, NV 89036-0307

US Department of Energy

Research \& Waste Management Division

Attn: Director

P.O. Box E

Oak Ridge, TN 37831

US Department of Energy (6)

Carlsbad Area Office

Attn: I. Triay

G. T. Basabilvazo

D. Galbraith

M. McFadden

D. Mercer

Mailroom

P.O. Box 3090

Carlsbad, NM 88221-3090

US Department of Energy

Office of Environmental Restoration and

Waste Management

Attn: M. Frei, EM-30

Forrestal Building

Washington, DC 20585-0002

US Department of Energy (3)

Office of Environmental Restoration and

Waste Management

Attn: J. Juri, EM-34, Trevion II

Washington, DC 20585-0002
US Department of Energy

Office of Environmental Restoration and Waste Management

Attn: S. Schneider, EM-342, Trevion II

Washington, DC 20585-0002

US Department of Energy (2)

Office of Environment, Safety \& Health

Attn: C. Borgstrom, EH-25

R. Pelletier, EH-231

Washington, DC 20585

US Department of Energy (2)

Idaho Operations Office

Fuel Processing \& Waste Mgmt. Division

785 DOE Place

Idaho Falls, ID 83402

US Environmental Protection Agency (2)

Radiation Protection Programs

Attn: M. Oge

ANR-460

Washington, DC 20460

US Environmental Protection Agency

Office of Radiation and Indoor Air

Region 6

Attn: C. Byrum, GT-ET

1445 Ross Avenue

Dallas, TX 75202

US Nuclear Regulatory Commission

Attn: N. E. Eisenberg

MS T7 F3

Washington, DC 20555-0001

\section{Boards}

Defense Nuclear Facilities Safety Board

Attn: D. Winters

625 Indiana Ave. NW, Suite 700

Washington, DC 20004

Nuclear Waste Technical Review Board (3)

Attn: Chairman

J. L. Cohon

C. Di Bella

2300 Clarendon Blvd. Ste 1300

Arlington, VA 22201-3367 


\section{State Agencies}

Attorney General of New Mexico

P.O. Drawer 1508

Santa Fe, NM 87504-1508

Environmental Evaluation Group (3)

Attn: Library

7007 Wyoming NE

Suite F-2

Albuquerque, NM 87109

NM Environment Department (3)

Secretary of the Environment

1190 St. Francis Drive

Santa Fe, NM 87503-0968

NM Bureau of Mines \& Mineral Resources Socorro, NM 87801

\section{Laboratories/Corporations}

Battelle Pacific Northwest Laboratories Battelle Blvd.

Richland, WA 99352

Los Alamos National Laboratory (3)

Attn: B. Erdal, INC-12

P.K. Parson, ESH-6

T. McLaughlin, HSE-5

P.O. Box 1663

Los Alamos, NM 87545

Idaho National Engineering and

Environmental Laboratory (3)

Bechtel BWXT Idaho, LLC

Attn: H. H. Loo, MS-3135

S. A. Eide, MS- 3250

K. D. Bulmahn, MS-3135

1955 Fremont Ave.

P.O. Box 1625

Idaho Falls, ID 83415

Tech Reps, Inc. (3)

Attn: J. Chapman (1)

Loretta Robledo (2)

5000 Marble NE, Suite 222

Albuquerque, NM 87110

Westinghouse Electric Corporation (5)

Attn: Library

J. Epstein

J. Lee

R. Kehrman

P.O. Box 2078

Carlsbad, NM 88221
S. Cohen \& Associates

Attn: Bill Thurber

1355 Beverly Road

McLean, VA 22101

J. K. Research Associates

Attn: T. Cotton

2650 Park Tower Drive, Suite 800

Vienna, VA 22180

Future Resources Associates, Inc.

Attn: R. J. Budnitz, President

2039 Schattuck Ave. Suite 402

Berkeley, CA 94704

Western Water Consultants (2)

Attn: P. A. Rechard

611 Skyline Road

Laramie, WY 82070-8909

Winston \& Strawn

Attn: F. S. Echols

$1400 \mathrm{~L}$ Street NW

Washington, DC 20005

ICF Consulting

Attn: C. G. Whipple

2101 Webster Street, Suite 1000

Oakland, CA 94612

PLG Incorporated

Attn: B. J. Garrick

4590 MacArthur Blvd., Suite 400

Newport Beach, CA 92660-2027

\section{National Academy of Sciences WIPP Panel}

Tom Kiess (15)

Staff Study Director

GF456

2101 Constitution Ave.

Washington, DC 20418

\section{Universities}

University of New Mexico

Geology Department

Attn: Library

141 Northrop Hall

Albuquerque, NM 87131 
University of Washington

College of Ocean \& Fishery Sciences

Attn: G. R. Heath

583 Henderson Hall, $\mathrm{HN}-15$

Seattle, WA 98195

University of New Mexico

Department of Civil Engineering

Attn: B. Thompson

Albuquerque, NM 87131

University of Minnesota

Attn: C. Fairhurst

Department of Civil and Mineral Engineering

500 Pillsbury Dr. SE

Minneapolis, MN 55455-0220

University of Michigan

Nuclear Engineering and Radiological Sciences

Attn: R. C. Ewing

2355 Bonisteel Blvd.

Ann Arbor, MI 48109-2104

University of California

Department of Nuclear Engineering

Attn: T. H. Pigford

4159 Etcheverry Hall

Berkeley, CA 94720

\section{Libraries}

Thomas Brannigan Library

Attn: D. Dresp

$106 \mathrm{~W}$. Hadley St.

Las Cruces, NM 88001

Government Publications Department

Zimmerman Library

University of New Mexico

Albuquerque, NM 87131

New Mexico Junior College

Pannell Library

Attn: R. Hill

Lovington Highway

Hobbs, NM 88240

New Mexico State Library

Attn: N. McCallan

325 Don Gaspar

Santa Fe, NM 87503

New Mexico Tech

Martin Speere Memorial Library

Campus Street

Socorro, NM 87810
WIPP Information Center

ATTN: Y. Acosta

4021 National Parks Highway

Carlsbad, NM 88220

\section{Foreign Addresses}

Atomic Energy of Canada, Ltd.

Whiteshell Laboratories

Attn: B. Goodwin

Pinawa, Manitoba, CANADA R0E 1L0

Francois Chenevier (2)

ANDRA

Parc de la Croix Blanche

1-7 rue Jean Monnet

92298 Chatenay-Malabry Cedex

FRANCE

Claude Sombret

Centre d'Etudes Nucleaires de la Vallee Rhone CEN/VALRHO

S.D.H.A. B.P. 171

30205 Bagnols-Sur-Ceze

FRANCE

Commissariat a L'Energie Atomique

Attn: D. Alexandre

Centre d'Etudes de Cadarache

13108 Saint Paul Lez Durance Cedex

FRANCE

Bundesanstalt fur Geowissenschaften und

Rohstoffe

Attn: M. Langer

Postfach 510153

D-30631 Hannover

GERMANY

Bundesministerium fur Forschung und

Technologie

Postfach 200706

5300 Bonn 2

GERMANY

Gesellschaft fur Anlagen und Reaktorsicherheit (GRS)

Attn: B. Baltes

Schwertnergasse 1

D-50667 Cologne

GERMANY

Dr.-Ing Klaus Kuhn

TU Clausthal Institut fur Bergbau

Erzstr. 20

D-38678 Clausthal-Zellerfeld

GERMANY 
Shingo Tashiro

Japan Atomic Energy Research Institute

Tokai-Mura, Ibaraki-Ken, 319-11

JAPAN

Netherlands Energy Research Foundation ECN

Attn: J. Prij

3 Westerduinweg

P.O. Box 1

1755 ZG Petten

THE NETHERLANDS

Svensk Karnbransleforsorjning AB

Attn: F. Karlsson

Project KBS (Kambranslesakerhet)

Box 5864

S-102 48 Stockholm

SWEDEN

Nationale Genossenschaft fur die Lagerung

Radioaktiver Abfalle (2)

Attn: S. Vomvoris

P. Zuidema

Hardstrasse 73

CH-5430 Wettingen

SWITZERLAND

AEA Technology

Attn: J. H. Rees

D5W/29 Culham Laboratory

Abington, Oxfordshire OX14 3DB

UNITED KINGDOM

AEA Technology

Attn: W. R. Rodwell

044/A31 Winfrith Technical Centre

Dorchester, Dorset DT2 8DH

UNITED KINGDOM

AEA Technology

Attn: J. E. Tinson

B4244 Harwell Laboratory

Didcot, Oxfordshire OX11 ORA

UNTTED KINGDOM

\section{Internal}

$\underline{\mathrm{MS}}$

0701

0733

0771

0776

0776

0779

0779

1395

1395

1395

1399

0731

0733

9018

0899

0612
Org.

6100 P. B. Davies

6832 J. T. Holmes

6800 M. Chu

6852 H. N. Jow

6852 R. P. Rechard (5)

6849 D. R. Anderson

6849 L. C. Sanchez

6821 M. Marietta

6810 P. E. Shoemaker

6860 P. E. Shoemaker (Acting)

6850 S. A. Orrell

6811 NWM Library (30)

6832 C. Northrop-Salazar (2)

8940-2 Central Technical Files

4916 Technical Library (2)

4912 Review and Approval Desk, 